Aus der Klinik für Kinder- und Jugendmedizin Geschäftsführender Direktor: Prof. Dr. med. Rolf F. Maier des Fachbereichs Medizin der Philipps-Universität Marburg in Zusammenarbeit mit dem Universitätsklinikum Gießen und Marburg GmbH, Standort Marburg

\title{
Analyse von B-lymphozytären Subpopulationen des darmassoziierten lymphatischen Gewebes
}

\author{
Inaugural-Dissertation zur Erlangung des Doktorgrades der \\ gesamten Humanmedizin \\ dem Fachbereich Medizin der Philipps-Universität Marburg \\ vorgelegt von
}

Corinna Maskow aus Erlenbach a. Main

Marburg, 2013 
Angenommen vom Fachbereich Medizin der Philipps-Universität Marburg am: 06.03.2013

Gedruckt mit Genehmigung des Fachbereichs.

Dekan: $\quad$ Prof. Dr. M. Rothmund

Referent: $\quad$ Prof. Dr. R. F. Maier

Korreferent: Prof. Dr. M. Schnare 


\section{$\underline{\text { Inhaltsverzeichnis }}$}

1 Einleitung............................................................................................................................. 6

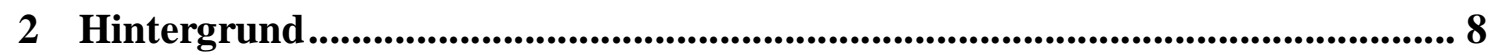

2.1 Die Struktur des Immunglobulinmoleküls .........................................................8 8

2.2 Der Genlocus für die schwere Kette des Immunglobulins................................. 10

2.3 Die Entstehung der Antikörpervielfalt .......................................................... 11

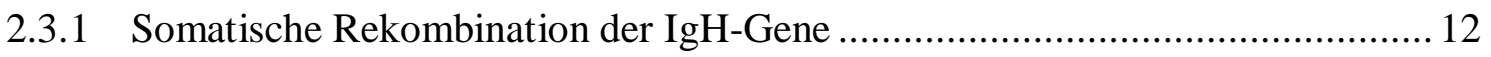

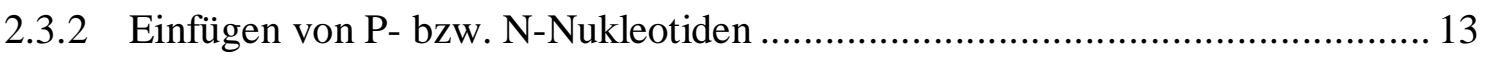

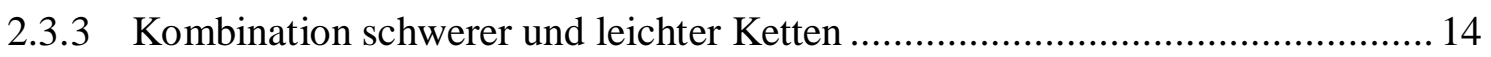

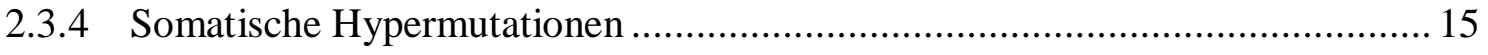

2.4 Besonderheiten des GALT (gut-associated lymphoid tissue) ...............................16

2.4.1 Anatomie der Peyerschen Plaques ........................................................... 17

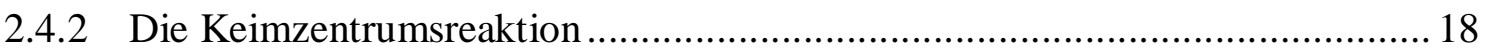

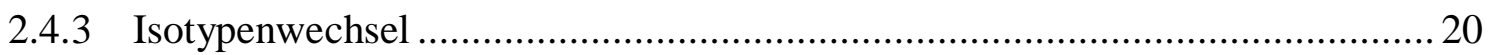

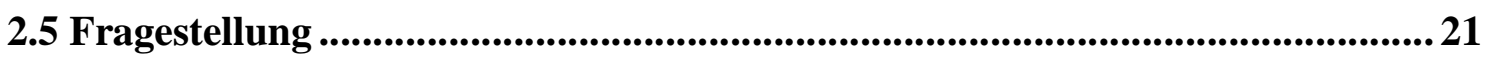

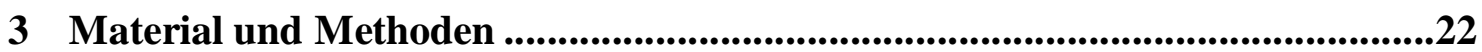

3.1 Sequenzierung der RNA-Transkripte für die variable Region der schweren

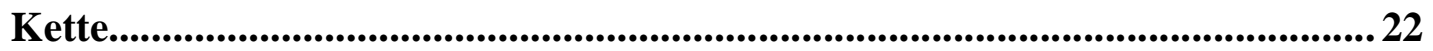

3.1.1 Haltung und Präparation der Mäuse ........................................................... 22

3.1.2 Antikörperfärbung der isolierten Zellen ............................................... 23

3.1.3 Durchflusszytometrie / FACS (Fluorescence-activated-cell-sorting) ...............225

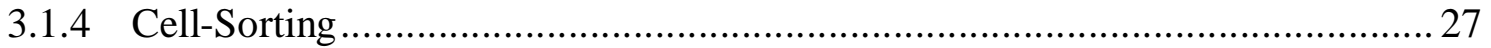

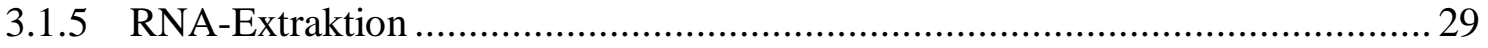

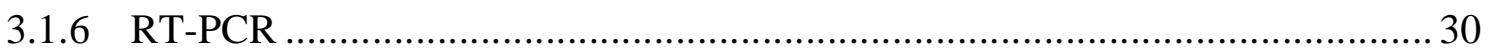

3.1.7 Agarosegelelektrophorese und Gelextraktion........................................ 33

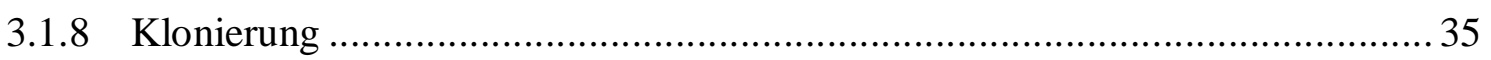

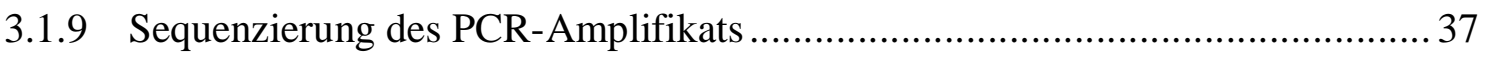


3.2 Computergestützte Sequenzanalyse der Amplifikate ......................................39

3.3 Statistische Auswertung der Untersuchungsergebnisse.................................... 40

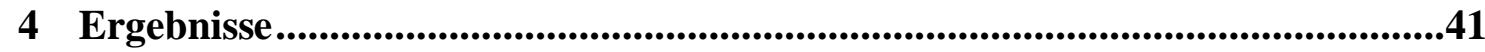

4.1 Diversität der Immunglobulinsequenzen ..................................................... 41

4.2 Häufigkeitsverteilung der Gensegmentnutzung................................................. 44

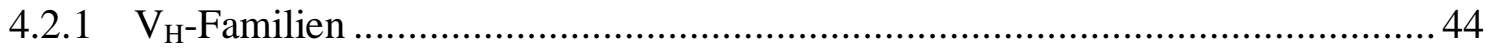

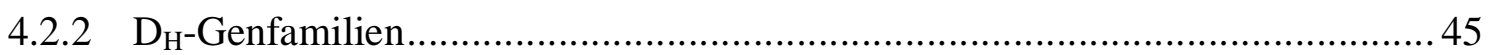

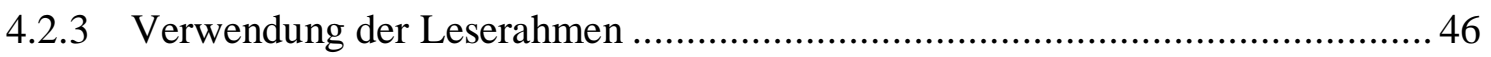

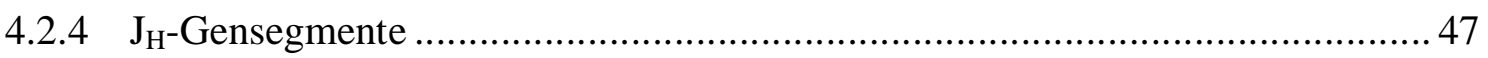

4.3 Eigenschaften der Complementarity Determining Region 3 (CDR3) ............... 48

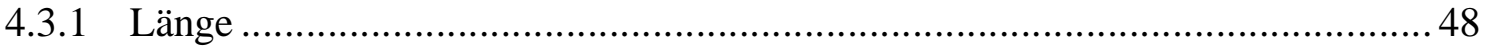

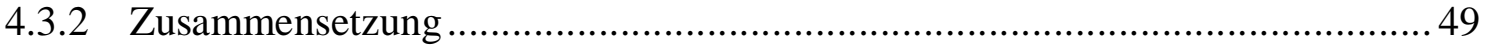

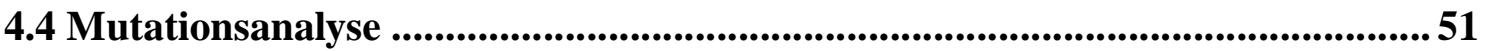

4.5 Hydrophobizitätsanalyse........................................................................... 54

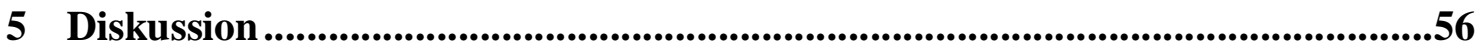

5.1 Die eingeschränkte klonale Diversität sowie die erhöhte Mutationsrate der IgA-Transkripte gegenüber IgM-Transkripten belegen eine Antigen-abhängige fokussierte Selektion während des Klassenwechsels von IgM zu IgA.............. 57

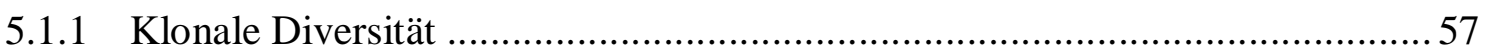

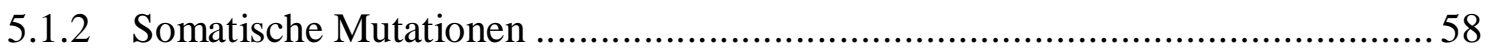

5.2 Seinem Reifegrad entsprechend enthält das sekundäre

Immunglobulinrepertoire vorwiegend D-distal gelegene $J_{H^{-}}$-Gensegmente. ..... 61

5.3 Zur Bildung des sekundären Repertoires werden Immunglobuline mit kürzeren CDR3-Regionen verwendet, die eine engere Antigen-Antikörper Interaktion mit höherer Affinität gewährleisten...........................................6 63

5.4 Beim Klassenwechsel und bei der Selektion in Subpopulationen spielt die Hydrophobizität der CDR3-Regionen eine Rolle.................................................. 66

5.5 Die Schwächen und Stärken der vorliegenden Untersuchungen........................ 67

6 Zusammenfassung ..........................................................................................67 


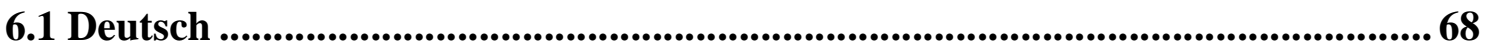

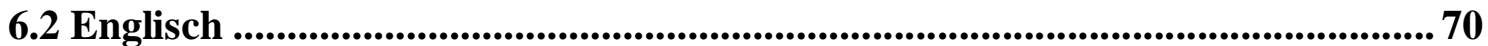

7 Abbildungs- und Tabellenanhang...................................................................71

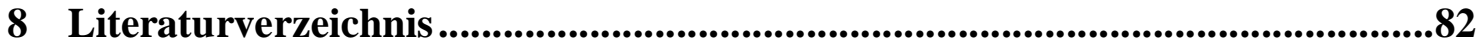

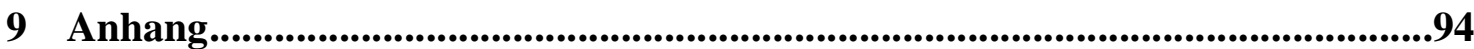

9.1 Abkürzungsverzeichnis ..........................................................................94

9.2 Abbildungsverzeichnis .......................................................................................... 97

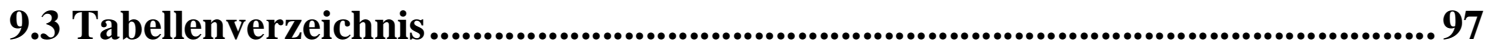

9.5 Verzeichnis der akademischen Lehrer .............................................................99

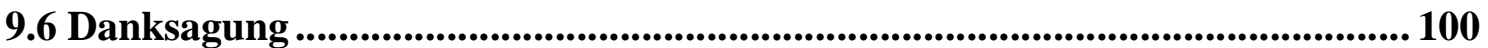




\section{Einleitung}

Im Rahmen der Evolution hat das Immunsystem gelernt, Fremdantigene zu erkennen und $\mathrm{zu}$ eliminieren, Eigenstrukturen jedoch $\mathrm{zu}$ respektieren und nicht anzugreifen. Dadurch schützt es den Körper vor Infektionen. Eine effektive Immunabwehr fordert das Zusammenspiel vieler verschiedener zellulärer und humoraler Faktoren.

Man unterscheidet die angeborene von der adaptiven Immunabwehr. In der Frühphase einer Infektion wird die angeborene Immunabwehr aktiviert, um die Vermehrung und Ausbreitung der Erreger zu verhindern. Die angeborene Immunantwort erfolgt an der Eintrittspforte, sie ist schnell, unspezifisch und wird durch Makrophagen, Granulozyten und Komplement bestimmt. Gelingt die Eliminierung der Erreger nicht, so beginnt mit einigen Tagen Latenz die Phase der adaptiven Immunantwort. Sie wird ausgelöst durch die Aktivierung des hochspezifischen adaptiven Immunsystems, deren wichtigste Komponenten die B-Lymphozyten, die T-Lymphozyten sowie die von den BLymphozyten synthetisierten Immunglobuline darstellen. Die adaptive Immunantwort führt zur Ausbildung eines immunologischen Gedächtnisses, so dass der Organismus bei einem Zweitkontakt mit dem gleichen Pathogen viel schneller und effizienter reagieren kann.

Viele pathogene Bakterien vermehren sich in den Extrazellularräumen des Körpers. BLymphozyten können spezifische Immunglobuline als Teil des B-Zell-Rezeptors membranständig tragen $(\mathrm{mIg})$ oder als Antikörper in den Extrazellulärraum sezernieren. Sekretorische Antikörper sind Glykoproteine, die Strukturen (Epitope) löslicher und gebundener Antigene erkennen können. Immunglobuline können extrazelluläre Mikroorganismen markieren und somit zur ihrer Zerstörung beitragen. Gebunden werden können Protein- und Kohlenhydratantigene, Toxine, sowie andere potentiell pathogene Strukturen.

Viren und intrazelluläre Bakterien nutzen bestimmte Oberflächenmoleküle ihrer Zielzelle, um in diese einzudringen und sich intazellulär zu vermehren. Antikörper können diese Bindung verhindern, indem sie sich an das Pathogen heften und dadurch den Erreger neutralisieren. Auf die gleiche Weise können auch bakterielle Toxine neutralisiert werden.

Vor sich extrazellulär vermehrenden Bakterien schützen Antikörper hauptsächlich durch die Erleichterung der Phagozytose. Haben sie an einen Erreger gebunden, können sie 
einerseits über ihren konstanten Teil von den Fc-Rezeptoren phagozytierender Zellen erkannt werden und so die Phagozytose einleiten (Opsonierung). Andererseits können Antikörper, die an die Oberfläche eines Erregers binden, dazu führen, dass die Komplementkaskade in Gang gesetzt und dadurch die direkte Zerstörung des Erregers eingeleitet wird (Cooper MD, 1987; Burrows PD, 1997).

In der vorliegenden Dissertationsarbeit untersuchten wir die Gesetzmäßigkeiten, nach denen die Populationen von IgM- und IgA-Antikörpern der Peyer-Plaques selektiert werden. Im folgenden Kapitel wird die Struktur des Immunglobulinmoleküls sowie der Gene beschrieben, die für die schwere Kette des Immunglobulinmoleküls kodieren (IgH). Anschließend werden die Entstehung der Antikörpervielfalt, die Reifung der BLymphozyten sowie die Besonderheiten des darmassoziierten lymphatischen Gewebes (gut-associated lymphoid tissues, GALT) dargestellt. 


\section{Hintergrund}

\subsection{Die Struktur des Immunglobulinmoleküls}

Immunglobuline (Ig) existieren in Form von membrangebundenen Molekülen (mIg) auf der Zelloberfläche reifer B-Lymphozyten oder werden von terminal differenzierten BLymphozyten als lösliche Antikörpermoleküle (Ak) ins Serum oder auf Schleimhäute sezerniert. Die Y-förmigen Glykoproteine bestehen aus zwei identischen leichten oder L-Ketten (light chain) mit annähernd $25 \mathrm{kDa}$ und zwei identischen schweren oder $\mathrm{H}$ Ketten (heavy chain) mit annähernd $50 \mathrm{kDa}$ (Abbildung 2.1).

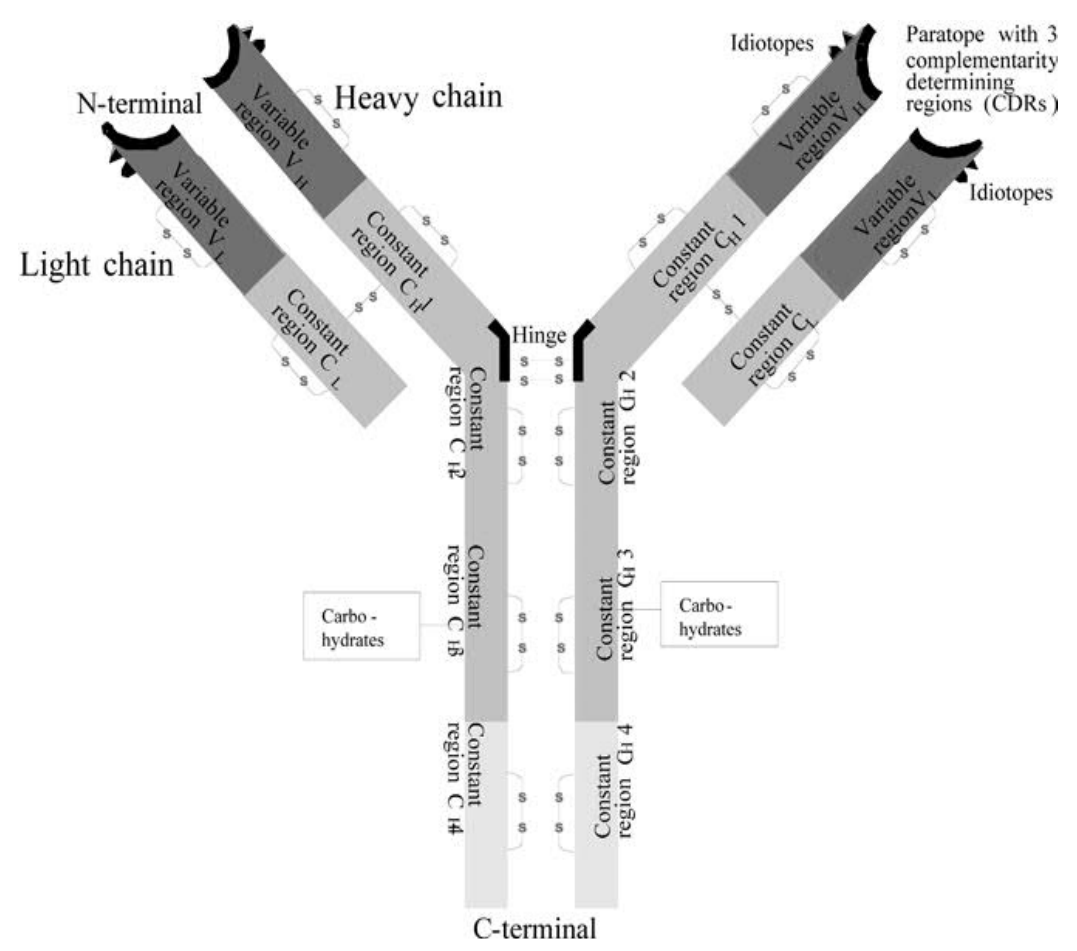

Abbildung 2.1: Schematische Darstellung eines Immunglobulinmoleküls. (aus Mix E, 2006)

Durch Cysteinreste werden die schweren Ketten untereinander und jeweils eine leichte mit einer schweren Kette über Disulfidbrücken verbunden. Es werden zwei verschiedene Versionen von leichten Ketten (Kappa $=\kappa, L a m b d a=\lambda)$ und fünf verschiedene Versionen von schweren Ketten unterschieden, wobei die Art der 
schweren Kette den Isotyp des Antikörpers definiert: $\gamma=$ Immunglobulin G (4 Unterklassen: $\operatorname{IgG} 1, \operatorname{IgG} 2 \mathrm{a}$, IgG $2 \mathrm{~b}, \operatorname{IgG} 3$ ), $\mu=$ Immunglobulin $\mathrm{M}, \delta=$ Immunglobulin D, $\alpha=$ Immunglobulin A, $\varepsilon=$ Immunglobulin E (Cooper MD, 1987; Burrows PD, 1997).

Das Immunglobulinmolekül weist zwei verschiedene Regionen auf. Die aminoterminale Domäne der schweren und leichten Ketten $\left(\mathrm{V}_{\mathrm{H}}\right.$ bzw. $\left.\mathrm{V}_{\mathrm{L}}\right)$, die eine große Variabilität in ihrer Aminosäuresequenz zeigt, stellt die variable Region (V-Region) des Antikörpers dar und verleiht ihm die Fähigkeit, ein spezifisches Antigen über zwei identische Rezeptoren zu binden. Zusätzlich zu der variablen Region weisen die leichten Ketten eine, die schweren Ketten drei (IgG, $\operatorname{IgA})$ bis vier ( $\operatorname{IgM}$, IgE) Domänen $\left(\mathrm{C}_{\mathrm{H} 1-4}\right.$ bzw. $\left.\mathrm{C}_{\mathrm{L}}\right)$ mit endständigen Carboxylgruppen auf, die zusammen die konstante Region (C-Region) des Antikörpers bilden. Hierüber wird die charakteristische Effektorfunktion des jeweiligen Immunglobulins (z.B. Komplementbindung, Interaktion mit spezifischen Rezeptoren verschiedener Zellen) vermittelt.

Zwischen $\mathrm{C}_{\mathrm{H} 1}$ und $\mathrm{C}_{\mathrm{H} 2}$ befindet sich die Hinge-Region, die eine Beweglichkeit in diesem Bereich und damit eine Veränderung des Abstandes beider Antigenbindungsstellen erlaubt.

Die Analyse der Aminosäuresequenz der variablen Region der leichten und schweren Kette zeigt, dass die Sequenzvariabilität zwischen unterschiedlichen Antikörpern nicht gleichmäßig über die V-Regionen verteilt ist, sondern sich in bestimmten Abschnitten konzentriert. Es gibt in den $\mathrm{V}_{\mathrm{H}^{-}}$und $\mathrm{V}_{\mathrm{L}}$-Domänen jeweils drei Regionen, die eine besonders hohe Variabilität aufweisen. In ihrer Tertiärstruktur, also der dreidimensionalen Form des Immunglobulinmoleküls, bilden sie drei 5-25 Aminosäuren lange hypervariable Schleifen, die nebeneinander positioniert eine Oberflächenstruktur darstellen, die das Antigen bindet. Man nennt sie daher Complementarity Determining Regions, CDR1-3. Den größten Einfluss auf die Antigen-Spezifität hat hierbei die aus drei verschiedenen rekombinierten Gensegmenten zusammengesetzte CDR3-Region der schweren Immunglobulinkette, die das Zentrum der Antigen-Bindungsstelle bildet (MacCallum RM, 1996; Xu JL, 2000). Umgeben sind diese Abschnitte sehr hoher Variabilität von vier weniger variablen Gerüstregionen, so genannten Framework Regions, FR1-4, die die strukturelle Integrität des Immunglobulinmoleküls gewährleisten (Padlan EA, 1994; Davies DR, 1990, 1996; Tonegawa S, 1983). 


\subsection{Der Genlocus für die schwere Kette des Immunglobulins}

Um den Organismus effektiv vor Pathogenen schützen zu können, kann eine Maus ähnlich wie der Mensch ca. $10^{8}$ bis $10^{9}$ unterschiedliche Antikörperspezifitäten bilden. Grundlage für diese Diversität ist die somatische Rekombination von Gensegmenten, die während der Entwicklung der genetisch identischen Pro-B-Zellen zu reifen, einzigartigen B-Lymphozyten stattfindet (Tonegawa S, 1983).

Der Genlocus für die schwere Immunglobulinkette liegt im Genom der Maus auf Chromosom 12 im Bereich F und ist ca. 3 Megabasen lang (Schroeder HW, 2006; Chowdhury D, 2004). Die Segmente sind in der Reihenfolge Leader - V(ariable) $D$ (iversity) - J(oining) $-C$ (onstant) Gensegment angeordnet (Abbildung 2.2).

Der exakte Aufbau des IgH-Genlocus differiert zwischen unterschiedlichen Mauslinien. Aktuell wird die Anzahl der IgHV-Gensegmente mit 134 angegeben, wobei etwa 97 Segmente funktionell aktiv sind (Chevillard C, 2002). Auf der Basis von Sequenzhomologien können sie in 15 Familien unterteilt werden (Mainville CA, 1996; Chevillard C, 2002). Die $15 \mathrm{D}_{\mathrm{H}}$-Gensegmente werden in 4 Familien eingeteilt (Chowdhury D, 2004). Außerdem gibt es $4 \mathrm{~J}_{\mathrm{H}^{-}}$Gensegmente (Sakano H, 1980) sowie 89 konstante Regionen (IgHC).

Eine international anerkannte Klassifikation ordnet Gensegmente nach ihrer Familienzugehörigkeit und Reihenfolge im Genom (Giudicelli V, 2004).

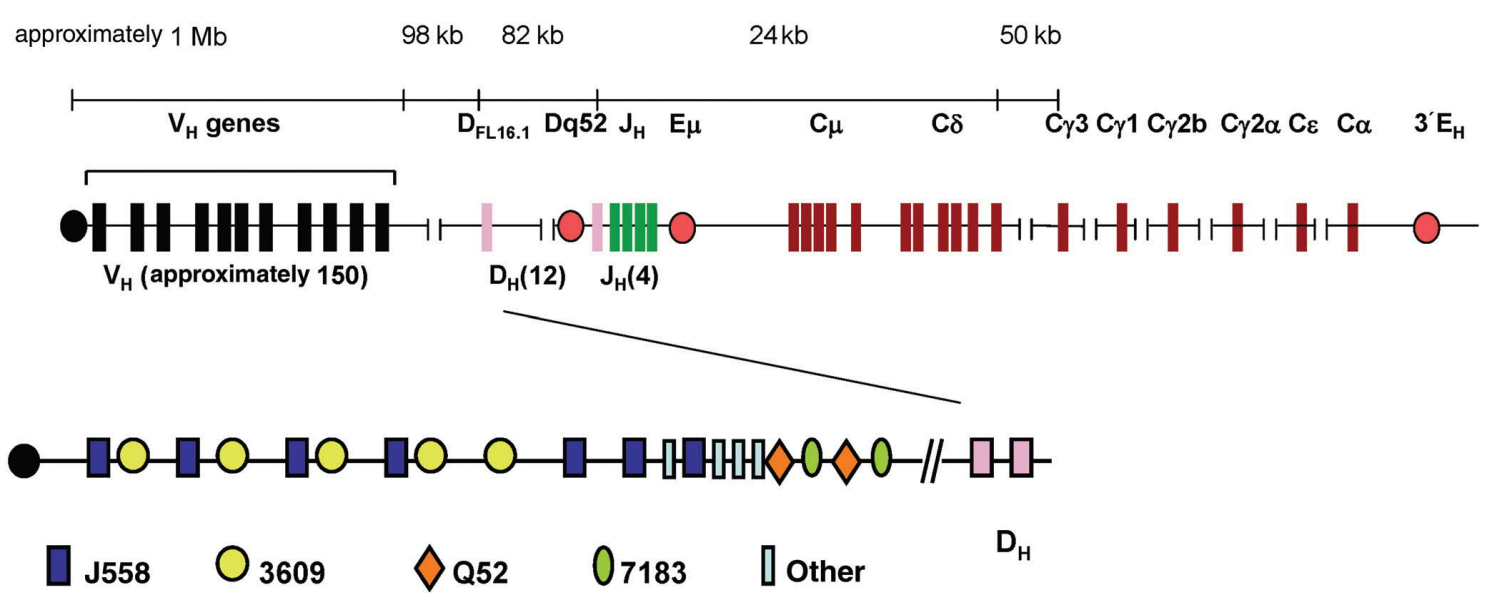

Abbildung 2.2: Organisation des murinen IgH-Locus (aus Chowdhury D, 2004)

Schematische Darstellung des murinen IgH-Locus mit ungefähren Abständen zwischen den Gensegmenten in Zeile 1. Ausgewählte VH-, DH-und JH Gensegmente, mit unterschiedlichen Isotypen der konstanten Region in Zeile 2. Darunter detaillierte schematische Darstellung der räumlichen Beziehungen der VH-Gene unterschiedlicher VH-Familien. 


\subsection{Die Entstehung der Antikörpervielfalt}

Die Immunglobulindiversität liegt im Wesentlichen begründet in der somatischen Rekombination der V-, D- und J-Gensegmente der schweren Kette und der V- und JGensegmente der leichten Kette im Rahmen der Reifung der B-Lymphozyten in den zentralen lymphatischen Organen (combinational diversity).

Zusätzlich gibt es weitere Mechanismen, die die Entstehung der nahezu unbegrenzten Antikörper-Vielfalt bedingen. Während der Rekombination werden zwischen den Gensegmenten auf DNA-Ebene sogenannte P- und N-Nukleotide eingefügt (junctional diversity, s.u.). Eine weitere Erhöhung der Diversität wird durch die Kombination von schwerer und leichter Kette erreicht. Manche Kombinationen von IgH- und IgL-Ketten sind jedoch, wahrscheinlich aufgrund sterischer Hinderungen, ausgeschlossen (Yurovsky VV, 1993).

Während der Affinitäsreifung kann die Antigen-Affinität durch Einfügung von somatischen Hypermutationen in der Variablen Region des Immunglobulin-Gens verändert werden (Nezlin R, 2001).

Gegenstand intensiver Forschungsbemühungen ist die Dynamik der RepertoireEntwicklung, wobei neuerdings auch Hochdurchsatz-Sequenzierungen zum Einsatz kommen, die sich duch einen Wegfall der Klonierung der zu sequenzierenden DNA auszeichnen sowie duch Parallelisierung vieler Millionen Sequenziervorgänge zu einer immensen Dantenproduktion führen (Vale AM, 2010; Boyd SD, 2010). Anhand der Diversitätsbestimmung und der Erstellung phylogenetischer Stammbäume der Sequenzen kann ermittelt werden, wie nah die Sequenzen einer Subpopulation untereinander verwandt sind (Zuckerkandl E, 1965). Ein hoher Verwandtschaftsgrad (geringe Diversität und stark fokussierter, asymmetrischer phylogenetischer Stammbaum) kann auf einen sehr starken, einseitigen Selektionsdruck beispielsweise durch ein kleines Spektrum an Fremd- oder Eigen-Antigenen hinweisen. Eine hohe Diversität und dementsprechend ein breit gefächerter, symmetrischer Stammbaum zeigt eine eher zufällige Zusammensetzung des Sequenzrepertoires an. Das IgM-Repertoire, das in der Regel Antigen-unabhängig entsteht, könnte daher eine höhere Diversität und einen breitgefächerteren phylogenetischen Stammbaum aufweisen als ein Antigenabhängig entstandenes sekundäres IgA-Repertoire. 


\subsubsection{Somatische Rekombination der IgH-Gene}

Im Gegensatz zu den Regionen CDR1 und CDR2, die durch das jeweilige $\mathrm{V}_{\mathrm{H}^{-}}$ Gensegment kodiert werden, wird CDR3 durch den enzymatischen Prozess der $\mathrm{V}_{\mathrm{H}} \mathrm{DJ}_{\mathrm{H}^{-}}$ Rekombination de novo synthetisiert (Tonegawa S, 1983; Alt FW, 1992). Wesentlich beteiligt sind die beiden rekombinationsaktivierenden Gene RAG1 und RAG2 (Oettinger MA, 1990; Alt FW, 1992; Lewis SM, 1997). Zunächst vollzieht sich eine D$\mathrm{J}_{\mathrm{H}}$-Umlagerung. Die Proteinprodukte der RAG1 und RAG2 erkennen konservierte DNA-Sequenzen, die das 3'-Ende jedes $\mathrm{V}_{\mathrm{H}}$-Segments, das 5'-Ende jedes $\mathrm{J}_{\mathrm{H}}$-Segments sowie beide Seiten jedes D-Segments flankieren. Diese RekombinationssignalSequenzen (RSS) bestehen aus einem konservierten palindromischen Heptamer 5'CACAGTG 3', einem nichtkonservierter Spacer von 12 oder 23 Basenpaaren und einem konserviertes Nonamer 5'ACAAAAACC 3' (Nadel B, 1995).

Die Länge des Spacer ist maßgeblich für das Gelingen der VDJ-Rekombination. Ein Gensegment, das von einer RSS mit einem 12 bp langen Spacer flankiert ist kann nur mit einem Gensegment verknüpft werden, das von einer RSS mit einem 23 bp langen Spacer flankiert ist: 12/23-Regel (Early $\mathrm{P}, 1980$ ). Da sowohl $\mathrm{V}_{\mathrm{H}^{-}}$als auch $\mathrm{J}_{\mathrm{H}^{-}}$ Gensegmente von 23 bp-Spacern und $\mathrm{D}_{\mathrm{H}^{-}}$Gensegmente auf beiden Seiten von 12 bpSpacern flankiert werden, kann eine sinnvolle Kombination stattfinden (Sanz I, 1991). Neueren Studien zu Folge kann diese Regel jedoch nicht als absolut angesehen werden (Koralov SB, 2005).

Haben die RAG-Proteinkomplexe die RSS des D- und J-Segmentes gebunden, lagern sie sich aneinander, stülpen dadurch ein zirkuläres DNA-Fragment aus und bringen die $\mathrm{zu}$ verknüpfenden Segmente haarnadelförmig aneinander. Es kommt zu Doppelstrangbrüchen. Von den $\mathrm{zu}$ verbindenden Gensegmenten werden durch Exonuklease-Aktivität beliebig viele Nukleotide entfernt. Anschließend fügt die terminale Desoxynukleotidyltransferase (TdT) schließlich beliebige, nicht auf der DNA kodierte Nukleotide (N-Nukleotide) an den Grenzen der rekombinierten Gensegmente ein (Alt FW, 1982; Desiderio SV, 1994).

Der gleiche Vorgang schließt sich für die $\mathrm{V}_{\mathrm{H}^{-}}-\mathrm{DJ}_{\mathrm{H}^{-}}-$Umlagerung an (Alt $\mathrm{FW}, 1992$; Lewis SM, 1997). Nach erfolgter VDJ-Rekombination wird ein primäres RNATranskript gebildet und durch Splicing-Vorgänge die aus vier Exons bestehende 
konstante Region angefügt, so dass eine $\mathrm{V}_{\mathrm{H}}-\mathrm{D}-\mathrm{J}_{\mathrm{H}}-\mathrm{C}_{\mathrm{H}}-$ Region entsteht (Honjo T, 2004; Honjo T, 2008; Abbildung 2.3).

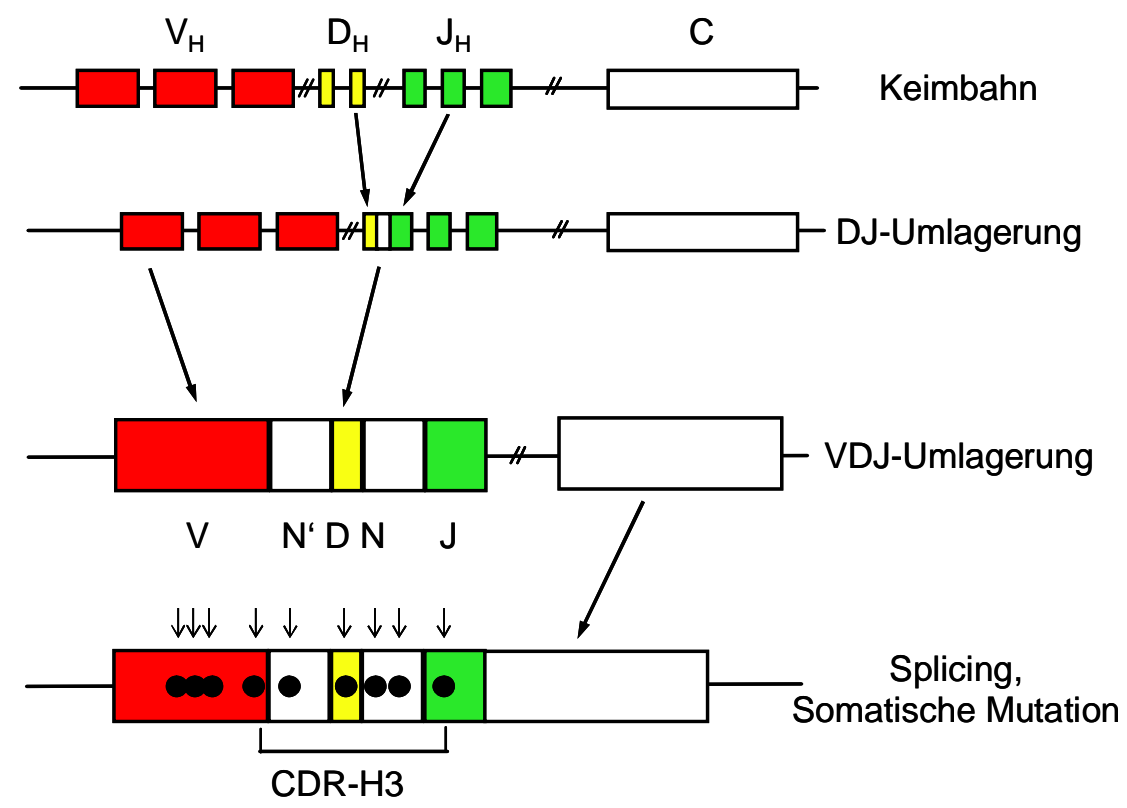

Abbildung 2.3: Schematische Darstellung der VDJ-Rekombination

\subsubsection{Einfügen von P- bzw. N-Nukleotiden}

Die dritte hypervariable Schleife liegt in der schweren Kette im Bereich der Verknüpfungsstelle zwischen dem $\mathrm{V}_{\mathrm{H}^{-}}, \mathrm{D}_{\mathrm{H}^{-}}$und $\mathrm{J}_{\mathrm{H}^{-}}$Gensegment. Durch Insertion und Deletion von P- und N-Nukleotiden kommt es zu einer weiteren Erhöhung der Variabilität.

Bei der somatischen Rekombination kommt es nach erfolgter Komplexbildung zum Entfernen der RSS (Nadel B, 1995; 1997). Die RAG-vermittelte Spaltung der Haarnadelstruktur (Sakano H, 1981) führt zu einer palindromartigen, komplementären Verdoppelung der letzten ein bis ca. vier Nukleotide am Ende eines Segments: P(palindromische) Nukleotide. Dieser Vorgang kann an allen an der somatischen Rekombination beteiligten Segmentenden stattfinden. 3'-Ende des $\mathrm{V}_{\mathrm{H}^{-}}$Segments, beide Enden des $\mathrm{D}_{\mathrm{H}}$-Segments und 5'-Ende des $\mathrm{J}_{\mathrm{H}^{-}}$-Segments.

Nach dem Aufschneiden der Haarnadelstruktur werden durch enzymatische Aktivität der terminalen Desoxynucleotidyltransferase (Desiderio SV, 1984; Komori T, 1993) nicht auf der Keimbahn-DNA kodierte N- (nontemplated) Nukleotide zwischen den 
rekombinierten $\mathrm{V}_{\mathrm{H}}-\mathrm{D}-\mathrm{J}_{\mathrm{H}}-$ Gensegmenten in die einzelsträngige DNA eingefügt (Gilfillan, 1993). Es kommt zur komplementären Basenpaarung der beiden Einzelstänge. Im Anschluß entfernen Reparaturenzyme ungepaarte Nukleotide, füllen die verbliebene einzelsträngige DNA mit komplementären Nukleotiden auf und ligieren die DNA schließlich mit den P-Nukleotiden.

Dies wird als junktionale Diversität bezeichnet und erfolgt unter Inkaufnahme von Verlusten in Form von nicht lesbaren Pseudogenen (,frame shift'). Durch die Deletion einer zufälligen Anzahl potentiell kodierender Nukleotide sowie die Insertion einer zufälligen Anzahl N-Nukleotide wird das Leseraster der kodierenden Sequenz bei zwei von drei somatischen Rekombinationen verschoben. Derartige Rasterverschiebungen führen zu B-Lymphozyten, die keine funktionsfähigen Immunglobuline synthetisieren. In diesen Zellen wird auch das zweite Allel des Immunglobulin-Locus umgelagert. Ist dies ebenfalls erfolglos, so wird die Zelle durch Rezeptor-Revision „,recycled“ (Zhang Z, 2003) oder verfällt der Apoptose.

\subsubsection{Kombination schwerer und leichter Ketten}

Beim Zusammenbau des Immunglobulinmoleküls kommt es zur Kombination zweier identischer schwerer Ketten mit zwei identischen leichten Ketten. Die Leichtketten bestehen aus zwei in etwa gleich großen Regionen. Der konstante Teil $\left(\mathrm{C}_{\mathrm{L}}\right)$ unterscheidet sich bei den verschiedenen Immunglobulinen nur geringfügig. Der ebenfalls mit drei $\mathrm{CDR}_{\mathrm{L}}$-Regionen an der Antigen-Bindungsstelle beteiligte variable Teil $\left(V_{L}\right)$ zeichnet sich hingegen durch eine große Variabilität der Aminosäuresequenz aus. Im Vergleich zur schweren Kette ist die Variabilität jedoch deutlich geringer. Dies rührt von der geringeren Anzahl der Gensegmente in der Keimbahn-DNA her. Je nach Art der Leichtkette ( $\kappa$ oder $\lambda$ ) finden sich 40 bzw. 30 funktionelle V-Segmente und 5 bzw. 4 funktionelle J-Segmente im jeweiligen menschlichen Immunglobulinlocus auf Chromosom 2 bzw. 22 (Joho R, 1980). D-Segmente sind für die leichten Ketten nicht vorhanden. Trotz ihres Beitrags zur Vergrößerung der Antikörpervielfalt hat keine der CDR-Regionen der leichten Ketten annähernd eine so große Vielfalt und einen so großen Einfluss auf die Antigen-Spezifität wie die CDR3-Region der schweren Kette (Xu JL, 2000). 


\subsubsection{Somatische Hypermutationen}

Somatische Hypermutation findet mit Ausnahme sporadischer extrafollikulärer Ereignisse vor allem während der Keimzentrumsreaktion statt. Nach Antigenkontakt kommt es in den umgelagerten variablen Bereichen zur Induktion von Punktmutationen (Neuberger MS, 1995; Jacobs H, 2001; Honjo T, 2004; Honjo T, 2008).

Die antigenbindenden Bereiche der Immunglobuline werden dabei mit einer Rate von 0,1 bis 1 Mutation pro $10^{3}$ Basenpaare mutiert. Da diese Rate ca. $10^{6}$ mal über der basalen, natürlichen Mutationsrate somatischer Zellen liegt, wird dieser Prozess als somatische Hypermutation bezeichnet (McKean D, 1984; Collins AM, 2003).

Der Abschnitt der Immunglobulingene, auf dem sich die Mutationsprozesse ereignen, beginnt ca. 150 bp unter der Initiationsstelle der Transkription. Er erstreckt sich über den gesamten kodierenden Sequenzbereich des rearrangierten V(D)J-Bereiches der variablen Region und endet ca. 1,5-2 kb unterhalb der Transkriptionsinitiationsstelle im nicht-kodierenden Bereich vor dem Intron-Enhancer und dem konstanten Bereich (Lebecque SG, 1990; Rada C, 1997; Rada C, 2001; Honjo T, 2004).

In der Regel handelt es sich bei der somatischen Hypermutation um einzelne Punktmutationen (Wagner SD, 1996; Papavasiliou FN, 2002), gelegentlich treten Insertionen oder Deletionen auf (Wilson PC, 1998). Die Verteilung der Mutationen läuft hierbei nicht zufällig ab (Betz AG, 1993). Bevorzugte Nukleotidsequenzen (für GC-

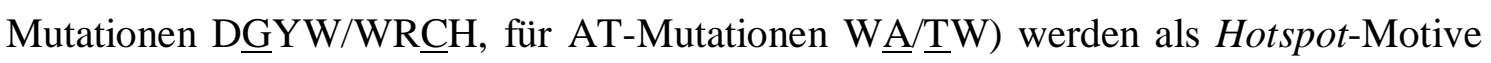
bezeichnet (Rogozin IB, 1992; Milstein C, 1998). Dabei steht D für ein A, G oder T, R für ein A oder G, $\mathbf{Y}$ für ein $\mathrm{C}$ oder $\mathrm{T}$ und $\mathbf{W}$ für ein $\mathrm{A}$ oder $\mathrm{T}$ an dieser Position.

Die Mutationen werden in die Aminosäuresequenz verändernde ReplacementMutationen und nicht sequenzwirksame silente Mutationen unterteilt. Diejenigen BLymphozyten, deren Immunglobuline durch eine veränderte Aminosäuresequenz eine größere Antigen-Affinität erreichen, werden selektiert und durchlaufen weitere Differenzierungsschritte, die sogenannte positive Selektion (Rajewsky K, 1996). Somit weisen antigenselektierte B-Lymphozyten vermehrt Replacement-Mutationen in den CDR-Regionen auf, die für die Antigenbindung von besonderer Bedeutung sind. Framework-Regionen, die für die wichtige Gerüststruktur der funktionellen Immunglobuline kodieren, sind deutlich seltener mutiert (Betz AG, 1993). Führt eine Replacement-Mutation zur Bildung eines Stop-Codons und damit zum Abbruch der 
Transkription, so wird in der entsprechenden Zelle die Apoptose induziert (Insel RA, 1998).

Das Schlüsselenzym, das sowohl für die somatische Hypermutation als auch für den Isotypenwechsel (siehe unten) essentiell ist, ist die Aktivierungsinduzierte Cytidindeaminase (AID) (Honjo T, 2004; Honjo T, 2008). Die AID triggert die Deamination von Cytidin zu Uridin in einer einzelsträngigen DNA (Petersen-Mahrt SK, 2002). Gegenläufig wird bei der Zweitstrangsynthese dann ein Adenosin komplementär zum Uridin anstelle eines Guanosins in die DNA eingebaut. Muramatsu et al. (Muramatsu M, 2000) konnten zeigen, dass eine Inaktivierung der AID über AIDKnockout-Mäuse eine völlige Abwesenheit von somatischer Hypermutation und Isotypenwechsel zur Folge hatte. Des Weiteren fand man Mutationen in der AID als Ursache für eine autosomal-rezessive Form des Hyper-IgM-Syndroms (HIGM2) (Revy P, 2000). Ein weiteres beteiligtes Enzym ist die Uracil-DNA-Glycosylase (UNG). Sie schneidet das durch die AID entstandene Uracil heraus. UNG-defiziente Mäuse zeigten keine Verminderung der Mutationsfrequenz, jedoch ein verändertes Mutationsmuster (Storb U, 2002). Nach dem Hypermutationsprozess durchlaufen die B-Lymphozyten eine positive Selektion. Die Zellen, deren Affinität angestiegen ist, erhalten ein Überlebenssignal (Ledermann S, 1992).

\subsection{Besonderheiten des GALT (gut-associated lymphoid tissue)}

Im Immunsystem unterscheidet man anatomisch unterschiedliche Kompartimente, von denen jedes einzelne gezielte Reaktionen gegen Pathogene auslösen kann. Diese Kompartimente können aufgrund zweier wesentlicher Merkmale definiert werden: Zum einen bleiben Immunreaktionen, die in einem dieser Kompartimente ausgelöst werden, weitestgehend darauf begrenzt. Zum anderen sind Lymphozyten aufgrund spezieller Rezeptoren auf bestimmte Kompartimente beschränkt.

Ein großes, hochspezialisiertes Kompartiment der adaptiven Immunität befindet sich in der Nähe der Oberflächen, über welche die meisten Pathogene in den Körper des Wirts eindringen: Das darmassoziierte lymphatische Gewebe oder GALT (gut-associated lymphoid tissue). Dieses von Geburt an kontinuierlichem Antigenkontakt ausgesetzte intestinale Immunsystem stellt den größten und komplexesten Teil des menschlichen Immunsystems dar (Mowat AM, 2003) und zählt zum common mucosal immune system 
(McGhee JR, 1992; Maheshwari A, 2006). Das GALT besteht aus zahlreichen schleimhaut-assoziierten Lymphfollikeln in der Lamina propria mucosae und Tela submucosa des Darms sowie intraepithelialen und diffus in der Darmmukosa verteilten Lymphozyten (Fujimura Y, 1996) sowie Makrophagen und dendritischen Zellen. Strukturell gesehen vereint das GALT u.a. Solitärfollikel im Jejunum, aggregierte Lymphfollikel der Appendix vermiformis sowie die spezialisierten Strukturen der Peyerschen Plaques im Ileum (Gebert A, 2000). Auch die von Saito H. et al. 1998 beschriebenen ,cryptopatches', Ansammlungen von Vorläufer-T-Tellen in den Krypten der Lamina propria mucosae, werden zum GALT gezählt (Saito H, 1998).

\subsubsection{Anatomie der Peyerschen Plaques}

Die nach ihrem Erstbeschreiber, dem Schweizer Anatomen Johannes Conrad Peyer (1653-1712) benannten Peyerschen Plaques gehören zum induktiven Anteil der Immunreaktion. Es handelt sich hierbei um Aggregationen von Lymphfollikeln in den mukosalen Wandanteilen v. a. des Dünndarms. Beim Menschen existieren zumeist ca. 20-30 dieser Plaques, bestehend aus durchschnittlich 10-60 Follikeln. Ihre Anzahl kann jedoch im terminalen Ileum auf mehrere Hundert Follikel ansteigen (Cornes JS, 1965). Die kuppel-(dom-)förmige Struktur der Peyerschen Plaques wird luminal durch das Follikel-Assoziierte Epithel (FAE) begrenzt, ein spezialisiertes Epithel ohne Krypten und Zotten, das nur wenige schleimproduzierende Becherzellen und keine exokrin sezernierenden Paneth-Körnerzellen enthält (Makala LH, 2002; 2003). Hierin findet man spezifische M(microfold)-Zellen, Mikrovilli-freie Epithelzellen, denen die Aufgabe des transepithelialen Transports luminaler Antigene zukommt (Neutra MR, 2001).

Unterhalb des Follikel-Assoziierten Epithels liegt, durch eine dünne Schicht subepithelialen Domareals (SED) getrennt, der eigentliche Follikel. Er besteht aus einer äußeren Mantelzone, die reich an B-Lymphozyten, CD4-T-Lymphozyten und reifen dendritischen Zellen ist (Abbildung 2.4). 

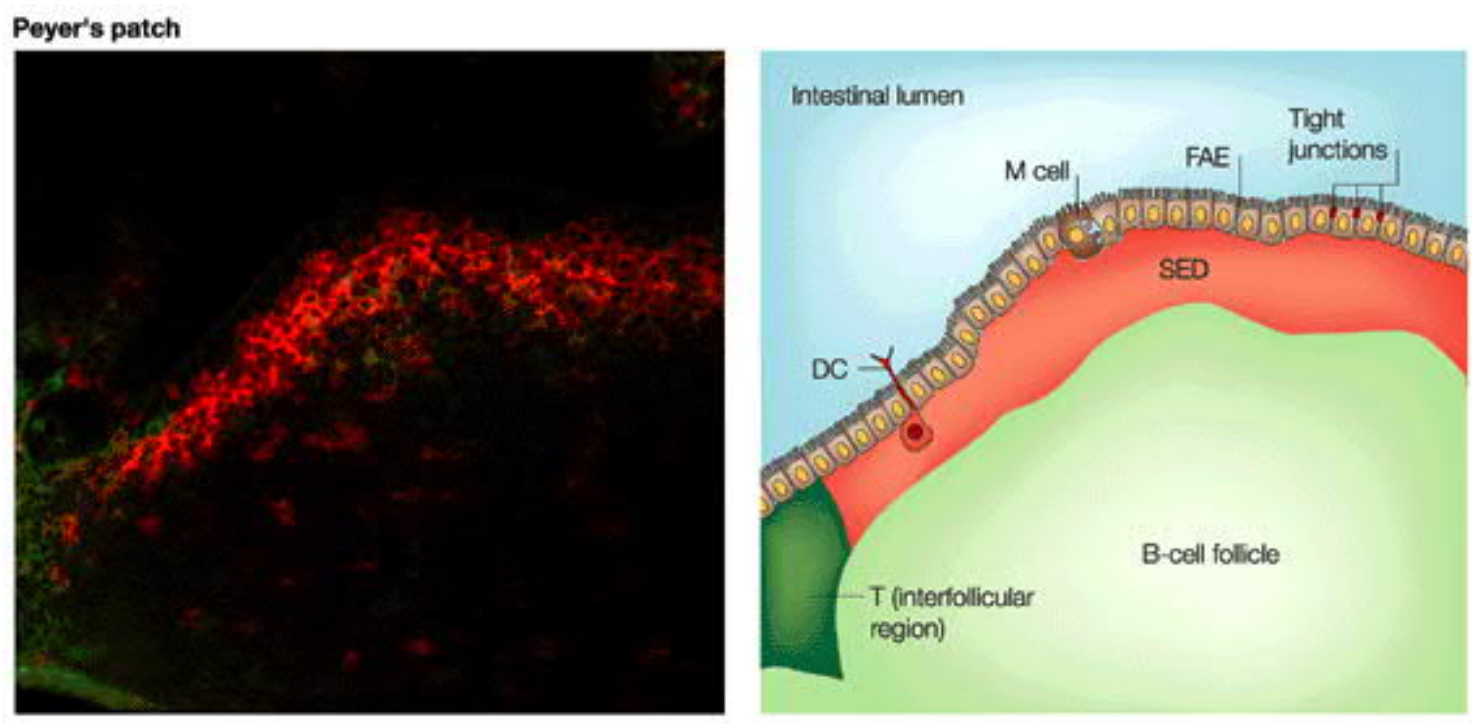

Abbildung 2.4: Immunfluoreszenz-Aufnahme (links) und schematische Darstellung eines Peyerschen Plaques (rechts) (aus: Nagler-Anderson C, 2001)

In der Immunfluoreszenz-Aufnahme werden T-Lymphozyten grün und dendritische Zellen (DC) rot dargestellt. Neben spezialisierten M-Zellen gewährleisten DCs den transepithelialen Transport. DCs sind sowohl im subepithelialen Domareal als auch im interfollikularen T-Zell-Areal als sternförmige rote Zellen sichtbar.

Vor allem im Dünndarm bilden B-Lymphozyten mit einem Netzwerk von dendritischen Zellen im Kern der Follikel ein Keimzentrum. Im Überlappungsbereich von B-Zellreichen Mantelregionen und T-Zell-reichen Interfollikularregionen finden wichtige B-TZell-Interaktionen statt (MacLennan IC, 1997). Fehlen antigenspezifische T-Zellen, ist die klonale Expansion nach einer Immunisierung deutlich reduziert (Garside P, 1998). Die Interaktion zwischen B- und T-Lymphozyten wird vor allem über CD40 und CD40L, zwei Rezeptoren der TNF-Rezeptor-Familie, vermittelt. Bei der Aktivierung reifer B-Lymphozyten kann die Keimzentrumsreaktion, der Klassenwechsel sowie die Reifung von B-Gedächtniszellen induziert werden (van Kooten C, 2000).

\subsubsection{Die Keimzentrumsreaktion}

Die meisten aktivierten B-Zellen migrieren in die rote Pulpa der Milz und in die Markstränge der Lymphknoten, wo sie zu kurzlebigen, niederaffinen Plasmazellen ausdifferenzieren. CD40L-aktivierte B-Lymphozyten durchlaufen innerhalb von zwei bis vier Tagen nach Aktivierung eine oligoklonale Proliferation und formieren sich in Kombination mit follikulären dendritischen Zellen und $\mathrm{T}_{\mathrm{H}}$-Zellen $\mathrm{zu}$ einem so genannten Keimzentrum (Liu YJ, 1991; Wolniak KL, 2004). 
In den folgenden Tagen entwickelt sich aus dem Primärfollikel ein Sekundärfollikel, der durch die Unterteilung in eine hellere und eine dunklere Zone mit umgebender Mantelzone charakterisiert ist (MacLennan IC, 1994). Die dunklere Zone beherbergt die alle sechs Stunden proliferierenden Zentroblasten, in denen durch somatische Hypermutation hochaffine B-Zell-Rezeptoren generiert werden (Liu YJ, 1991; Liu YJ, 1996) (Abbildung 2.5). In der hellen Zone findet die Selektion der aus Zentroblasten hervorgehenden, nicht mehr proliferierenden Zentrozyten über ihren B-Zell-Rezeptor statt. Nur diejenigen B-Lymphozyten, die durch die somatische Hypermutation eine höhere Affinität zu ihrem Antigen erworben haben (Affinitätsreifung), erhalten über ihren B-Zell-Rezeptor und CD40L ein Überlebenssignal (Lederman S, 1992).

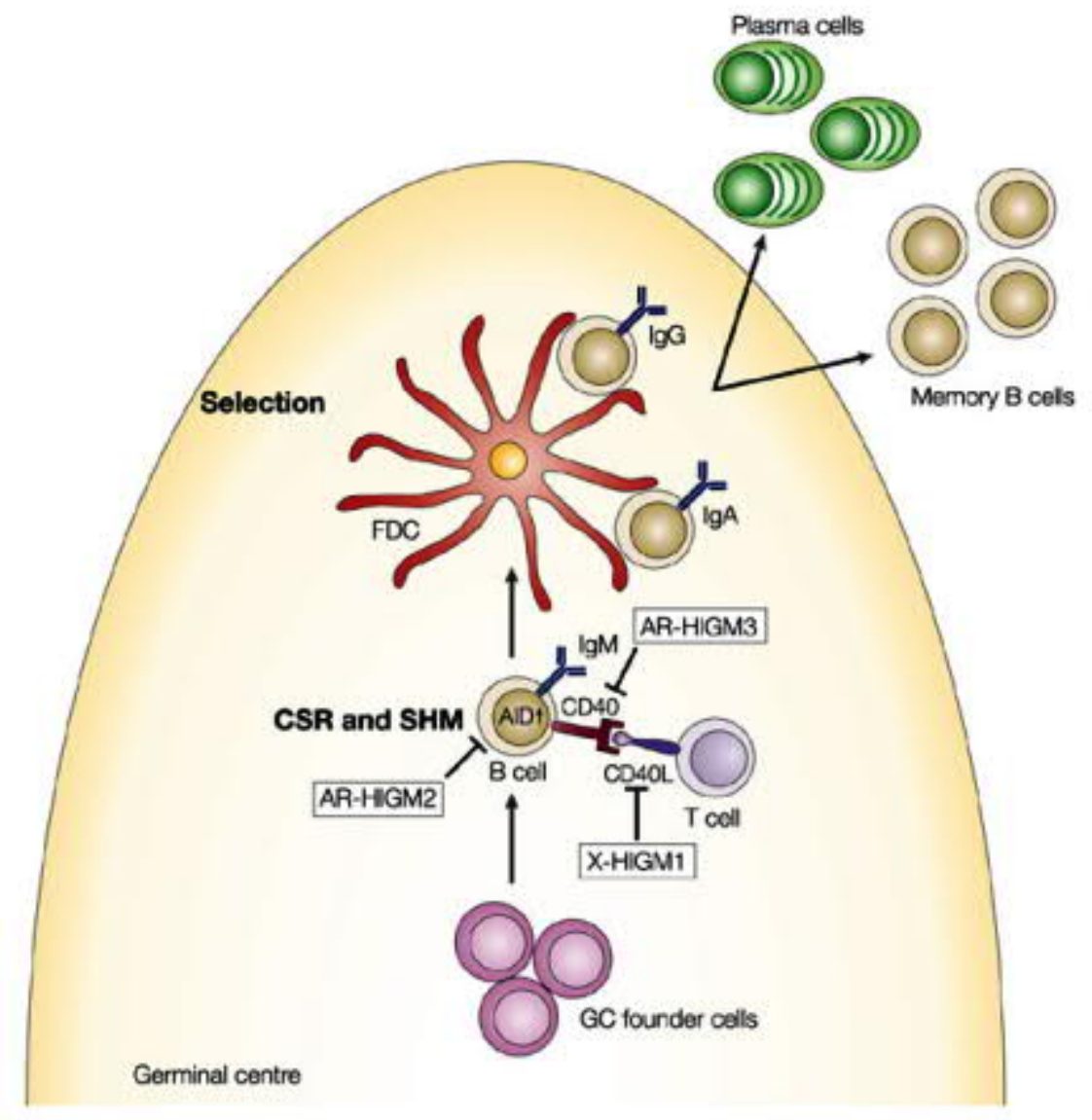

Nature Reviews | Immunology

Abbildung 2.5: Schematische Darstellung eines Keimzentrums (de Villartay JP, 2003)

Innerhalb des Keimzentrums finden bei CD40-CD40L-Interaktion und AID-Aktivität Klassenwechsel (CSR) und somatische Hypermutation (SHM) naiver B-Lymphozyten in Kooperation mit aktivierten $\mathrm{CD}^{+}$T-Lymphozyten statt. Nach SHM verläuft der Selektionsprozess in engem Kontakt mit follikulären dendritischen Zellen (FDC). Mutationen in den Genen für CD40, CD40L und AID können zu verschiedenen Formen des Hyper-IgM-Syndroms (HIGM) führen. 
B-Zellen, die keine erhöhte Affinität zum Antigen erlangt haben, werden apoptotisch. Positiv selektionierte B-Lymphozyten können weitere Zyklen der Reifung und Selektion durchlaufen, bis schließlich klonal verwandte Zellen mit unterschiedlichen Mutationsstrukturen in IgVH das Keimzentrum verlassen (Liu YJ, 1997) und sich zu langlebigen, Antikörper-sezernierenden Plasmablasten oder $\mathrm{zu}$ ruhenden BGedächtniszellen entwickeln, die im Falle einer Reinfektion mit dem gleichen Pathogen zu einer sehr viel schnelleren, hochaffinen Immunantwort führen (Tarlinton DM, 2000).

\subsubsection{Isotypenwechsel}

Die Effektorfunktion des Immunglobulinmoleküls ist abhängig von der jeweiligen Antikörperklasse und wird über die konstanten carboxyterminalen Domänen der schweren Ketten reguliert. Die Gene für die konstanten Regionen der Immunglobulinmoleküle liegen in einem großen Cluster von ca. $200 \mathrm{~kb}$ vor, der sich auf der 3'-Seite der $\mathrm{J}_{\mathrm{H}^{-}}$-Gensegmente erstreckt. Dabei liegt das $\mathrm{C}_{\mu}$-Gensegment den $\mathrm{J}_{\mathrm{H}^{-}}$ Gensegmenten und damit dem nach erfolgter somatischer Rekombination zusammengesetzten Exon für die variable Region am nächsten. Darum werden die $\mu$ Schwerketten zuerst exprimiert und IgM ist der erste Immunglobulinisotyp, der im Rahmen der B-Zellentwicklung produziert wird (Bengtén E, 2000).

Der Wechsel zu anderen Isotypen erfolgt erst, wenn B-Lymphozyten durch ein Antigen stimuliert wurden. Hierbei spielen Bereiche repetitiver DNA, so genannte Schalter(oder switch) Regionen, eine entscheidende Rolle, die im Intron vor dem jeweiligen CGensegment liegen. Die Sequenzen der jeweiligen Schalterregionen unterscheiden sich in Einzelheiten, alle enthalten jedoch Wiederholungen von „GAGCT“- und „GGGGGT“-Sequenzen. Der Isotypenwechsel erfolgt durch Rekombination zwischen diesen repetitiven Sequenzen, wobei die zwischenliegende DNA deletiert wird (Stavnetzer J, 1996). Schlüsselenzym hierbei ist wiederum die Cytidin zu Uridin deaminierende aktivierungsinduzierte Cytidindeaminase (AID). Ein Mangel an AID durch Verminderung des Transkriptionsfaktors E47, wie er natürlicherweise im Alter entsteht, führt über eine Verminderung des Isotypenwechsels und der somatischen Mutationen zur Bildung niederaffiner Antikörper (Frasca D, 2008).

Die Aktivierung von B-Lymphozyten wird induziert durch die Interaktion zwischen Bund $\mathrm{T}_{\mathrm{H}}$-Lymphozyten über den CD40-CD40L-Komplex sowie durch 
isotypenspezifische Zytokine. Mutationen von CD40L können beim Menschen und bei der Maus zum fehlenden Klassenwechsel und somit zur Bildung eines Hyper-IgMSyndroms führen (Xu JL, 1994). Für den Klassenwechsel von IgM zu IgA sind die isotypenspezifischen Zytokine TGF- $\beta$, IL-10, IL-4, IL-5 und IL-6 obligatorisch (Brandtzaeg P, 2005). Ist der Isotypenwechsel einmal vollzogen, übernimmt IgA an mukosalen Oberflächen drei verschiedene Aufgaben. Auf luminaler Seite verhindert sekretorisches IgA die Anheftung und das Eindringen von Antigenen in das Epithel (Nagler-Anderson C, 2001). Innerhalb der Lamina propria können IgA-Antikörper Antigene binden und diese luminal absondern (Robinson JK, 2001). Zusätzlich können sie eine intraepitheliale Virusproduktion inhibieren (Fujioka H, 1998) oder proinflammatorische Antigene neutralisieren (Fernandez MI, 2003).

\subsection{Fragestellung}

B-Lymphozyten durchlaufen eine Antigen-unabhängige und eine Antigen-abhängige Reifungsphase. In beiden Phasen werden die B-Zellen unter anderem anhand der Eigenschaften der Antigen-Bindungsstelle des membranständigen Immunglobulins selektiert (Zemlin M, 2002). Wir haben die Hypothese aufgestellt, dass IgA-bildende Subpopulationen der Gedächtnis- und Plasmazellen nicht zufällig, sondern aufgrund ihrer Antigen-Bindungseigenschaften rekrutiert werden.

Mit dieser Arbeit sollen grundlegende Fragen zur Entwicklung des B-Zell- bzw. Antikörper-Repertoires im GALT beantwortet werden:

- Welchem Selektionsdruck unterliegt das B-Zell-Repertoire während des Klassenwechsels zu IgA?

- Nach welchen Kriterien entwickeln sich Zellen zu Plasma- oder Gedächtniszellen?

Um diese Fragen zu beantworten wurden die Repertoires von IgM und IgA exprimierenden Plasma- und Gedächtniszellen anhand ihrer klonalen Diversität, der Verwendung von $\mathrm{V}_{\mathrm{H}^{-}}, \mathrm{D}_{\mathrm{H}^{-}}$und $\mathrm{J}_{\mathrm{H}^{-}}$Gensegmente sowie der Art und Verteilung der somatischen Mutationen verglichen. 


\section{Material und Methoden}

\subsection{Sequenzierung der RNA-Transkripte für die variable Region der schweren Kette}

\subsubsection{Haltung und Präparation der Mäuse}

\section{Arbeitsmaterialien:}

MACS-Puffer

Kulturschalen

Terralin $®$ Liquid

Chirurgische Pinzette und Schere
Miltenyi Biotec; Bergisch Gladbach, D Klinikum der Philipps-Universität, Marburg, D Schülke \& Mayr GmbH, Norderstedt, D Aesculap Incorporation, Center Valley, USA

Für die Gewinnung der Zellen der Peyerschen Plaques wurden vier acht bis zehn Wochen alte BALB/c Mäuse von Harlan Winkelmann (Borchen, D) bezogen. Die Haltung erfolgte unter spezifisch pathogenfreien Bedingungen (SPF-Mäuse) in einzeln belüfteten Käfigen mit einem Hell-/Dunkelrhythmus von 12/12 Stunden. Die Tiere erhielten Futter und Wasser nach Belieben. Die Tötung der Tiere erfolgte durch zervikale Dislokation. Die entsprechende Genehmigung des Regierungspräsidiums Gießen für die Durchführung der Tierexperimente und gentechnischen Arbeiten liegt vor (V54-19 c 20-15(1) MR 36-05/2007).

Für die Zellisolation wurde jede der vier Mäuse separat seziert. Nach Tötung wurde die Maus mittels Stecknadeln auf einer Styroporplatte fixiert. Das Fell wurde mit alkoholischer Desinfektionslösung besprüht und die Peritonealhöhle durch einen Längsschnitt eröffnet. Der Dünndarm wurde freigelegt und die Peyerschen Plaques wurden aufgesucht. Mittels einer chirurgischen Pinzette und einer Schere konnten sie vom übrigen Gewebe getrennt werden. Zur besseren Erhaltung der Zellen wurden die entnommenen Peyerschen Plaques sofort in eine mit kaltem MACS-Puffer befüllte Kulturschale auf Eis gelegt. 
3.1.2 Antikörperfärbung der isolierten Zellen

\section{Arbeitsmaterialien:}

MACS Puffer

Zellsiebe $100 \mu \mathrm{m}$

$15 \mathrm{ml} / 50 \mathrm{ml}$ Falconröhrchen

96 Well Mikrotiterplatte
Miltenyi Biotec GmbH, Bergisch Gladbach, D Nunc GmbH \& Co. KG, Wiesbaden, D Eppendorf AG, Hamburg, D Nunc GmbH \& Co. KG, Wiesbaden, D

\section{Geräte:}

Zellzähler K-800

Sysmex GmbH, Norderstedt, D

Centrifuge 5810R

Eppendorf AG, Hamburg, D

Monoklonale Antikörper gegen murine Zelloberflächenmoleküle:

\begin{tabular}{|l|l|l|l|l|}
\hline Antikörper & Klon & Isotyp & Markierung & Quelle \\
\hline CD19 & 6 D5 & IgG2ak & $\begin{array}{l}\text { Spectral Red } \\
\text { (SPRD) }\end{array}$ & Southern Biotec \\
\hline CD21 & 7 G6 & IgG2bk & Phycoerythrin (PE) & BD Pharmingen \\
\hline CD23 & B3B4 & IgG2ak & Fluorescein (FITC) & BD Pharmingen \\
\hline CD138 & $281-2$ & IgG2ak & PE & BD Pharmingen \\
\hline IgM & & & Cyanine 5 (Cy5) & Jackson Immuno \\
\hline IgA & C10-3 & IgG1k & FITC & BD Pharmingen \\
\hline
\end{tabular}

Tabelle 3.1: Monoklonale Antikörper gegen Zelloberflächenmoleküle

Bevor mit der Aufreinigung des entnommenen Gewebes begonnen wurde, wurden Verdünnungsreihen der Antikörper sowie die benötigten MasterMixe (Antikörpergemische) hergestellt. Dabei wurde stets auf Eis und möglichst unter Lichtausschluss gearbeitet.

Die Färbungen erfolgten nach folgendem Schema:

MasterMix 1:

\begin{tabular}{|l|l|l|}
\hline Antikörper & Verdünnung & $\mu 1 /$ Pellet \\
\hline CD23-FITC & $1: 200$ & 1 \\
\hline CD21-PE & $1: 200$ & 0,5 \\
\hline CD19-SPRD & $1: 200$ & 0,5 \\
\hline IgM-Cy5 & $1: 200$ & 0,5 \\
\hline & & Ad $100 \mu 1$ \\
\hline
\end{tabular}


MasterMix 2:

\begin{tabular}{|l|l|l|}
\hline Antikörper & Verdünnung & $\mu 1 /$ Pellet \\
\hline IgA-FITC & $1: 500$ & 0,2 \\
\hline CD138-PE & $1: 200$ & 0,5 \\
\hline CD19-SPRD & $1: 200$ & 0,5 \\
\hline & & Ad $100 \mu 1$ \\
\hline
\end{tabular}

Single Color Control:

\begin{tabular}{|l|l|l|}
\hline Antikörper & Verdünnung & $\mu 1 /$ Pellet \\
\hline CD19-SPRD & $1: 200$ & 0,25 \\
\hline CD21-PE & $1: 200$ & 0,25 \\
\hline CD23-FITC & $1: 200$ & 0,5 \\
\hline CD138-PE & $1: 200$ & 0,25 \\
\hline IgM-Cy5 & $1: 200$ & 0,25 \\
\hline IgA-FITC & $1: 500$ & 0,1 \\
\hline & & Jeweils getrennt ad \\
& & $50 \mu 1$ \\
\hline
\end{tabular}

Um die Zellen der Peyerschen Plaques vom umgebenden Bindegewebe und von eventuellen Verunreinigungen zu separieren, wurden sie mithilfe eines Spritzenstempels und ca. $3 \mathrm{ml}$ MACS-Puffer vorsichtig durch ein $100 \mu \mathrm{m}$ Zellsieb gestrichen. Mittels eines Zellzählers konnte die Anzahl der Zellen pro Mikroliter bestimmt und auf die benötigte Menge der Zellsuspension umgerechnet werden, um $1 \times 10^{6}$ (1 Million) Zellen für die FACS-Analyse und anschließende Sortierung zu erhalten.

Die erhaltene Zellsuspension wurde nach Verrechnung entsprechend ihrer Verwendung zur Sortierung $\left(10^{6}\right.$ Zellen) oder als Single Color Control $\left(10^{5}\right.$ Zellen) in die 96-WellMikrotiterplatte pipettiert. Die Zellen wurden mit $1200 \mathrm{rpm}$ bei $4^{\circ} \mathrm{C}$ für 5 Minuten zentrifugiert und die überschüssige Flüssigkeit verworfen.

Jede zur Zellsortierung verwendete Färbung bestand aus einer Kombination von vier bzw. drei fluorochrom-gekoppelten Antikörpern gegen Zelloberflächenproteine.

Die Färbung wurde durch Zugabe der Antikörperlösungen und Resuspension der Zellen gestartet. Die Inkubation erfolgte 30 Minuten lang auf Eis und unter Ausschluss von Tageslicht. 
Pipettierschema:

\begin{tabular}{|c|c|c|c|c|}
\hline & 1 & 2 & 3 & 4 \\
\hline$\overline{\mathbf{A}}$ & PP & & & \\
\hline B & $\begin{array}{l}\text { IgM-Cy5 + } \\
\text { PP }\end{array}$ & $\mathrm{CD} 21-\mathrm{PE}+\mathrm{PP}$ & $\begin{array}{l}\text { CD23-FITC + } \\
\text { PP }\end{array}$ & $\begin{array}{l}\text { CD19-SPRD }+ \\
\text { PP }\end{array}$ \\
\hline $\mathbf{C}$ & $\begin{array}{l}\text { IgA-FITC }+ \\
\mathrm{PP}\end{array}$ & $\begin{array}{l}\text { CD138-PE + } \\
\text { PP }\end{array}$ & & \\
\hline D & $\begin{array}{l}\text { IgM + CD21 } \\
+\quad \mathrm{CD} 23+ \\
\mathrm{CD} 19+\mathrm{PP} 1\end{array}$ & $\begin{array}{l}\operatorname{IgM}+\mathrm{CD} 21+ \\
\mathrm{CD} 23+\mathrm{CD} 19 \\
+\mathrm{PP} 2\end{array}$ & $\begin{array}{l}\operatorname{IgM}+\mathrm{CD} 21 \\
+\quad \mathrm{CD} 23+ \\
\mathrm{CD} 19+\mathrm{PP} 3\end{array}$ & $\begin{array}{l}\mathrm{IgM}+\mathrm{CD} 21+ \\
\mathrm{CD} 23+\mathrm{CD} 19+ \\
\text { PP4 }\end{array}$ \\
\hline $\mathbf{E}$ & $\begin{array}{l}\operatorname{Ig} \mathrm{A}+\mathrm{CD} 19 \\
+\mathrm{CD} 138+ \\
\text { PP1 }\end{array}$ & $\begin{array}{l}\operatorname{IgA}+\mathrm{CD} 19+ \\
\mathrm{CD} 138+\mathrm{PP} 2\end{array}$ & $\begin{array}{l}\operatorname{IgA}+\text { CD19+ } \\
\text { CD138 + PP3 }\end{array}$ & $\begin{array}{l}\operatorname{IgA}+\mathrm{CD} 19+ \\
\mathrm{CD} 138+\mathrm{PP} 4\end{array}$ \\
\hline
\end{tabular}

Tabelle 3.2: Pipettierschema

(PP: Peyersche Plaque-Zellen)

Darauf folgend wurden $50 \mu \mathrm{l}$ kalter MACS-Puffer zupipettiert und damit die überschüssigen, nicht gebundenen Antikörper diluiert. Um die ungebundenen Antikörper anschließend wegzuwaschen, wurde die Suspension zentrifugiert und der Überstand verworfen. Diese Vorgänge wurden zur vollständigen Elimination ungebundener Antikörper ein weiteres Mal mit $150 \mu 1$ MACS-Puffer wiederholt und die Zellen bis zur Messung unter Lichtausschluss auf Eis gelagert.

Die durchflusszytometrische Messung wurde an einem FACSCalibur® Gerät der Firma Becton Dickinson durchgeführt. Die Auswertung der Daten erfolgte mit geeigneter Software (Cell Quest Pro ${ }^{\mathrm{TM}}$ ).

\subsubsection{Durchflusszytometrie / FACS (Fluorescence-activated-cell-sorting)}

\section{Arbeitsmaterialien:}

MACS-Puffer:

FACS Clean ${ }^{\circledR}$

FACS Rinse $®$

FACS Flow ${ }^{\circledR}$
Miltenyi Biotec, Bergisch Gladbach, D

BD (Becton Dickinson), Heidelberg, D

BD (Becton Dickinson), Heidelberg, D

BD (Becton Dickinson), Heidelberg, D 
FACS Röhrchen

BD (Becton Dickinson), Heidelberg, D

\section{Geräte:}

FACS Calibur ${ }^{\circledR}$

BD (Becton Dickinson), Heidelberg, D

Mixer Vortex Reax top

Fa. Kobe, Marburg, D

Software CELL Quest Pro ${ }^{\mathrm{TM}}$

BD (Becton Dickinson), Heidelberg, D

Die Fluoreszenz-Aktivierte-Zellanalyse (FACS-Analyse) ist ein Verfahren zur quantitativen Bestimmung von Zellen anhand von Oberflächenmolekülen und intrazellulären Proteinen. Zudem ist es möglich, Aussagen über Zellgrößen und Binnenstrukturen zu treffen und somit zum Beispiel Leukozytensubpopulationen zu differenzieren. Grundlage ist eine Antigen-Antikörper-Reaktion, die mit fluoreszenzfarbstoffmarkierten Antikörpern durchgeführt wird.

Eine Zellsuspension, die mit fluoreszierenden Antikörpern gefärbte Zellen enthält, wird mit Druckluft aus dem Probenröhrchen durch einen dünnen Schlauch und ein Metallröhrchen in eine Düse gepresst. Die Zellen treten in das Zentrum der Düse ein und aus einer $70 \mu \mathrm{m}$ großen Öffnung wieder aus. Seitlich wird eine isotone Hüllflüssigkeit zugeführt. Im Inneren der Düse werden die Zellen stark beschleunigt (bis $10.000 \times$ Erdbeschleunigung), wodurch sie die Düse mit einer Geschwindigkeit von ca. $9 \mathrm{~m} / \mathrm{s}$ verlassen. Direkt unterhalb der Düse trifft ein fokussierter Laserstrahl den austretenden Flüssigkeitsstrahl. Das Laserlicht wird beim Auftreffen auf zelluläre Strukturen gestreut und die emittierte Streustrahlung durch Photodetektoren registriert. Zusätzlich senden die zuvor mit fluoreszierenden Antikörpern gekoppelten Zellen Fluoreszenzlicht aus. Bei exakter Anregung der Elektronen des Fluoreszenzfarbstoffs durch den Laserstrahl werden diese auf ein höheres Energieniveau angehoben. Nach Abschwächung des Laserimpulses fallen die Elektronen unter Abgabe von Energie (in Form von Photonen) auf ihr Ursprungsniveau zurück. Diese Photonenkonzentration, die durch einen Photodetektor registriert wird, verhält sich proportional zur Menge der gebundenen Antikörper pro Zelle.

Das von den Zellen in Richtung des Lasers gestreute Licht wird mit einem Photodetektor als so genanntes Vorwärtsstreulicht gemessen (FSC) und ist ein Maß für die Größe der Zellen. Das hinter der Düse aufgefangene Licht ist die Summe aus dem so genannten Seitwärtsstreulicht (SSC) und dem emittierten Fluoreszenzlicht der Antikörper-Fluoreszenzkonjugate. Maßgeblich für die Granularität ist hierbei das Seitwärtsstreulicht; das Fluoreszenzlicht ist für die jeweils verwendeten Fluorochrome 
spezifisch. Durch einen optischen Interferenzfilter wird es nach Wellenlängen getrennt und gelangt auf die hochempfindlichen Photodetektoren.

Das hier verwendete Analysegerät FACSCalibur ${ }^{\circledR}$ der Firma Becton Dickinson ist mit einem Argonlaser $(488 \mathrm{~nm})$ und einer roten Laserdiode $(633 \mathrm{~nm})$ ausgestattet und erlaubt die gleichzeitige Analyse von bis zu vier verschiedenen Farben. Eine gleichzeitige Messung verschiedener Fluoreszenzfarbstoffe ist möglich, da sich die eingesetzten Farbstoffe zwar bei derselben Wellenlänge anregen lassen, aber über unterschiedliche, für den jeweiligen Farbstoff charakteristische Emissionsspektren verfügen.

Tabelle 3.3 zeigt die Absorptions- und Emissionswellenlängen der verwendeten Markierungen.

\begin{tabular}{|llll|}
\hline Fluoreszenzkanal & Farbstoff & Absorptionsmaximum & Emissionsmaximum \\
FL1 & FITC & $495 \mathrm{~nm}$ & $519 \mathrm{~nm}$ \\
FL2 & PE & $480 / 565 \mathrm{~nm}$ & $578 \mathrm{~nm}$ \\
FL3 & SPRD & $589 \mathrm{~nm}$ & $615 \mathrm{~nm}$ \\
FL4 & Cy5 & $650 \mathrm{~nm}$ & $670 \mathrm{~nm}$ \\
\hline
\end{tabular}

Tabelle 3.3: Spezifizierung der Fluorochrome

Über die zugehörige Software CELL Quest Pro ${ }^{\mathrm{TM}}$ wurde die „Dot Plot“-Darstellung gewählt, eine zweidimensionale Darstellung zweier Parameter. Jede Zelle wird entsprechend ihrer Werte für Parameter 1 und Parameter 2 zwischen X- und Y-Achse als Punkt eingetragen. Durch das Setzen von Analysefenstern kann die Expressionsanalyse einzelner Oberflächenmoleküle auf bestimmte Zellpopulationen beschränkt werden.

\subsubsection{Cell-Sorting}

\section{Arbeitsmaterialien:}

RLT Puffer

$\beta$-Mercaptoethanol

$70 \mu 1$ Zellsiebe
Qiagen GmbH, Hilden, D Fluka Chemie GmbH, Buchs, $\mathrm{CH}$ Dako Cytomation GmbH, Hamburg, D 


\section{Geräte:}

$\mathrm{MoFlo}^{\mathrm{TM}}$

Dako Cytomation GmbH, Hamburg, D

Zur Zellsortierung mittels eines abreißenden Flüssigkeitsstrahls, wie sie in dieser Arbeit durchgeführt wurde, benötigt man eine Einzelzellsuspension. Die mit Hilfe von Fluoreszenzfarbstoffen markierte Zellsuspension wird in einer Trägerflüssigkeit so durch eine Düse gepresst, dass die Zellen einzeln nacheinander in die Mitte des Flüssigkeitsstrahls gelangen (hydrodynamische Fokussierung). Die Intensität der Fluoreszenz jeder Zelle wird wie bei einer durchflusszytometrischen Messung analysiert und die Ergebnisse als mehrparametrige Verteilungen auf einem Bildschirm dargestellt. Diejenigen Zellpopulationen, die angereichert werden sollen, werden auf dem Bildschirm markiert. Durch einen mit einer Frequenz von $100 \mathrm{kHz}$ schwingenden piezoelektrischen Kristall wird die Flüssigkeitssäule in hochfrequente Schwingungen versetzt. Der Strahl löst sich so in einem definierten Abstand in Tröpfchen auf. Während dieses Vorgangs werden die Tröpfchen mit elektrischer Ladung versehen. Nach diesem so genannten Tropfenabriss gelangt die identifizierte Zelle in ein von zwei geladenen Metallplatten $(\mathrm{U}=3 \mathrm{kV})$ erzeugtes elektrostatisches Feld und kann so in entsprechende Auffangröhrchen sortiert werden.

In dieser Arbeit wurden Peyersche Plaques von vier einzelnen, sieben Wochen alten BALB/c-Mäusen verwendet. Die Zellpellets wurden mit je 300 - $400 \mu 1$ MASC-Puffer resuspendiert und durch ein $70 \mu$ Z Zellsieb laufen gelassen, um eine Verstopfung der hochsensiblen Messelektronik des MoFlo zu vehindern. Aus dem Lymphozyten-Gate wurden drei verschiedene Subpopulationen sortiert:

- IgM Zellen:

IgM positive, CD19, CD21 und CD23 positive Zellen

- Plasmazellen: CD19 negative, CD138 positive Zellen

- Gedächtniszellen:

CD19 positive, CD138 negative Zellen

Die sortierten Zellen wurden in 1,5 ml Eppendorf-Gefäßen aufgefangen, die $350 \mu 1$ RLT-Puffer enthielten, der zuvor mit $\beta$-Mercaptoethanol nach Herstellerangaben (10 $\mu 1$ $\beta$-Mercaptoethanol auf $1 \mathrm{ml}$ RLT Puffer) versetzt worden war, und bis zur weiteren Aufarbeitung bei $-80^{\circ} \mathrm{C}$ gelagert.

Für die Durchführung der Zellsortierung danke ich Frau Dr. C. Brendel aus der Klinik für Innere Medizin, Schwerpunkt Hämatologie, Onkologie und Immunologie des 
Universitätsklinikums Giessen und Marburg, Standort Marburg; Direktor: Prof. Dr. A. Neubauer.

\subsubsection{RNA-Extraktion}

\section{Arbeitsmaterialien:}

RNeasy Mini Kit

RNase freies Wasser

$\beta$-Mercaptoethanol

Ethanol

DNAse Zap ${ }^{\circledR}$

\section{Geräte:}

Tischzentrifuge $5417 \mathrm{R}$

Mixer Vortex Reax top

Thermoschüttler HLC
QIAGEN GmbH, Hilden, D

Eppendorf AG, Hamburg, D Fluka Chemie GmbH, Buchs, $\mathrm{CH}$

Merck KGaA, Darmstadt, D Ambion / Applied Biosystems, Darmstadt, D

Die Isolierung von RNA aus den Geweben der Maus erfolgte mit Hilfe des RNeasy® Mini Kit von Qiagen. Die Technik der RNA-Isolierung mit der RNeasy® Mini-Säule kombiniert die selektiv bindenden Eigenschaften einer Silica-Gel-Membran mit der Geschwindigkeit der Mikrospintechnologie. Ein spezialisiertes, hochkonzentriertes Salz-Puffersystem ermöglicht es bis zu $100 \mu \mathrm{g}$ RNA an die Silica-Membran zu binden. Mit der RNeasy-Methode werden RNA-Moleküle mit einer Größe von über 200 Basenpaaren gebunden, was die Selektivität für mRNA erhöht. In Anwesenheit eines stark denaturierenden Guanidine-Thiocyanat enthaltenden Puffers (RLT-Puffer mit $\beta$ Mercaptoethanol) werden die Proben lysiert und homogenisiert, was garantiert, dass die RNasen sofort inaktiviert werden und die RNA intakt bleibt.

Von Bedeutung ist eine DNAse- und RNase-freie Arbeitsweise. Zur Homogenisierung der bei $-80^{\circ} \mathrm{C}$ eingefrorenen Proben wurde der gesamte Inhalt in eine QIAshredder-spinColumn überführt und bei maximaler Drehzahl zwei Minuten lang zentrifugiert. Das Homogenisat wurde mit $350 \mu 1$ 70\%igem Äthanol versetzt und effektiv gemischt, um die Bindungsbedingungen für die RNA zu optimieren. Jeweils $700 \mu 1$ der Probe wurden auf eine RNeasy-Mini-Spin-Säule gegeben und für $15 \mathrm{sec}$ bei $11.000 \mathrm{rpm}$ und 
Raumtemperatur zentrifugiert. Der Durchlauf wurde verworfen. Die RNA war damit an die Silica-Membran gebunden.

Die Säule wurde daraufhin einmal mit $700 \mu$ RW1-Puffer und zweimal mit $500 \mu 1$ RPE-Puffer gewaschen (und ebenfalls jeweils $15 \mathrm{sec}$ bei $11.000 \mathrm{rpm}$ und RT zentrifugiert) um Zellreste und Kontaminationen zu entfernen.

Die Spin-Säule wurde nun 1 min bei $11.000 \mathrm{rpm}$ zentrifugiert, um Pufferreste zu beseitigen und die Membran zu trocken.

Um die RNA zu eluieren wurden $50 \mu 1$ RNase-freies Wasser auf die Säule gegeben und für $1 \mathrm{~min}$ bei $11.000 \mathrm{rpm}$ und RT zentrifugiert. Der Durchlauf wurde noch einmal auf die Säule gegeben und erneut zentrifugiert. Der Durchlauf enthielt jetzt die extrahierte RNA.

\subsubsection{RT-PCR}

\section{Arbeitsmaterialien:}

One-Step RT-PCR Kit

Antisense Primer $c \mu 2$

Antisense Primer BP4

Sense Primer AF303

Sense Primer J558/1

Sense Primer J558/2

0,5ml Eppendorf-Gefäße
QIAGEN GmbH, Hilden, D MWG Biotech AG, Ebersberg, D MWG Biotech AG, Ebersberg, D MWG Biotech AG, Ebersberg, D MWG Biotech AG, Ebersberg, D MWG Biotech AG, Ebersberg, D Eppendorf AG, Hamburg, D

\section{Geräte :}

Sterilwerkbank PCR omni Nunc GmbH \& Co. KG, Wiesbaden, D GeneAmp® PCR System 2700 Ambion/Applied Biosystems, Darmstadt, D

Die PCR (Polymerase-Kettenreaktion) bewirkt eine selektive Vervielfältigung (Amplifikation) eines beliebigen Abschnitts in einem DNA-Molekül.

Bei der Amplifikation von DNA mittels PCR werden spezifische Polymerasen verwendet, welche nicht in der Lage sind, RNA zu amplifizieren. Daher wird zuerst eine Reverse Transkriptase (RT) eingesetzt, eine RNA-abhängige DNA-Polymerase, welche die Bildung der DNA-Stränge katalysiert, mit deren Hilfe RNA in cDNA 
umgeschrieben wird. Die cDNA kann im Anschluss als Ausgangsprodukt der PCR verwendet werden, um spezifische Sequenzen aus dieser zu amplifizieren.

Das Qiagen One-Step RT-PCR-Kit verwendet ein Enzymgemisch aus einer reversen Tanskriptase, die durch Hitze inaktiviert wird, und einer DNA-Polymerase, die durch Hitze aktiviert wird. Dieses Enzymgemisch wird mit den Primern und der zuvor eluierten RNA in ein PCR-Tube pipettiert und in den Thermocycler eingebracht. Ein Zyklus benötigt zwei Primer, vier Desoxyribonukleosidtriphosphate (dATP, dTTP, dGTP, dCTP), eine DNA-Polymerase (Taq-Polymerase) und eine reverse Transkriptase. Primer sind kurze Oligonukleotide, die zu DNA-Sequenzen am 5 Anfang der zu amplifizierenden DNA-Sequenz komplementär sind.

\section{Die Proben durchliefen im Thermocycler folgendes Programm:}

Zuerst wurde bei $50^{\circ} \mathrm{C}$ (30 min) die RNA in cDNA durch die Reverse Transkriptase umgeschrieben. Zu dieser Zeit war die DNA-Polymerase durch die geringe Temperatur inaktiviert. Anschließend wurde die Reverse Transkriptase bei $95^{\circ} \mathrm{C}$ ( $15 \mathrm{~min}$ ) inaktiviert und die DNA-Polymerase aktiviert. Es folgten nun die drei regulären PCR-Schritte.

Beim ersten Schritt (Denaturierung) wurde die DNA durch Erhitzen $\left(94^{\circ} \mathrm{C}\right.$ für $\left.15 \mathrm{sec}\right)$ in zwei Einzelstränge, den kodierenden und den komplementären Strang aufgespalten. Im zweiten Schritt (Annealing) band der Sense-Primer an die komplementäre Sequenz am 5 -Anfang des kodierenden Strangs und der Antisense-Primer an die komplementäre Sequenz am 5`Anfang des komplementären Stranges, so dass beide 3`-Enden der Primer aufeinander zeigten. Während des dritten Schrittes (Amplifikation) wurden die DNA-Einzelstränge vom 3`-Ende der Primer ausgehend durch die Taq-Polymerase wieder zu einem Doppelstrang ergänzt, der dem ursprünglich eingesetzten Originalstrang exakt glich. Dieser letzte Schritt fand bei $72^{\circ} \mathrm{C}$ statt, dem Temperaturoptimum der Taq-Polymerase.

Bei dem folgenden PCR-Zyklus wurde der gerade entstandene Doppelstrang wieder denaturiert, so dass nach vielen PCR-Zyklen die Anzahl der Kopien der Sequenz exponentiell anstieg.

\section{Durchführung der Maus-RT-PCR für die variable Region der IgH-Kette:}

Die Maus-VDJ-RT-PCR wurde mit einem Thermocycler der Firma Ambion / Applied Biosystems durchgeführt. Um Kontaminationen $\mathrm{zu}$ vermeiden, fanden sämtliche Pipettierschritte (außer der Zugabe der RNA) unter einer Sterilwerkbank statt. Zunächst 
wurde ein MasterMix, bestehend aus destilliertem Wasser, 5-fach Qiagen-Puffer, dNTP Mix, Enzym Mix, RNAsein und sowohl Sense- als auch Antisense-Primer angesetzt und pro RNA-Probe auf drei PCR-Tubes verteilt, so dass je ein Tube zur Qualitätskontrolle mit destilliertem Wasser statt RNA zu Verfügung stand. Außerhalb der Sterilwerkbank wurde dann die RNA zugefügt und das PCR-Programm zügig gestartet.

Für die Amplifikation wurden drei verschiedene Sense-Primer:

- $\mathbf{A F 3 0 3}$, ein $\mathrm{V}_{\mathrm{H}} 5$-spezifischer Primer: 5' - GGG GCT CGA GGA GTC TGG GGG A - 3'

- $\quad \mathbf{J 5 5 8}$ - 1, ein $\mathrm{V}_{\mathrm{H}} 1$-spezifischer Primer: 5' - AGG T(CT)C AGC T(GCT)C AGC AGT CGG G - 3'

- $\quad \mathbf{J 5 5 8}$ - 2, ein $\mathrm{V}_{\mathrm{H}} 1$-spezifischer Primer: 5' - AGG T(CT)C AAC T(GCT)C AGC AGC CGG G - 3'

Und zwei verschiedene Antisense-Prime verwendet:

- $\mathbf{C \mu 2}$, ein Primer für IgM-Transkripte 5' - CAG GAG ACG AGG GGG AAG ACA TTT GG - 3'

- BP4, ein Primer für IgA-Transkripte 5' - CGG TGG TTA TAT CCT TCC CAC - 3'

Die Reagenzien wurden in folgendem Verhältnis verwendet:

\begin{tabular}{|lc|}
\hline VDJ-Amplifikation von RNA & 1 PCR $[\mu \mathrm{l}]$ \\
\hline Aqua dest. & 21,7 \\
5xQiagen Puffer & 10 \\
dNTP Mix & 2 \\
Sense-Primer $[15 \mathrm{pmol} / \mu \mathrm{l}]$ & 2 \\
Antisense-Primer $[15 \mathrm{pmol} / \mu \mathrm{l}]$ & 2 \\
Enzym-Mix & 2 \\
RNAsein $[50 \mathrm{U} / \mu \mathrm{l}]$ & 0,3 \\
RNA & 10 \\
\hline Reaktionsvolumen & $\mathbf{5 0}$ \\
\hline
\end{tabular}


Die Sense-Primer banden an die Framework-Region 1 (FR1) der variablen Segmente, die Antisense-Primer an die konstante Region der Gene der schweren Immunglobulinkette. Somit konnte durch Verwendung spezifischer Antisense-Primer separat das Repertoire von IgM- und IgA-Transkripten einer Probe amplifiziert und untersucht werden.

Das Cycler-Programm: Maus-VDJ-RNA enthielt folgende Reaktionsschritte:

1. $50^{\circ} \mathrm{C} \quad 30 \mathrm{Min}$ Reverse Transkription in cDNA

2. $95^{\circ} \mathrm{C} \quad 15 \mathrm{Min}$. Initiale Denaturierung zur Einzelstrangbildung

3. $94^{\circ} \mathrm{C} 15 \mathrm{Sec}$ Denaturierung

4. $59^{\circ} \mathrm{C} 1 \mathrm{Min}$. Primer Anlagerung an die Ziel-Sequenzen = Annealing

5. $72^{\circ} \mathrm{C} \quad 1 \mathrm{Min}$. DNA-Synthese von den Primern ausgehend $=$ Amplifikation

Schritte 3 bis 5 werden 40-mal wiedeholt

6. $72^{\circ} \mathrm{C} \quad 10 \mathrm{Min}$. Abschließende Amplifikation

7. $4^{\circ} \mathrm{C}$ halten Ende

Die entstandenen Amplifikate wurden für die weiteren Analyseschritte (Gelelektrophorese, Klonierung, Sequenzierung) verwendet.

\subsubsection{Agarosegelelektrophorese und Gelextraktion}

\section{Arbeitsmaterialien:}

Seakem GTG Agarose

Ethidiumbromid $(5 \mathrm{mg} / \mathrm{ml})$

6×Orange Loading Dye

1 Kilobasen -Leiter

$10 \times$ TBE Puffer: $\quad 54 \mathrm{~g}$ Tris Base

27,5 g Borsäure

4,65 g EDTA
Biozym Scientific GmbH, Hess.Oldendorf; D

Roche GmbH., Mannheim, D

Fermentas GmbH, St. Leon-Rot, D

Invitrogen GmbH, Karlsruhe, D

Acros Organics, Geel, B

Roth GmbH \& Co. KG, Karlsruhe, D

Sigma Chemie GmbH, Deisenhofen, D

In $500 \mathrm{ml}$ Aqua dest. lösen 
$1 \times$ TBE Puffer: $\quad 100 \mathrm{ml} 10 \times$ TBE Puffer

In 900 ml Aqua dest. lösen

QIAquick Gel Extraction Kit

Ethanol

Isopropanol
QIAGEN GmbH, Hilden, D

Merck KGaA, Darmstadt, D

Merck KGaA, Darmstadt, D

\section{Geräte:}

Mikrowellenherd intellowave

LG Electronics GmbH, Willich, D

Wage Adventura ${ }^{\circledR}$

OHAUS Headquarters, Pine Brook, USA

Elektrophoresekammer (incl. Gelschlitten)

Elektrophorese-Apparatur Station 300Plus

Geldokumentationssystem

Thermoschüttler HLC

OWI Separation Systems, Porthmouth, NL

Labnet International, Woodbridge, USA

Vilber Lourmat GmbH, Eberhardzell, D

Tischzentrifuge $5417 \mathrm{R}$

Fa. Kobe, Marburg, D

Eppendorf AG, Hamburg, D

Jeder B-Lymphozyt einer polyklonalen Population besitzt eine einzigartige NDNRegion. Deswegen entstehen bei der VDJ-PCR Amplifikate unterschiedlicher Längen, die durch die Gelelektrophorese aufgrund ihrer negativen Ladungen der Größe nach getrennt werden können. Durch das Maschenwerk des Laufgels wandern kleinere DNAFragmente schneller zur Kathode als größere. Zur Herstellung des Agarosegels wurden $2 \mathrm{~g}$ Seakem Agarose in $100 \mathrm{ml}$ 1×TBE Puffer in der Siedehitze gelöst und in einen Gelschlitten mit platziertem Probenkamm gegossen. Nach der Polymerisation des Gels wurden der Kamm entfernt und die Geltaschen befüllt. Zur Größenbestimmung wurden bei jeder Gelelektrophorese $10 \mu \mathrm{l}(=2 \mu \mathrm{g})$ eines Größenstandards aufgetragen $(1 \mathrm{kB}$ Ladder). Je $16 \mu$ l eines Amplifikats wurden mit $4 \mu$ l Loading Buffer gemischt und in eine Geltasche eingebracht. Die Amplifikate wurden bei 110 V über 35-40 Minuten aufgetrennt und bildeten aufgrund der unterschiedlichen Längen keine scharf begrenzte „Bande“, sondern einen unscharfen sogenannten 'smear'. Dieser Bandenschmier differierte in einem Bereich von ca. 380-420 Basenpaaren. Das Gel wurde für 20 Minuten in einer Lösung aus $200 \mathrm{ml}$ TBE-Puffer mit ca. $5 \mu$ l Ethidiumbromid gefärbt. Unter ultraviolettem Licht wurde die DNA sichtbar gemacht (rote Fluoreszenz) und fotografiert. Der fluoreszierende Bereich wurde großzügig ausgeschnitten und in ein 2 ml Eppendorfgefäß eingebracht, in dem sich $300 \mu$ l QG-Puffer befanden. 
Zur Extraktion der DNA aus dem Agarosegel wurde das Qiaquick Gel Extraction Kit der Firma Qiagen verwendet. Die Puffer besitzen einen hohen Salzgehalt und einen $\mathrm{pH}-$ Wert unter 7,5, was die Bindungseigenschaften der DNA an die Silica-Membran optimiert. Die Gelextraktion wurde nach Herstellerangaben durchgeführt. Durch mehrere Waschvorgänge wurden diverse Rückstände wie überschüssige Primer, Agarose, Ethidiumbromid usw. entfernt. Abschließend wurde die reine DNA mittels 50 $\mu$ l EB-Puffer eluiert.

\subsubsection{Klonierung}

\section{Arbeitsmaterialien:}

TOPO TA Cloning Kit

One Shot ${ }^{\circledR}$ Top 10 Kompetente E.Coli

Invitrogen $\mathrm{GmbH}$, Karlsruhe, D

Sterile 0,5 ml Eppendorf Gefäße

Invitrogen $\mathrm{GmbH}$, Karlsruhe, D

Ampicillin

Eppendorf AG, Hamburg, D

S.O.C.Medium

Sigma Chemie GmbH, Deisenhofen, D

X-gal

Invitrogen $\mathrm{GmbH}$, Karlsruhe, D

Promega Corp., Madison, USA

LB-Agar:

3,2 g LB Agar

Sigma Chemie GmbH, Deisenhofen, D

In 100 ml Aqua dest. lösen

$100 \mu 1$ Ampicillin

LB-Medium

10 g LB Broth Base Sigma Chemie GmbH, Deisenhofen, D In $500 \mathrm{ml}$ Aqua dest. lösen

QIAprep Miniprep Kit

QIAGEN GmbH, Hilden, D

$10 \times$ Puffer $\mathrm{H}$

Roche GmbH, Mannheim, D

EcoRI Restriktionsenzym

Roche GmbH, Mannheim, D

\section{Geräte:}

Wasserbad

Memmert GmbH\&Co. KG, Schwabach, D

Thermoschüttler HLC

Fa. Kobe, Marburg, D

Bunsenbrenner

CampingGaz, Hungen, D

Brutschrank B15

Heraeus GmbH, Hanau, D 
Tischzentrifuge $5417 \mathrm{R}$

Werkbank aura mini

Elektrophoresekammer (incl. Gelschlitten)

Elektrophorese-Apparatur Station 300 Plus
Eppendorf AG, Hamburg, D Nunc GmbH \& Co. KG, Wiesbaden, D OWI Systems, Porthmouth, NL Labnet International, Woodbridge, USA

Durch die Klonierung wird das polyklonale Amplifikationsprodukt in monoklonale Produkte überführt, die dann als Ausgangsmaterialien zur Analyse der Sequenzen genutzt werden können. Dabei wurde jeweils ein einzelnes Amplifikat in einen Vektor (Plasmid) eingebaut (Ligation) und in kompetente Escherichia Coli-Zellen eingebracht (Transformation). Auf einer Agarplatte wurden diese transformierten Zellen kultiviert. Jede Zelle einer entstandenen Kolonie enthielt somit eine bestimmte, immer gleiche DNA-Sequenz des ursprünglichen Amplifikatgemisches. Durch Minipräparation wurde die DNA der E. Coli-Klone extrahiert und mittels Insertkontrollverdau überprüft, ob die Plasmid-DNA das gewünschte Amplifikat enthielt.

\section{- Ligation:}

Bei der Ligation wurde das Amplifikat in das Plasmid eingebaut. Es enthielt eine Ampicillin-Resistenz als Selektionsmarker, war vorgeschnitten und besaß freie T-Enden. Das Amplifikat enthielt ein terminales A, das sich mit dem T-Ende des Vektors verband. Es wurden dazu je $4 \mu$ l eluiertes frisches PCR-Produkt mit $1 \mu 1$ Salt Solution, $2 \mu 1$ sterilem Wasser und $1 \mu$ l PCR-TOPO-Vektor vorsichtig auf Eis gemischt und 5-10 Minuten bei Raumtemperatur inkubiert.

\section{- Transformation:}

Der mit dem DNA-Amplifikat ligierte Vektor wurde anschließend in E. ColiZellen transformiert, das heißt, er penetrierte die Wände der Bakterien. Hierzu wurden die E. Coli-Zellen mit $2 \mu 1$ Ligationsansatz vermischt und 30 Minuten auf Eis inkubiert. Durch Erwärmen der Bakterien im $42^{\circ} \mathrm{C}$ warmen Wasserbad (genau 30 Sekunden) wurden die Bakterienwände permeabel und das Plasmid konnte in die Zellen eindringen. Danach wurden sie wiederum 2 Minuten auf Eis gestellt. Die Bakterien wurden nun mit $250 \mu$ S S.O.C. Medium (Brutmedium) eine Stunde lang bei $37^{\circ} \mathrm{C}$ im Thermoschüttler bebrütet, wodurch sich die E. Coli-Zellen ohne Selektionsdruck von Ampicillin vermehren konnten.

Die transformierten Zellen $(70 \mu \mathrm{l})$ wurden auf Ampicillin enthaltende und mittels X-gal (35 $\mu 1)$ imprägnierte Agarplatten gestrichen und 12-16 Stunden bei $37^{\circ} \mathrm{C}$ bebrütet. Die weißlichen Klone wuchsen einzeln und enthielten jeweils 
eine spezifische DNA-Sequenz in ihrem Plasmid. Blaue Kolonien konnten den Farbstoff nicht abbauen, enthielten also kein Plasmid. Von den weißlichen Kolonien der Agarplatten wurden ca. 30 Klone aufgenommen und in je einem Eppendorfgefäß mit 1,75 ml eines löslichen Kulturmediums (hier LB-Medium mit Ampicillin) über Nacht im Thermomixer bei $37^{\circ} \mathrm{C}$ bebrütet.

- Minipräparation:

Bei der Minipräparation der Plasmid-DNA der E. Coli-Zellen wurden diese alkalisch lysiert. Mittels hochkonzentrierten Salzpuffers wurde die DNA an die Silica-Membran der Spin-Säulen gebunden. Die restlichen Zellbestandteile wurden über mehrere Zentrifugationsschritte und Waschungen entfernt. Mit einem alkalischen Puffer wurde die DNA schließlich eluiert.

\section{- Insertkontrollverdau}

Der Insertkontrollverdau diente der Überprüfung, ob ein einzelnes Amplifikat eingebaut wurde und ob es die richtige Länge besaß.

Hierzu wurde das Amplifikat (Insert) mittels einer Restriktionsendonuclease aus dem Plasmid herausgetrennt. Man verwendete dazu $2 \mu 1$ 10×Puffer H und $1 \mu 1$ EcoRI-Enzym, verdünnt in $13 \mu \mathrm{l}$ Aqua dest. und $4 \mu \mathrm{l}$ Plasmid-DNA. Die Reagenzien wurden gemischt und eine Stunde bei $37^{\circ} \mathrm{C}$ inkubiert. Durch Agarose-Gelelektrophorese konnte überprüft werden, ob tasächlich Plasmid- und Insert-DNA vorhanden war. Hatte das Amplifikat die richtige Länge von ca. 400 bp, wurde es für die Sequenzierung weiterverwendet.

\subsubsection{Sequenzierung des PCR-Amplifikats}

\section{Gerät:}

Kapillarsequenzer ABI 3730

Ambion/Applied Biosystems, Darmstadt, D

Die Sequenzanalyse wurde bei der GATC-Biotech AG, Konstanz, D durchgeführt.

Die DNA-Sequenzierung basierte auf einer modifizierten Kettenabbruchmethode nach Sanger. Die DNA lag als Einzelstrang vor und fungiert als Matrize für die in vitroSynthese eines neuen komplementären DNA-Strangs. Ein Primer (T7: TAATACGACTCACTATAGGG) lagerte sich an das $\mathrm{zu}$ sequenzierende DNAFragment an und wurde durch eine geeignete DNA-Polymerase verlängert. Es wurden 
neben den vier Desoxyribonuleotidtriphosphaten (dNTP) vier Didesoxyribonukleotidtriphosphate (ddNTP) benutzt, die mit vier verschiedenen fluoreszierenden Farbstoffen markiert waren, wobei jeder Base ein bestimmter Farbstoff zugeordnet war. Beim zufälligen Einbau in die neu synthetisierte DNA führten sie zum Kettenabbruch. Somit erhielt man am Kettenende eines jeden neu synthetisierten DNAMoleküls eine Markierung, die einer bestimmten Base entsprach. Es entstand also eine zufällige Verteilung von Amplifikaten mit einer Länge von 1 bis ca. 600 Basen, die alle am Ende ein farbmarkiertes ddNTP aufwiesen.

Bei der anschließenden Acrylamid-Gelelektrophorese wurden die Sequenzprodukte der Länge nach aufgetrennt und durch Laserbestrahlung der Fluoreszenzfarbstoffe zur Photoemission angeregt. Die unterschiedlichen Wellenlängen der fluoreszierenden Farbstoffe in den ddNTPs wurden mittels Kapillarsequenzer ABI 3730 detektiert und so die klonspezifische V-N-D-N-J-Sequenz ermittelt (Abbildung 3.1).
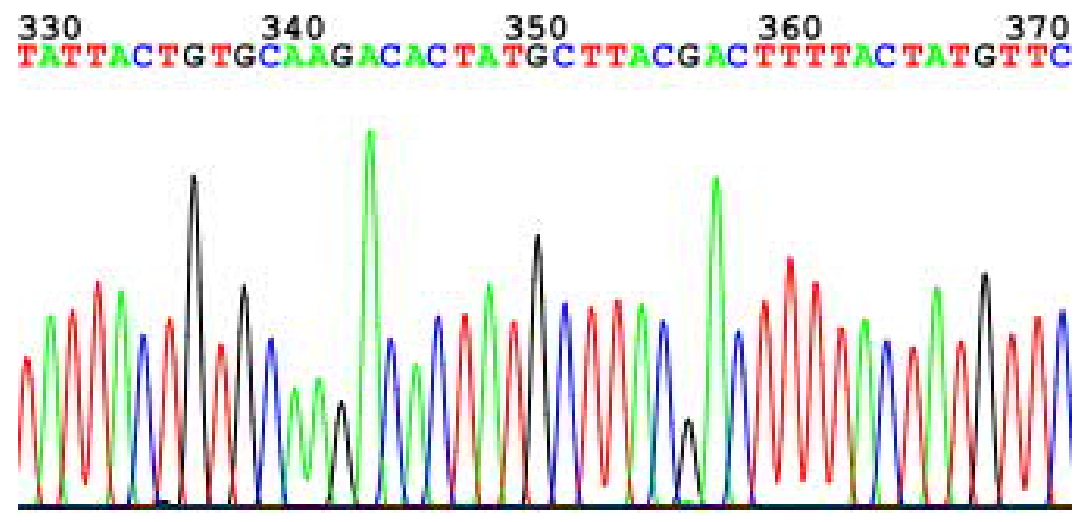

Abbildung 3.1: Beispielhaftes Ergebnis der mittels Kapillarsequenzer detektierten Nukleotidabfolge 


\subsection{Computergestützte Sequenzanalyse der Amplifikate}

Die Sequenzanalyse erfolgte mit der Datenbank ImMunoGentics (IMGT ${ }^{\circledR}$, the international ImMunoGeneTics information system ${ }^{\circledR}$ http://imgt.cines.fr). Dies ist eine von Marie-Paule Lefranc initiierte Datenbank für die Analyse komplexer, für die spezifische Immunantwort relevanter Genfamilien des Menschen und anderer Vertebraten. Der IMGT-Server ermöglicht den Zugang zu mehreren SequenzDatenbanken, einer Genom-Datenbank und einer 3D-Struktur-Datenbank. Darüber hinaus bietet IMGT über die ,IMGT/V-QUEST search page' eine Maske zur Sequenzanalyse eigener Daten. Die Datenbank enthält u.a sämtliche bekannte Keimbahngene der Maus, die Informationen über Kongruenzen einer Antikörpersequenz mit Maus-Immunglobulinen liefern.

Die über die Sequenzreaktion ermittelten Basenabfolgen wurden jeweils separat in die Datenbank eingegeben und analysiert. Dabei wurde die Sequenz einer variablen Region in ihre CDR- und FR-Bereiche unterteilt und durch einen koordinierten Abgleich (Alignment) mit Keimbahngenen das jeweilig verwendete Segment ermittelt. Der durch VDJ-Rekombination entstandene CDR3-Bereich lag hierbei zwischen dem konservierten Cystein (C) der V-Region an Position 104 und dem konservierten Tryptophan (W) der J-Region an Position 118 (Giudicelli V, 2004) (Abbildung 3.2).

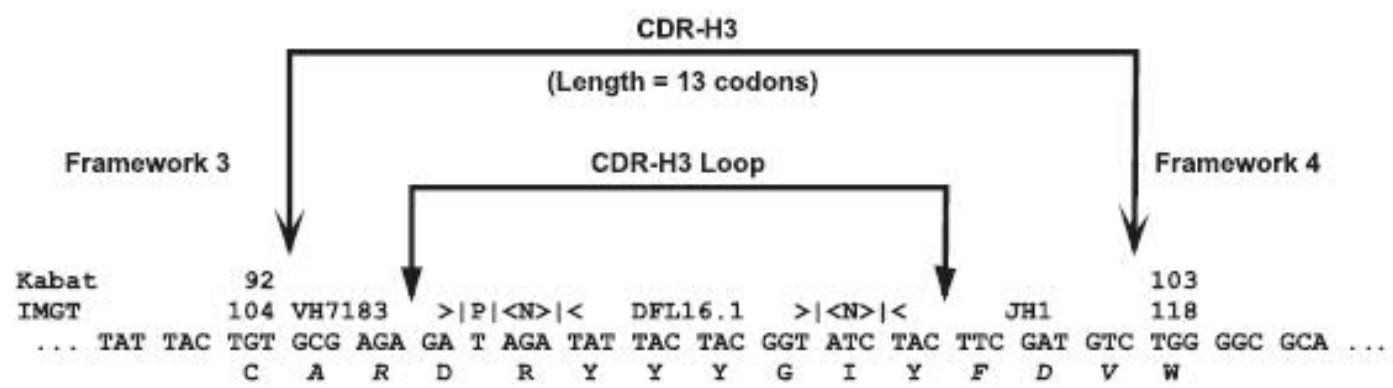

Abbildung 3.2: Anayse der CDR3 - Region (aus Ivanov II, 2005).

In der fiktiven Sequenz werden FR3, CDR3 und FR4 gezeigt und VH-, DH- und JH-Segment sowie Pund N-Nukleotide analysiert. Die Nukleotidsequenz wird in die Aminosäuresequenz übersetzt.

Durch ein Alignment mit Keimbahngenen wurde das $\mathrm{V}_{\mathrm{H}^{-}}, \mathrm{D}_{\mathrm{H}^{-}}$und $\mathrm{J}_{\mathrm{H}^{-}}$Gensegment mit der jeweils größten Übereinstimmung bestimmt und aufgetretene Mutationen analysiert. Es wurde zwischen stummen (,silent“) und produktiven Mutationen (,replacement“) 
unterschieden. Stumme Mutationen bewirken ein Nukleotid-Triplet, das für die gleiche Aminosäure kodiert wie die Originalsequenz, und haben somit keinen Einfluss auf die Tertiärstruktur des Proteins. Produktive Mutationen führen zu einer Veränderung der Aminosäure und damit zu einer Veränderung der Tertiärstruktur des Proteins. Zur analytischen Identifikation einer Antikörpersequenz dienten drei konservierte Aminosäuren, die an definierten Positionen in den Rahmenregionen der Antikörpersequenzen liegen (siehe Abbildung 3.2).

Die Berechnung und Darstellung der phylogenetischen Stammbäume wurde mithilfe der Website: www.treedyn.org vorgenommen (Chevenet F, 2006).

\subsection{Statistische Auswertung der Untersuchungsergebnisse}

Die Daten wurden mit dem Kolmogorow-Smirnow-Test auf Normalverteilung überprüft. Bei normalverteilten Variablen wurde ein zweiseitiger T-Test durchgeführt, bei nicht normalverteilten Variablen wurde ein Mann-Whitney-U-Test durchgeführt. Zur Untersuchung des Zusammenhangs mehrerer Variablen wurde eine Varianzanalyse (ANOVA) angewendet. Kontingenztafeln wurden mittels $\mathrm{Chi}^{2}$-Test mit Post-HocAnalyse analysiert; bei einer Stichprobe von fünf oder weniger Beobachtungen wurde ein Fisher Exact Test angewendet.

Ein Unterschied mit $\mathrm{p}<0,05$ wurde als signifikant gewertet.

In den Tabellen und Abbildungen sind, soweit nicht anders angegeben, arithmetische Mittelwerte mit Standardabweichungen aufgeführt. 


\section{Ergebnisse}

Aus den sortierten B-Zell-Subpopulationen der Peyer-Plaques von 8 Wochen alten Wildtyp- (Balb/c) Mäusen wurden insgesamt 413 Transkripte der schweren Immunglobulinkette gewonnen. Die Daten stammen aus vier unabhängigen Experimenten. Acht Sequenzen wiesen ein Stopcodon und/oder eine Verschiebung des Leserahmens (,frameshift') auf und wurden als nicht funktionell eingestuft. Die übrigen 405 Transkripte $(98,1 \%)$ besaßen einen offenen Leserahmen und wurden somit als funktionell klassifiziert (Tabelle 4.1).

Zur weiteren Analyse wurden nur die funktionellen Immunglobulinseqenzen herangezogen.

\begin{tabular}{|llllr|}
\hline & $\begin{array}{l}\text { Anzahl lesbare } \\
\text { Rohdaten }\end{array}$ & $\begin{array}{l}\text { Anzahl nicht } \\
\text { funktionelle } \\
\text { Sequenzen }\end{array}$ & $\begin{array}{l}\text { Anzahl } \\
\text { funktionelle } \\
\text { Sequenzen }\end{array}$ & \\
& 78 & 0 & 78 & $100,0 \%$ \\
IgA_MC_AF303 & 81 & 0 & 81 & $100,0 \%$ \\
IgA_PC_AF303 & 85 & 6 & 79 & $92,9 \%$ \\
IgM_AF303 & 56 & 0 & 56 & $100,0 \%$ \\
IgA_MC_J558 & 56 & 0 & 56 & $100,0 \%$ \\
IgA_PC_J558 & 57 & 2 & 55 & $96,5 \%$ \\
IgM_J558 & & & & \\
\hline
\end{tabular}

Tabelle 4.1: Funktionelle Sequenzen. Die Daten sind unterteilt nach Isotyp (IgA und IgM, B-ZellSubpopulation (Gedächtniszellen, MC und Plasmazellen, PC) und verwendeter VH-Familie.

\subsection{Diversität der Immunglobulinsequenzen}

Um die Zusammensetzung der Subpopulationen $\mathrm{zu}$ charakterisieren wurde die Diversität berechnet (Anzahl unterschiedlicher Sequenzen pro Anzahl erhobener Sequenzen) und die klonale Verwandschaft anhand von Sequenzvergleichen berechnet (phylogenetischer Stammbaum). Insgesamt waren 323 der 405 funktionellen Sequenzen einzigartig, somit lag die Diversität bei $79,8 \%$. Sequenzen mit identischen $\mathrm{V}_{\mathrm{H}} \mathrm{DJ}_{\mathrm{H}^{-}}$und $\mathrm{N}-N u k l e o t i d e n$ wurden von der weiteren Analyse ausgeschlossen. Im folgenden wurden die Sequenzen entsprechend den VH-Familien VH5 und VH1/14 separat analysiert. Mit dem Primer AF303 wurden $166 \mathrm{~V}_{\mathrm{H}}$ 5-Sequenzen erhoben: $44 \operatorname{IgA} \mathrm{MC}\left(\operatorname{IgA}{ }^{+}, \mathrm{CD}_{19}{ }^{+}\right.$, 
CD138-), $49 \operatorname{IgA}$ PC (IgA $\left.{ }^{+}, \mathrm{CD}^{-}, \mathrm{CD}^{-}{ }^{+}\right)$und $73 \mathrm{IgM}\left(\operatorname{IgM}^{+}, \mathrm{CD}^{+}{ }^{+}, \mathrm{CD} 21^{+}\right.$, $\mathrm{CD}^{2} 3^{+}$). Die J558-Amplifikation führte zu 157 funktionellen, genetisch einzigartigen $\mathrm{V}_{\mathrm{H}}$ 1/14-Sequenzen: $55 \operatorname{IgA~MC}\left(\operatorname{IgA}^{+}, \mathrm{CD}^{+} 9^{+}, \mathrm{CD}_{138^{-}}\right), 49 \operatorname{IgA} \mathrm{PC}\left(\operatorname{IgA}^{+}, \mathrm{CD} 19^{-}\right.$, $\left.\mathrm{CD} 138^{+}\right)$und $53 \operatorname{IgM}\left(\operatorname{IgM}^{+}, \mathrm{CD} 19^{+}, \mathrm{CD} 21^{+}, \mathrm{CD} 23^{+}\right)$.

Innerhalb der AF303 amplifizierten Gruppe zeigte sich eine deutlich geringere Diversität $(69,7 \%)$ als in der J558 amplifizierten Gruppe (94\%). Innerhalb der $\mathrm{V}_{\mathrm{H}} 5$ Sequenzen zeigte IgM eine deutlich höhere Diversität $(85,9 \%)$ als IgA-Plasmazellen (PC) $(60,5 \%)$ und IgA-Gedächtniszellen (MC) $(56,4 \%)$.

Insgesamt zeigten IgA-Gedächtniszellen eine geringgradige, nicht signifikant höhere Diversität als IgA-Plasmazellen (73,9\% zu 71,5\%). Hingegen unterschieden sich die Diversitäten zwischen IgA- (72,7\%) und IgM-Sequenzen (94\%) signifikant: p < 0,01 (Tabelle 4.2).

\begin{tabular}{|lrlll|}
\hline & $\begin{array}{l}\text { Anzahl Immunglobulin } \\
\text { Sequenzen }\end{array}$ & $\begin{array}{l}\text { unique + } \\
\text { clonally related' }\end{array}$ & Diversität & \\
IgA_MC_AF303 & 78 & 44 & $56,4 \%$ & \\
IgA_PC_AF303 & 81 & 49 & $60,5 \%$ & $69,7 \%$ \\
IgM_AF303 & 79 & 73 & $85,9 \%$ & \\
IgA_MC_J558 & 56 & 55 & $98,2 \%$ & \\
IgA_PC_J558 & 56 & 49 & $87,5 \%$ & $94,0 \%$ \\
IgM_J558 & 55 & 53 & $93,0 \%$ & \\
\hline IgA_MC & 134 & 99 & $73,9 \%$ & \\
IgA_PC & 137 & 98 & $71,5 \%$ & $72,7 \%$ \\
IgM_both & 134 & 126 & $94,0 \%$ & \\
\hline & & & & \\
gesamt & 405 & 323 & $79,8 \%$ & \\
\hline
\end{tabular}

Tabelle 4.2: Diversität der Immunglobulin-Sequenzen. Die Daten sind unterteilt nach Isotyp (IgA und IgM, B-Zell-Subpopulation (Gedächtniszellen, MC und Plasmazellen, PC) und verwendeter VH-Familie.

Die Diversität einer Sequenzgruppe gibt Aufschluss über die genetische Verwandtschaft. Evolutionäre Beziehungen zwischen den analysierten Sequenzgruppen können anhand so genannter phylogenetischer Bäume graphisch dargestellt werden.

Dabei berechnet man ein Sequenzalignment der zu untersuchenden Genabschnitte und verwendet die im Alignment erscheinenden Ähnlichkeiten und Unterschiede, um den Baum aufzubauen. Arten, deren Sequenzen sich ähneln liegen im Baum dann als Cluster näher beieinander als solche mit stark unterschiedlichen Sequenzen (Abbildung $4.1,4.2,4.3)$. 


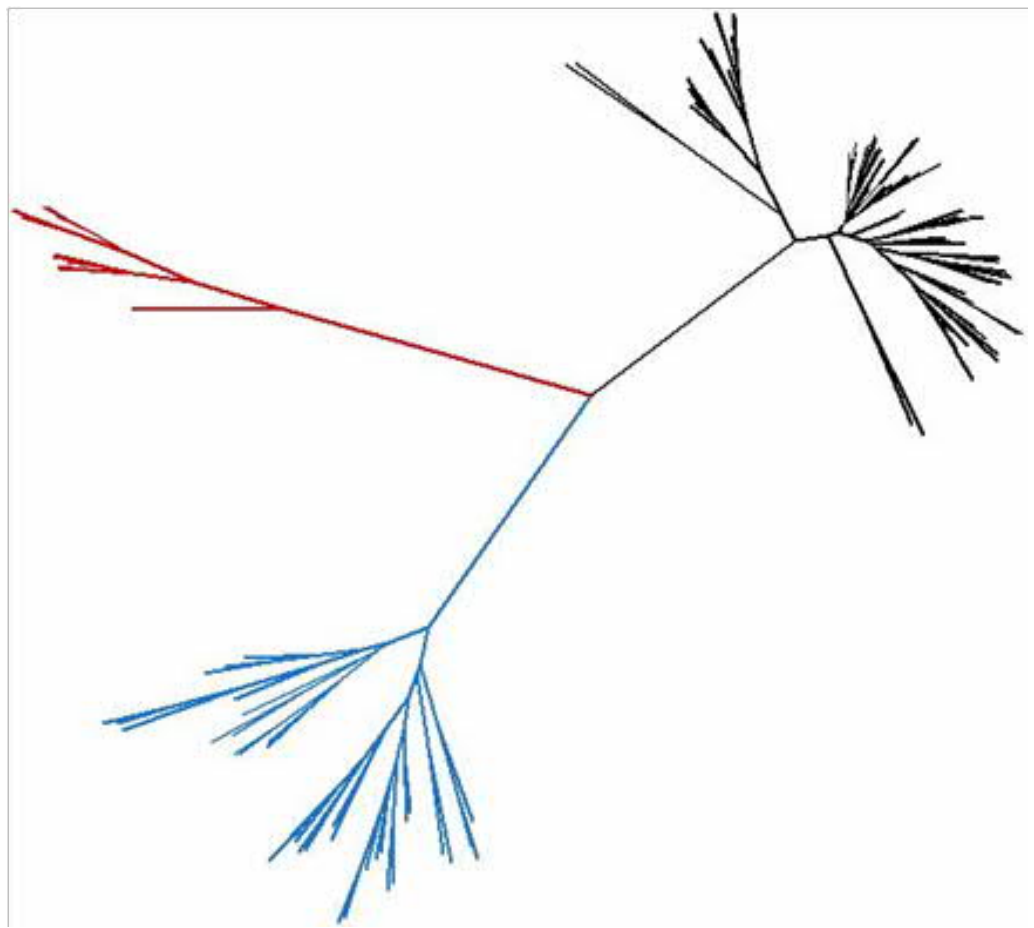

Abbildung 4.1: Phylogenetischer Baum der funktionellen IgM-Sequenzen ( $n=126)$

Blau: Sequenzen der V1-Familie; Rot: Sequenzen der V14-Familie, Schwarz: Sequenzen der V5-Familie

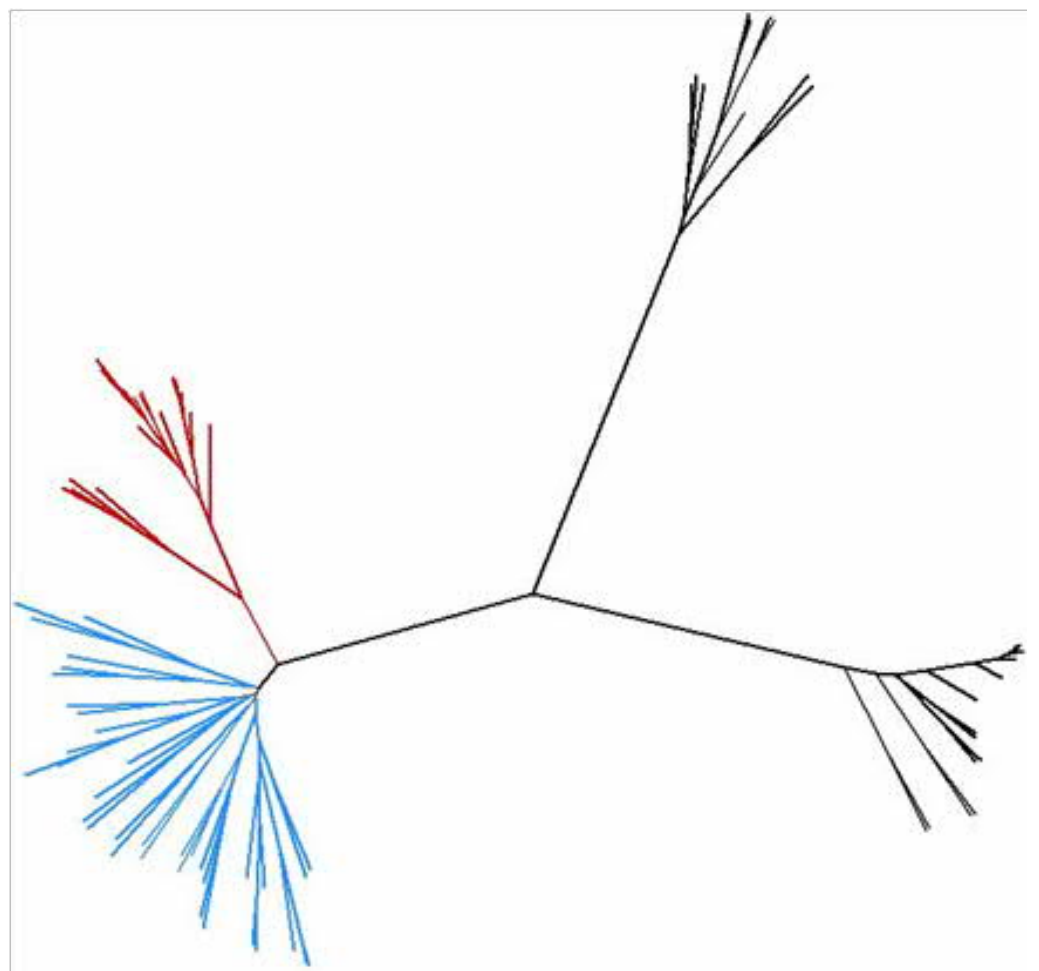

Abbildung 4.2: Phylogenetischer Baum der funktionellen IgA-Gedächtniszell-Sequenzen (n=99)

Blau: Sequenzen der V1-Familie; Rot: Sequenzen der V14-Familie, Schwarz: Sequenzen der V5-Familie 


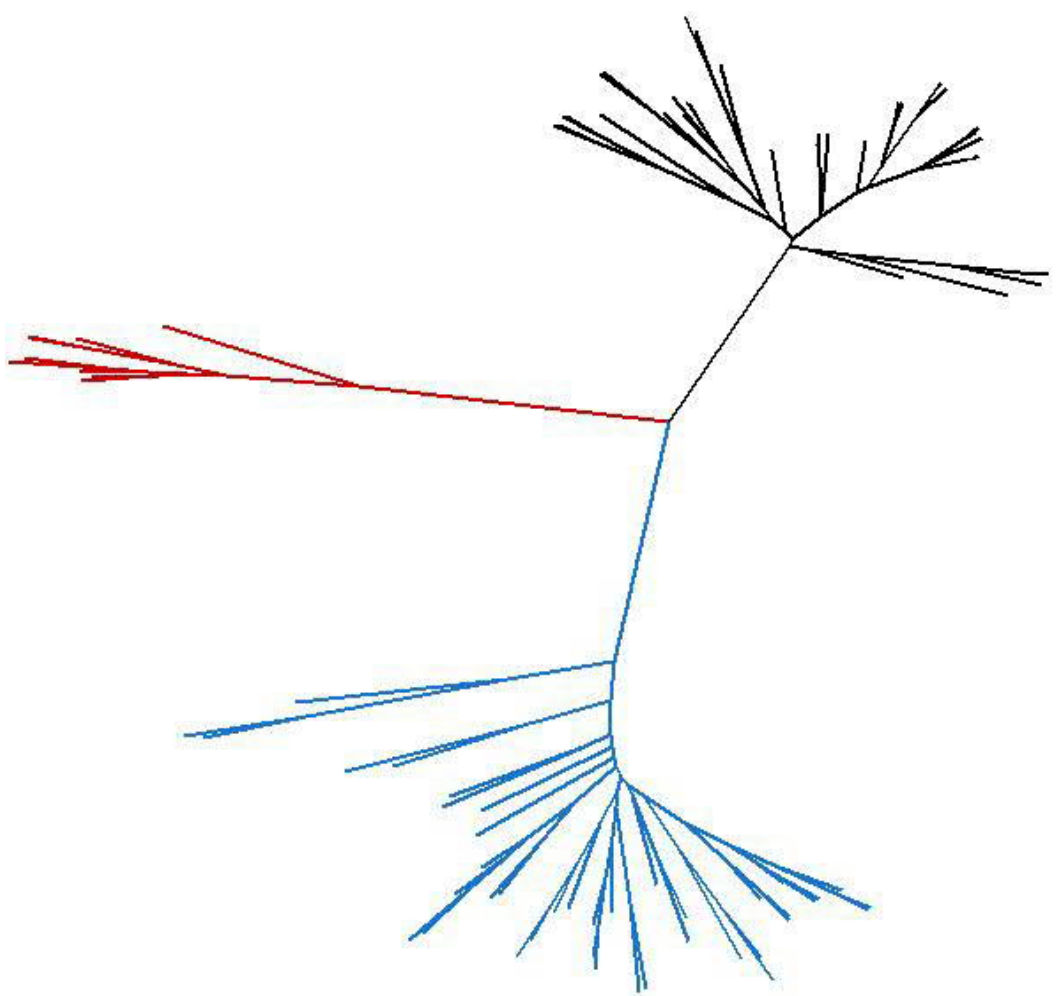

Abbildung 4.3: Phylogenetischer Baum der funktionellen IgA-Plasmazell-Sequenzen (n=98)

Blau: Sequenzen der V1-Familie; Rot: Sequenzen der V14-Familie, Schwarz: Sequenzen der V5-Familie

\subsection{Häufigkeitsverteilung der Gensegmentnutzung}

\subsection{1 $\mathrm{V}_{\mathrm{H}}$-Familien}

Die RT-PCR der schweren Immunglobulinkette wurde mit einem $\mathrm{V}_{\mathrm{H}} 1$-spezifischen Primer (J558) und einem $\mathrm{V}_{\mathrm{H}}$ 5-spezifischen Primer (AF303) durchgeführt. Aufgrund der $\mathrm{V}_{\mathrm{H}^{-}}$-Familiengrößen auf Keimbahngenen konnten somit rechnerisch ca. $75 \%$ aller bekannten $\mathrm{V}_{\mathrm{H}}$-Sequenzen amplifiziert werden.

Die $\mathrm{V}_{\mathrm{H}}$-Familiennutzung derjenigen Sequenzen, die mit AF303 amplifiziert worden waren, lag zu $100 \%$ bei $\mathrm{V}_{\mathrm{H}}$-Familie 5. Im Falle einer Amplifizierung mit dem Primer $\mathrm{J} 558$ wurde die $\mathrm{V}_{\mathrm{H}} 1$-Familie in $67,3 \%-81,6 \%$ und die $\mathrm{V}_{\mathrm{H}}$ 14-Familie in $18,4 \%-32,7 \%$ verwendet. (Abbildung 4.4). In den folgenden Analysen wurden die Sequenzen der $\mathrm{V}_{\mathrm{H}} 1$ - und $\mathrm{V}_{\mathrm{H}} 14-$ Familie zusammengefasst. 


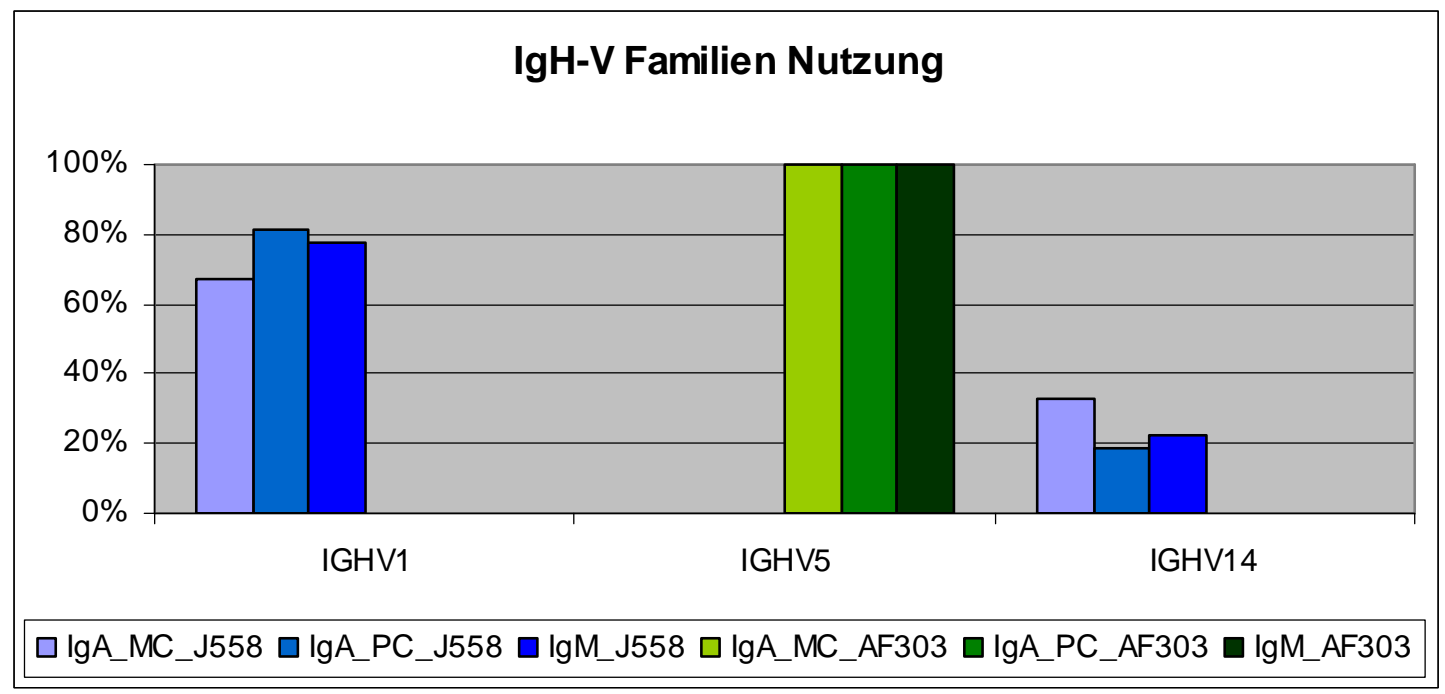

Abbildung 4.4: Relative Häufigkeit der IgH V-Familien Nutzung. $\mathrm{PC}=$ Plasmazellen, $\mathrm{MC}=$ Gedächtniszellen.

Die Nutzung der individuellen VH-Gensegmente wird in Abbildung 7.1 im Anhang dargestellt.

\subsection{2 $\mathrm{D}_{\mathrm{H}^{-}}$Genfamilien}

Bei 322 der 323 funktionalen, genetisch einzigartigen Sequenzen war ein $\mathrm{D}_{\mathrm{H}^{-}}$ Gensegment identifizierbar $(99,7 \%)$. Die $\mathrm{D}_{\mathrm{H}}$ 2-Familie wurde sowohl bei $\mathrm{V}_{\mathrm{H}} 1 / 14$ Sequenzen als auch bei $\mathrm{V}_{\mathrm{H}}$ 5-Sequenzen am häufigsten verwendet $(57,0 \%)$. Innerhalb der verschiedenen Sequenzgruppen variierten die Häufigkeiten hierbei von 49,2\% (IgM) bis $69,7 \%$ (IgA MC). Die zweitstärkste Familie stellte die $\mathrm{D}_{\mathrm{H}} 1$-Familie mit insgesamt 26,9\%. Im Gegensatz zur Nutzung der $\mathrm{D}_{\mathrm{H}} 2$-Familie beliefen sich die Verwendungshäufigkeiten hier auf 13,1\% (IgA MC) bis 37,3\% (IgM) (Abbildung 4.5).

Statistische Signifikanzen der Verteilungseigenschaften zwischen den einzelnen Sequenzgruppen lagen jedoch nicht vor.

Zwischen den AF303-amplifizierten und J558-amplifizierten Sequenzen traten ebenfalls keine signifikanten Unterschiede $\left(\mathrm{Chi}^{2}\right.$-Test) in ihrer Nutzung der $\mathrm{D}_{\mathrm{H}}$-Familien auf. Aus Gründen der Übersicht wurde das Diagramm daher zusammengefasst und nicht nach $\mathrm{V}_{\mathrm{H}}$-Familien getrennt (Abbildung 4.5). 


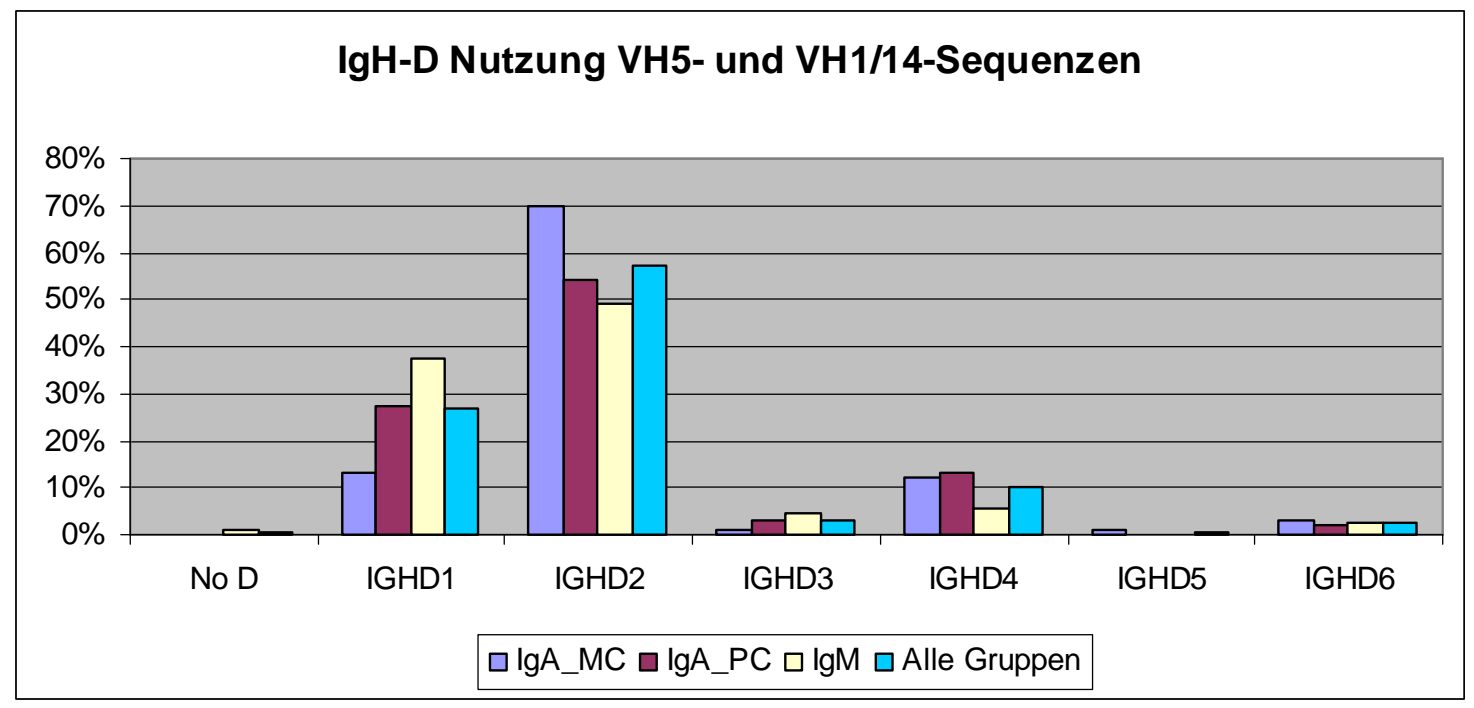

Abbildung 4.5: IgH D-Familiennutzung $V_{H}$ 5- und $V_{H}$ 1/14-Sequenzgruppe.

$\mathrm{PC}=$ Plasmazellen, $\mathrm{MC}=$ Gedächtniszellen. Rohdaten siehe Abbildung 7.2 und Tabelle 7.2 im Anhang.

\subsubsection{Verwendung der Leserahmen}

Das D-Segment kann in allen drei Leserahmen $(\mathrm{RF}=$ reading frame $)$ verwendet werden. Bei allen untersuchten Subpopulationen wurde der erste Leserahmen (RF1) bevorzugt ( $\mathrm{Chi}^{2}$-Test nicht signifikant). IgM-Sequenzen nutzten zu 64,8\%, IgA MC zu 67,7\% und IgA PC zu 70,4\% den RF1. RF2 (19,4\%-27,2\%) und RF3 (8,0\%-10,2\%) wurden jeweils signifikant seltener verwendet (Abbildung 4.6), $\mathrm{V}_{\mathrm{H}}$-Familienspezifische Unterschiede wurden dabei nicht beobachtet.

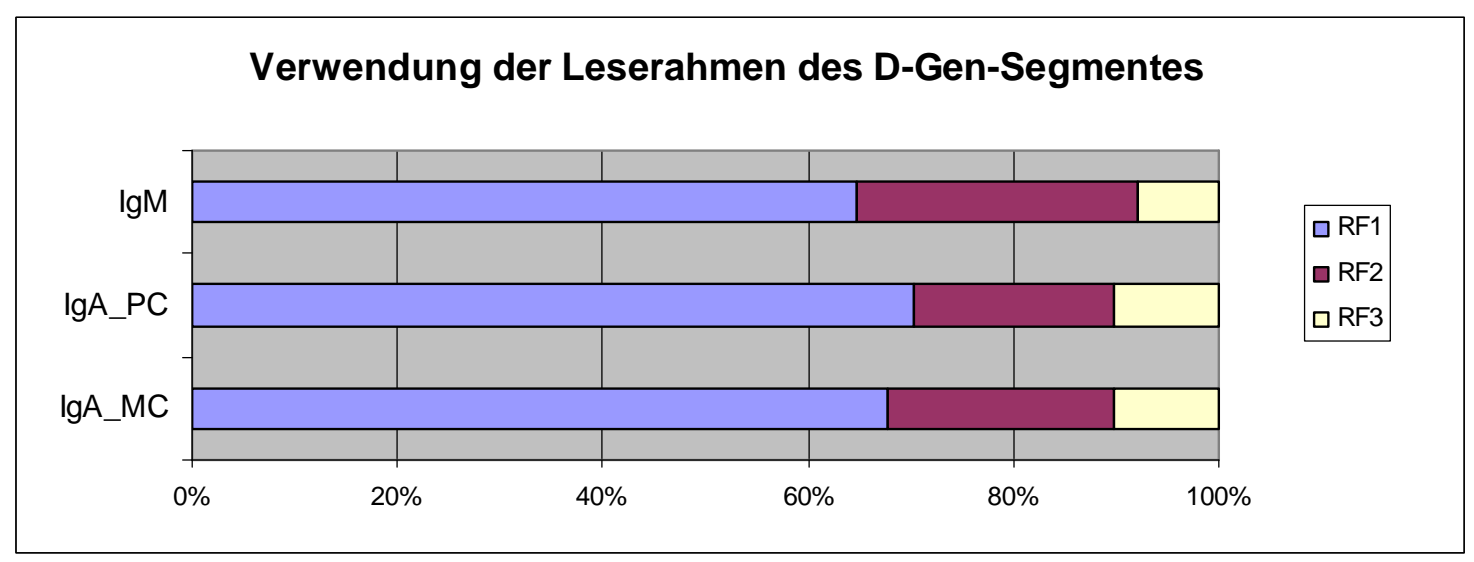

Abbildung 4.6: Verwendung der Leserahmen des D-Gen-Segmentes.

$\mathrm{RF}=$ Leserahmnen (reading frame). $\mathrm{PC}=$ Plasmazellen, $\mathrm{MC}=$ Gedächtniszellen. 


\subsection{4 $\mathrm{J}_{\mathrm{H}^{-}}$Gensegmente}

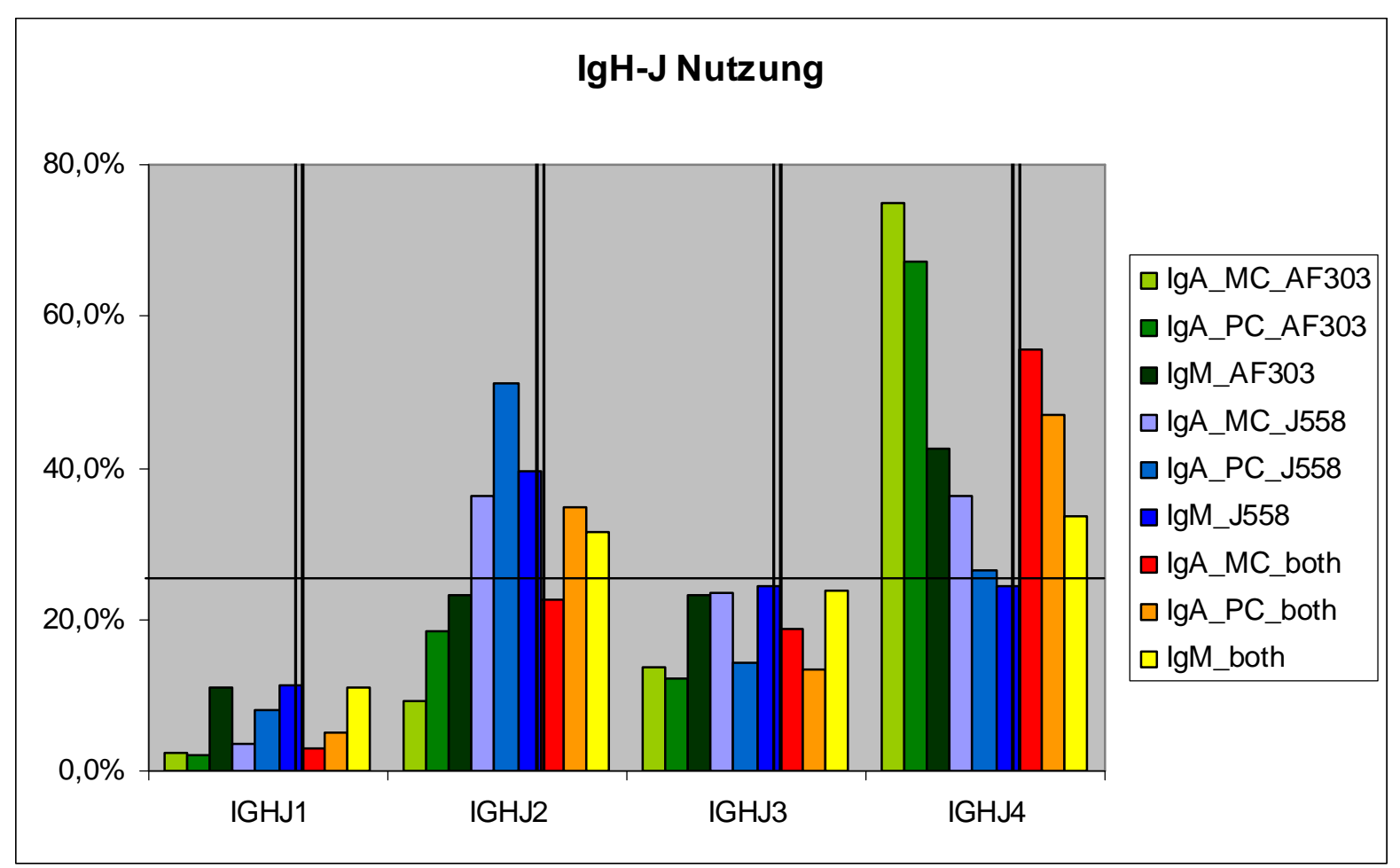

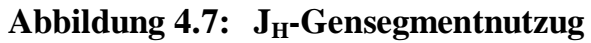

Die durchgezogene Horizontallinie gibt die statistische Wahrscheinlichkeit der Nutzung eines Gensegments an; die vertikalen Doppellinien unterteilen $\mathrm{V}_{\mathrm{H}}$-familienspezifische Sequenzen von zusammengefassten Sequenzen einer Zellpopulation. $\mathrm{PC}=$ Plasmazellen, $\mathrm{MC}=$ Gedächtniszellen. Rohdaten siehe Tabelle 7.2 im Anhang.

Die $\mathrm{J}_{\mathrm{H}}$-Gensegmente der Sequenzgruppen unterteilt in ihre Zugehörigkeit $\mathrm{zu} \mathrm{V}_{\mathrm{H}} 1 / 14$ oder $\mathrm{V}_{\mathrm{H}} 5$ wurden nicht in ihrer Zufallswahrscheinlichkeit von $25 \%$ verwendet. IgH-J1, IgH-J2 und IgH-J3 waren mit $2,0 \%$ bis $23,3 \%$ in der $\mathrm{V}_{\mathrm{H}} 5$-Gruppe unterrepräsentiert, IgH-J4 mit 42,5\% bis 75\% überrepräsentiert (Abbildung 4.7, Tabelle $7.1 \mathrm{im}$ Anhang). Unter der $\mathrm{V}_{\mathrm{H}}$ 5-Gruppe waren IgM-Sequenzen in der Nutzung der $\mathrm{J}_{\mathrm{H}}$-Segmente am ausgeglichensten (11\% J1 bis 42,5\% J4), IgA MC zeigten die größte Zentrierung zur Verwendung des J4-Segments (2,3\% J1 bis 75\% J4).

Eine Überrepräsentation der Nutzung des J2-Segments (36,4\% bis 51,0\%) war hingegen in der $\mathrm{V}_{\mathrm{H}}$ 1/14-Gruppe sichtbar. War die $\mathrm{J} 1$-Nutzung mit 3,6\% bis $11,3 \%$ wiederum vermindert, so näherten sich $\mathrm{J} 3-$ und J4-Verwendung der statistischen Zufallswahrscheinlichkeit an (Abbildung 4.7, Tabelle 7.2 im Anhang).

Statistische Signifikanzen der Verteilungseigenschaften wurden nicht beobachtet. 


\subsection{Eigenschaften der Complementarity Determining Region 3 (CDR3)}

\subsubsection{Länge}

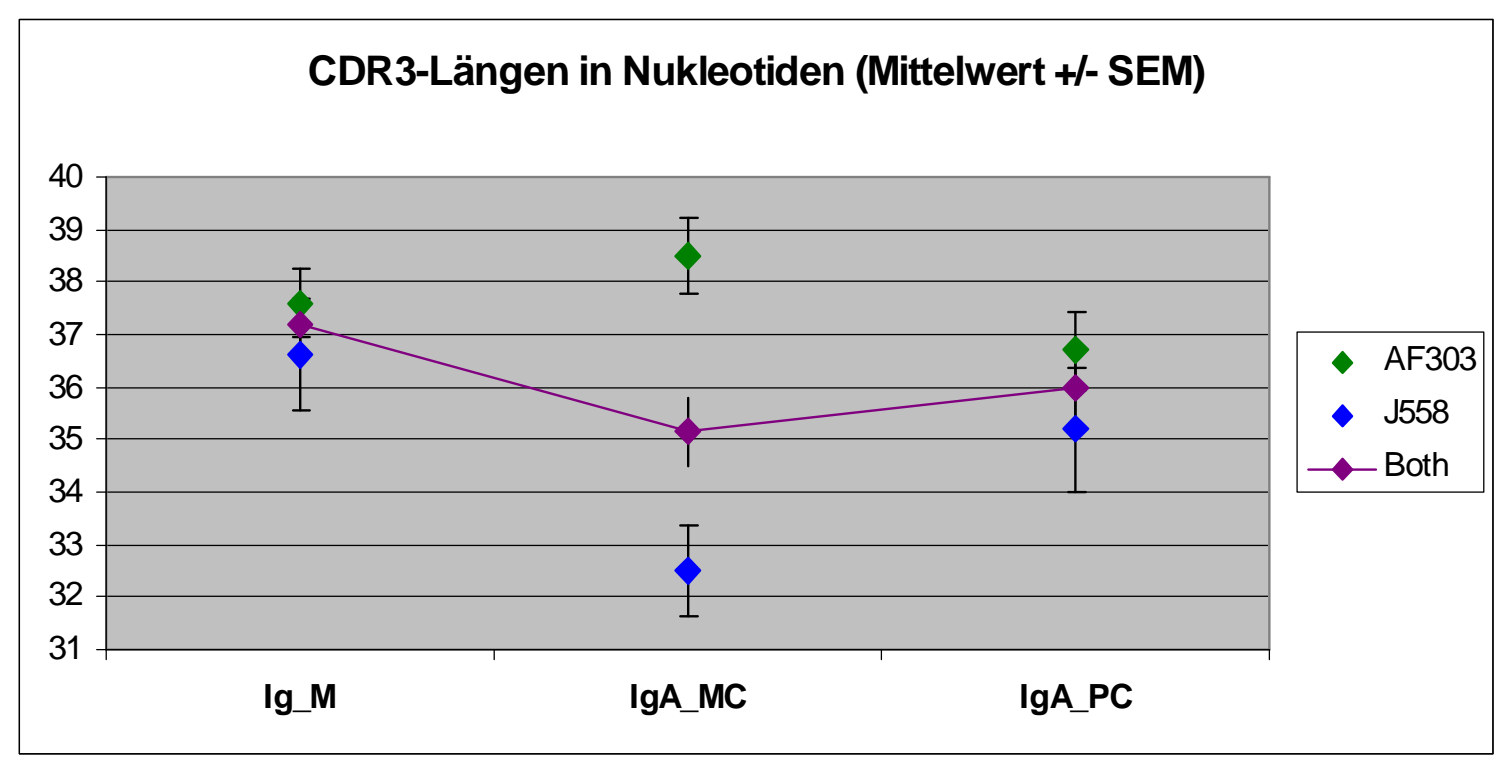

Abbildung 4.8: CDR3-Längen in Nukleotiden

(Mittelwert \pm Standard-Irrtum des Mittelwerts). PC= Plasmazellen, MC=Gedächtniszellen .

Die Länge der CDR3-Regionen unterschied sich bei IgM mit 37,2 \pm 6,6 Nukleotide (Mittelwert \pm Standardabweichung) und IgA MC mit 35,2 \pm 6,7 Nukleotide signifikant ( $\mathrm{p}=0,02$ ) (Abbildung 4.8 und Tabelle 7.4, 7.5 im Anhang). Dies wurde überwiegend durch eine signifikant kürzere $\mathrm{ND}_{\mathrm{H}} \mathrm{N}$-Region von 17,7 $\pm 5,7(\operatorname{IgM})$ bzw. 15,1 \pm 4,1 Nukleotiden (IgA MC) verursacht ( $\mathrm{p}=0$,0002) (Abbildung 4.9, Tabelle 7.4, $7.6 \mathrm{im}$ Anhang). Die CDR3-Länge von IgA PC-Sequenzen (36,0 \pm 7 Nukleotide) unterschied sich nicht signifikant von derjenigen der IgA MC- und IgM-Sequenzen. Jedoch hatten IgA PC mit 17,0 \pm 5,7 Nukleotiden eine längere $\mathrm{ND}_{\mathrm{H}} \mathrm{N}$-Region als $\operatorname{Ig} \mathrm{A} \mathrm{MC}(\mathrm{p}=0,008)$. Der größte Unterschied in der CDR-Länge fand sich zwischen IgA MC-Sequenzen, die die $\mathrm{V}_{\mathrm{H}}$ 5-Familie verwendeten (AF303 Primer) und solchen, die die $\mathrm{V}_{\mathrm{H}}$ 1/14-Familie verwendeten (J558 Primer) $(38,5 \pm 4,9$ Nukleotide vs. 32,5 $\pm 6,5$ Nukleotide, $\mathrm{p}=$ 1,5482E-06) trotz ähnlicher $\mathrm{ND}_{\mathrm{H}} \mathrm{N}-$ Längen (Abbildung 4.8, 4.9, Tabelle 7.4, 7.5). Die CDR3-Länge und $\mathrm{ND}_{\mathrm{H}} \mathrm{N}$-Länge unterschied sich nicht signifikant zwischen den Gruppen. Die CDR3-Längen waren normalverteilt (Abbildung 7.3 und 7.4 im Anhang). 


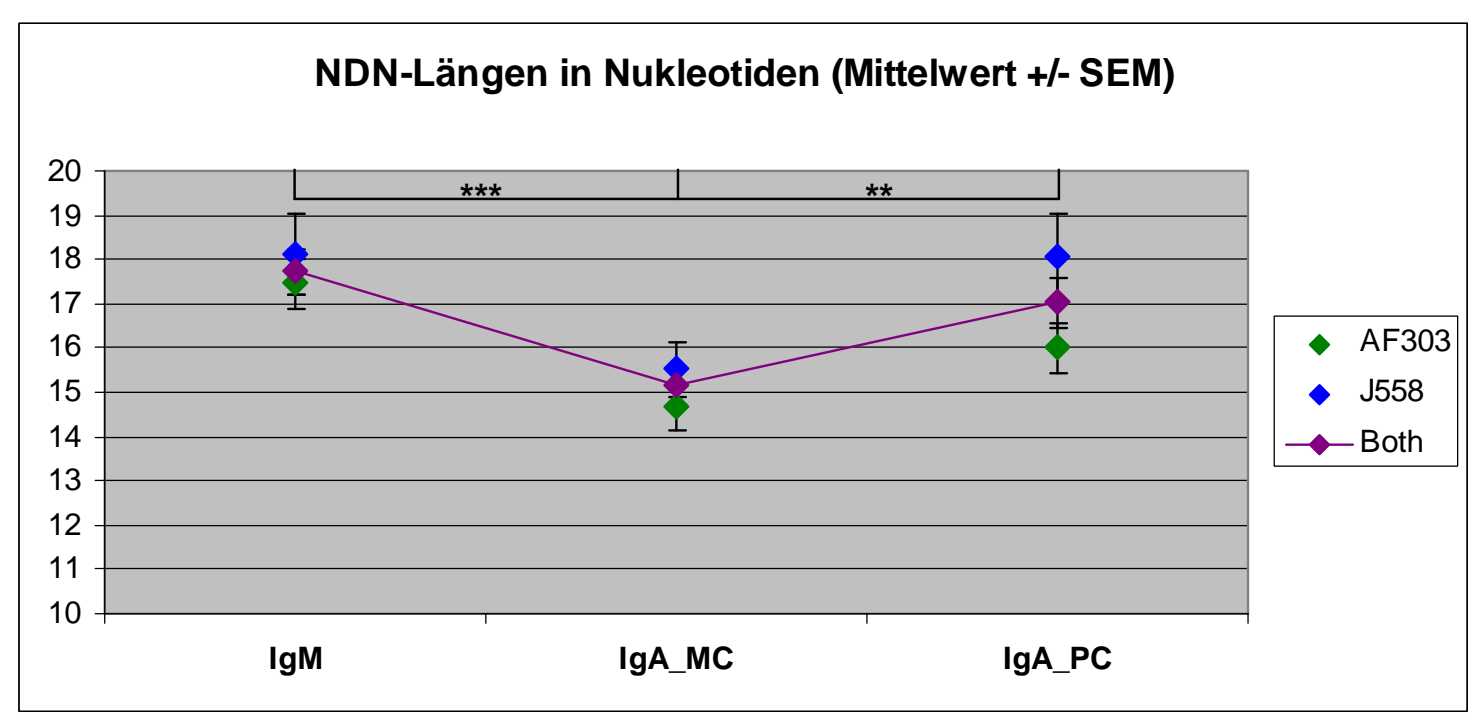

Abbildung 4.9: $\mathrm{ND}_{\mathrm{H}} \mathrm{N}$-Längen in Nukleotiden

(Mittelwert \pm Standard-Irrtum des Mittelwerts). PC= Plasmazellen, MC=Gedächtniszellen .

\subsubsection{Zusammensetzung}

Die Längenunterschiede in CDR3- und $\mathrm{ND}_{\mathrm{H}} \mathrm{N}$-Regionen zwischen $\operatorname{IgM}$ und $\operatorname{IgA} \mathrm{MC}$ waren vor allem durch einen signifikanten Längenverlust der N1-Region (N-Nukleotide am 5'Ende der D-Region) ( $\mathrm{p}=0,0156)$ sowie der $\mathrm{D}_{\mathrm{H}}$-Region $(\mathrm{p}=0,0089)$ bedingt. Demgegenüber wurde die $\mathrm{ND}_{\mathrm{H}} \mathrm{N}$-Längenvermehrung zwischen IgA MC und IgA PC hauptsächlich über die N1-Region herbeigeführt. Alle weiteren Unterschiede in der Zusammensetzung der CDR3-Region zeigten keine Signifikanzen (Abbildung 4.10, Tabelle 7.7 im Anhang).

Betrachtet man $\mathrm{V}_{\mathrm{H}}$ 5- und $\mathrm{V}_{\mathrm{H}} 1 / 14-$ Sequenzen separat, so konnte im Falle der IgASequenzen der CDR3-Längenunterschied auf hochsignifikante Unterschiede in der Länge ihrer $\mathrm{V}_{\mathrm{H}^{-}}$Segmente (MC: $\mathrm{p}=3,2153 \mathrm{E}-14$; PC: 7,5711E-08) sowie $\mathrm{J}_{\mathrm{H}^{-}}$Segmente (MC: $\mathrm{p}=1$ 1,4393E-08; PC: 0,0078) in der CDR3-Region zurückgeführt werden. Im Falle der IgM-Sequenzen beschränkte sich diese Differenz auf die Länge von $V_{H}$ in CDR3 ( $\mathrm{p}=3,9004 \mathrm{E}-09)$. $\mathrm{V}_{\mathrm{H}}$ 5-spezifische IgA MC und PC zeigten bei nicht signifikantem CDR3-Längenunterschied signifikante Unterschiede in der Länge ihrer $\mathrm{V}_{\mathrm{H}^{-}}$Segmente $(\mathrm{p}=0,001)$ sowie $\mathrm{J}_{\mathrm{H}^{-}}$Segmente $(\mathrm{p}=0,002)$ (Abbildung 4.10, Tabelle 7.7 im Anhang). 


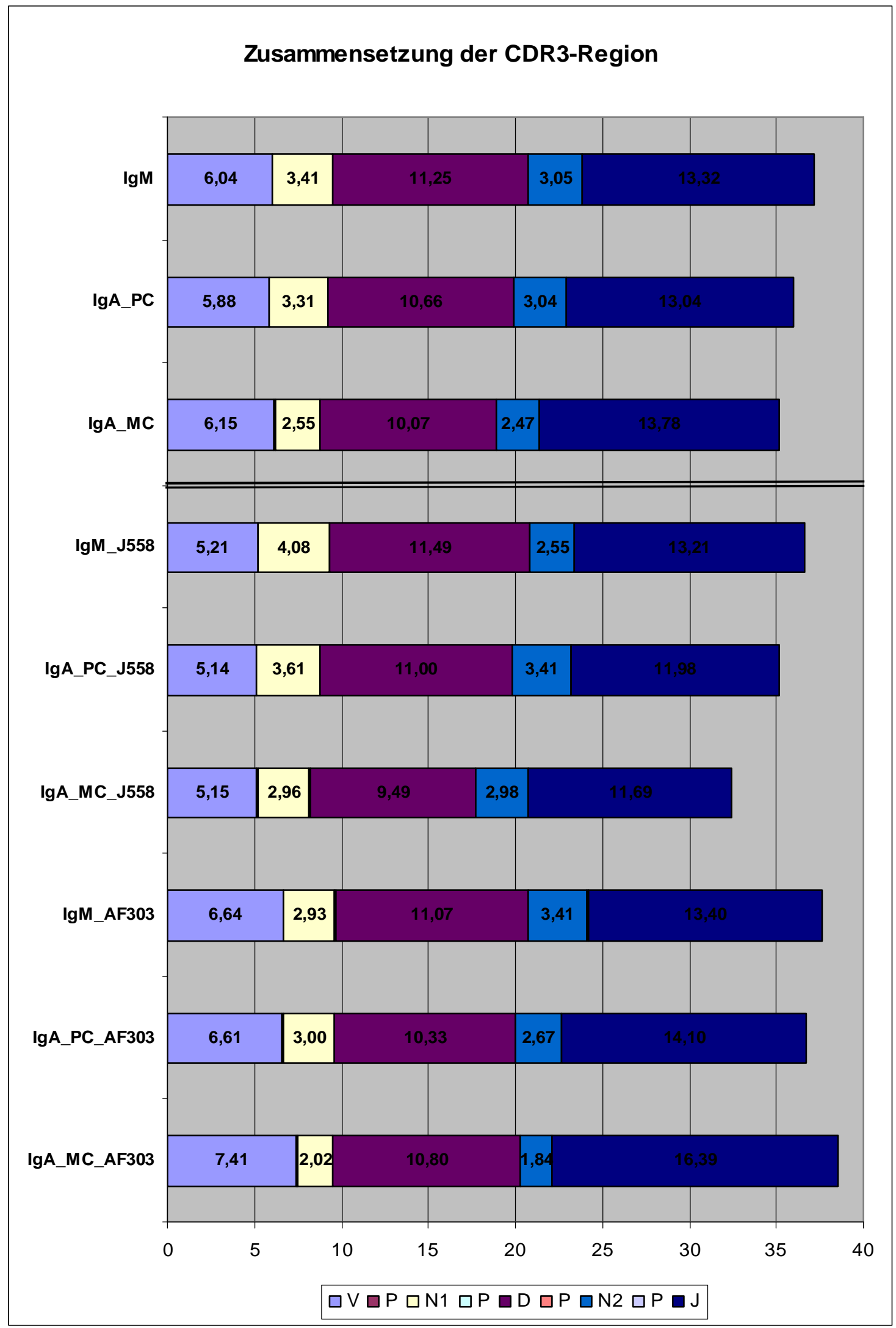

Abbildung 4.10: Zusammensetzung der CDR3-Region in Nukleotiden (Mittelwerte)

$\mathrm{V}$ : $\mathrm{V}_{\mathrm{H}^{-}}$Segment Länge in CDR3; P: Anzahl der P-Nukleotide; N1: Anzahl der N-Nukleotide am 5'-Ende des D-Segments; D: Länge des D-Segments; N2: Anzahl der N-Nukleotide am 3'-Ende des D-Segments; $\mathrm{J}$ : Länge des $\mathrm{J}_{\mathrm{H}^{-}}$Segments. $\mathrm{PC}=$ Plasmazellen, $\mathrm{MC}=$ Gedächtniszellen. 


\subsection{Mutationsanalyse}

Unterschiede zwischen der Nukleotidsequenz der umgelagerten Genabschnitte und der Keimbahnsequenz wurden im Bereich der CDR2- und FR3-Region des $\mathrm{V}_{\mathrm{H}^{-}}$ Gensegments ausgewertet.

IgA-Sequenzen wiesen hierbei eine deutlich höhere Mutationsrate auf als IgMSequenzen. IgA MC besaßen in nur 3,03\% der Fälle $\mathrm{V}_{\mathrm{H}^{-}}$-Gensegmente, die identisch mit Keimbahngenen waren. Drei der 99 genetisch einzigartigen Seqenzen wiesen keine Mutation im Bereich der variablen Region (CDR1-2, FR2-3) auf. Die Mutationsrate (silente und Replacement-Mutationen bezogen auf 1000 Nukleotide) lag durchschnittlich bei 36,91 / 1000 nt, im Median bei 37,56 / 1000 nt bei einem TaqFehler von 1,65 / 1000 nt. Das Verhältnis der Mutationsraten im Bereich der FR3- und CDR2-Regionen belief sich hierbei auf 1: 2,9.

IgA PC wiesen in 9,2\% der Sequenzen (9 von 98 genetisch einzigartigen Sequenzen) keimbahnidentische $\mathrm{V}_{\mathrm{H}}$-Regionen auf. Die Mutationsrate der CDR2 und FR3 lag hier durchschnittlich bei 31,74 / 1000 nt, im Median bei 35,21 / 1000 nt bei einem TaqFehler von 1,39 / 1000 nt. Die Mutationsraten der FR3- und CDR2-Regionen standen in einem Verhältnis von 1:2,5.

IgM-Sequenzen enthielten deutlich mehr keimbahnidentische $\mathrm{V}_{\mathrm{H}}$-Gensegmente. Vierundfünfzig von 126 Sequenzen $(42,68 \%)$ besaßen keine Mutationen in der variablen Region (CDR1-2, FR2-3). Die Mutationsrate lag hierbei mit durchschnittlich 14,46 / 1000 nt, im Median bei 4,69 / 1000 nt und einem Taq-Fehler von 1,36 / 1000 nt deutlich tiefer, jedoch blieb die Verteilung der Mutationen zwischen FR3 und CDR2 mit einem Verhältnis von 1: 2,2 im Bereich der der IgA-Sequenzen (Abbildung 4.11, Abbildung 7.5 im Anhang). 


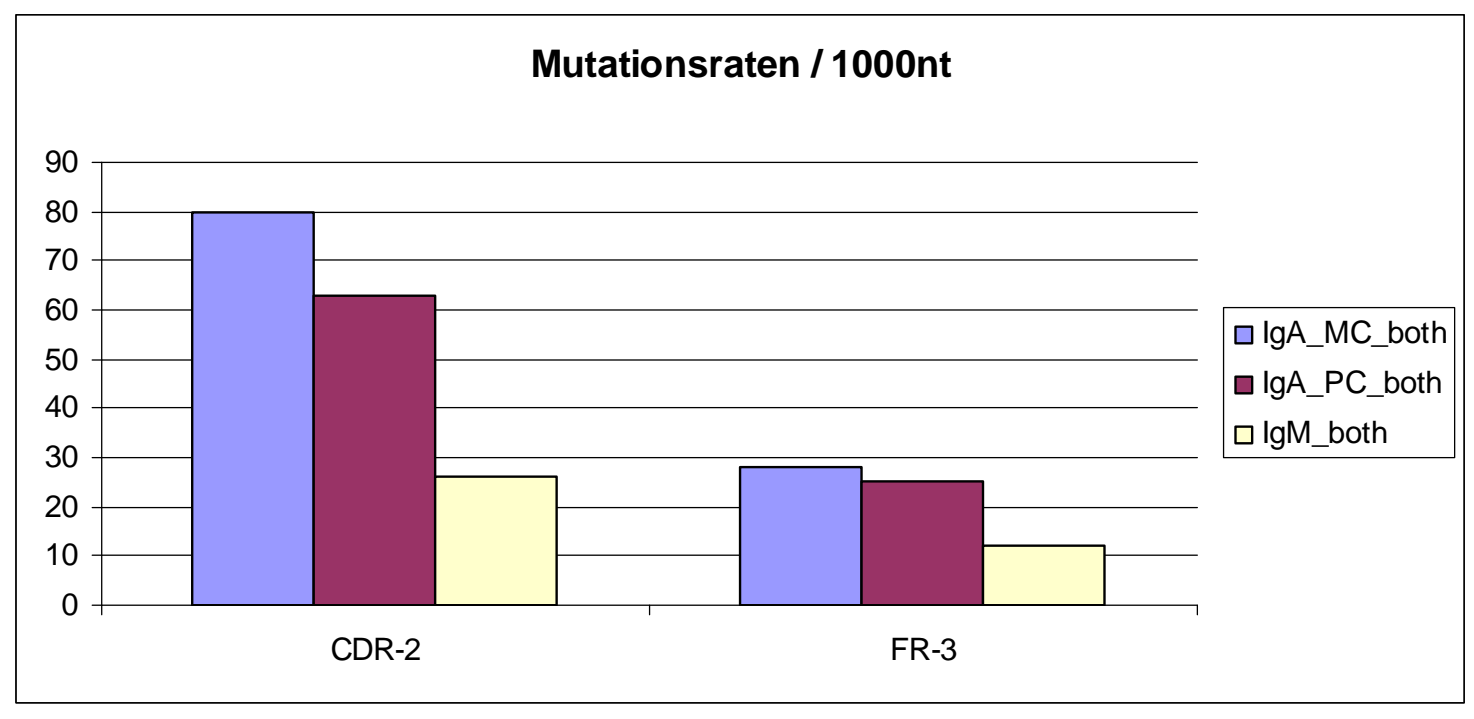

Abbildung 4.11: Mutationsraten

Mutationsraten der VH5- und VH1/14-Sequenzgruppen in Complementarity Determining Region 2 (CDR2) und Framework Region 3 (FR3). PC= Plasmazellen, MC=Gedächtniszellen.

Die Verteilung der Mutationen zwischen CDR2 und FR3 unterschied sich signifikant zwischen IgA- und IgM-Sequenzen. (IgA MC zu IgM: p = 1,63624E-57, IgA PC zu $\operatorname{IgM}: \mathrm{p}=9,27778 \mathrm{E}-39)$. Auch IgA MC und IgA PC zeigten signifikante Unterschiede in den Verteilungseigenschaften ihrer Mutationsraten $(p=0,006)$.

Bei einer separaten Untersuchung der $\mathrm{V}_{\mathrm{H}}$ 5- und $\mathrm{V}_{\mathrm{H}} 1 / 14$-spezifischen Sequenzen fand sich eine Erhöhung der Mutationsraten in allen Gruppen zugunsten $V_{H} 1 / 14$.

Das Verhältnis der Replacement-Mutationen zu silenten Mutationen lag im Bereich der CDR2- und FR3-Region zwischen 1,9 und 5,1. Bei IgA PC- und IgM-Sequenzen lagen Replacement-Mutationen bevorzugt im Bereich der CDR2-Region (Tabelle 4.3).

\begin{tabular}{|lrr|}
\hline & Verhältnis Mutationen Replacement/Silent \\
& CDR2 & FR3 \\
IgM & 3,00 & 1,90 \\
IgA MC & 2,50 & 2,70 \\
IgA PC & 5,10 & 2,50 \\
\hline
\end{tabular}

Tabelle 4.3: Verhältnis von Replacement-Mutationen zu silenten Mutationen

in Complementarity Determining Region 2 (CDR2) und Framework Region 3 (FR3). PC= Plasmazellen, $\mathrm{MC}=$ Gedächtniszellen.

Dies spiegelt sich in der Varianz der Aminosäuren wieder, die die Antigenbindungsstelle bilden (CDR1-3). Gerüstregionen (FR1-3) verbleiben weit weniger mutiert (Abbildung 4.12). 


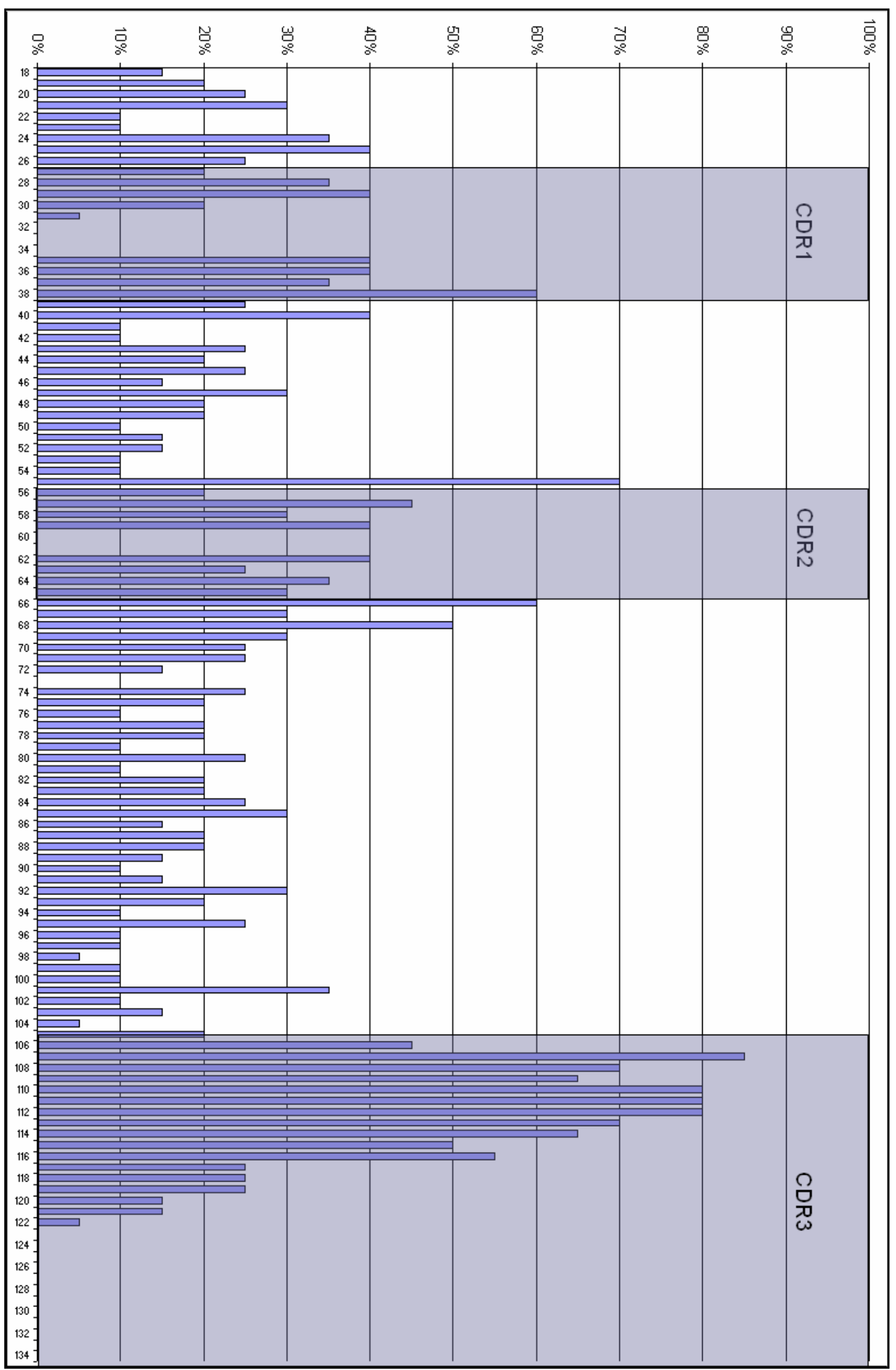

Abbildung 4.12: Aminosäuren-Varianz am Beispiel der IgA PC-Sequenzen.

Blauschraffierte Bereiche entsprechen den CDR1-3-Regionen. 


\subsection{Hydrophobizitätsanalyse}

Der Kyte-Doolittle-Index (Kyte J, 1982; Eisenberg D, 1984) bewertet die Hydrophobizität der Aminosäuren. Jeder Aminosäure wird nach ihren hydrophoben bzw. hydrophilen Eigenschaften ein Wert zwischen -1.3 und +1.7 zugeordnet, über deren Mittelwert die relative Hydrophobizität eines Peptids berechnet werden kann

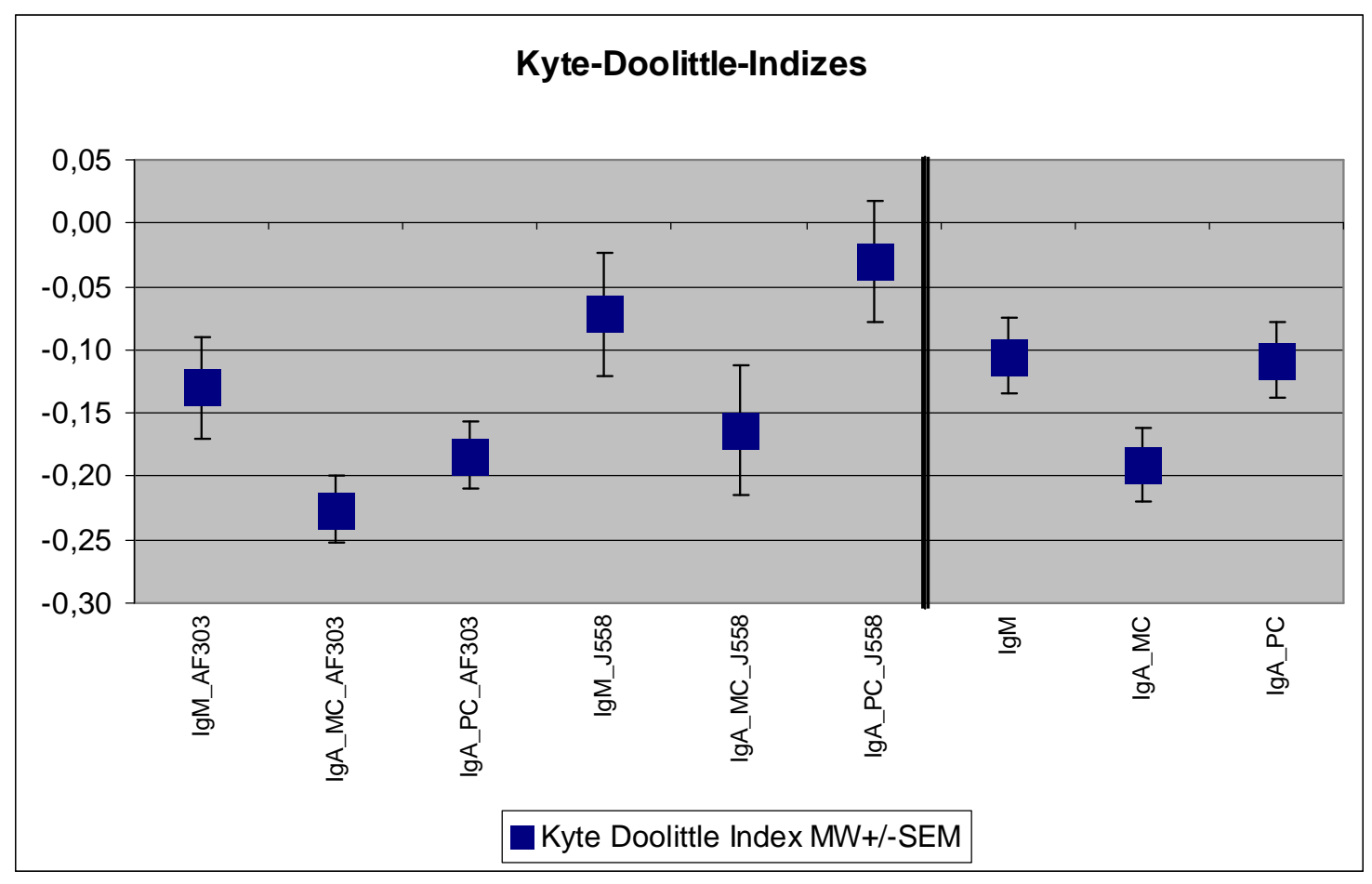

\section{Abbildung 4.13: Durchschnittliche Kyte-Doolittle-Indizes der CDR3-Regionen.}

(Mittelwert \pm Standard-Irrtum des Mittelwerts) Links der vertikalen Linie: familienspezifische Darstellung; rechts der vertikalen Linie: kombinierte (d.h. familienunspezifische) Darstellung. Rohdaten siehe Tabelle 7.8 im Anhang)

Die Immunglobulinsequenzen lagen im neutralen bis schwach polaren Bereich (Abbildung 4.13). IgA MC wiesen mit einem durchschnittlichen Kyte-Doolittle-Index von -0,19 die stärkste Polarität auf (Tabelle 4.4). Sie waren somit signifikant polarer als IgM-Sequenzen $(\mathrm{p}=0,04)$ und IgA PC $(\mathrm{p}=0,04)$. Die Verteilung der Kyte-DoolittleIndizes wurde mit einer Gaußschen Normalverteilung verglichen (Abbildung 4.14). Dabei wies die Sequenzgruppe der IgA MC eine Linksverschiebung der Kyte-Doolittle Indizes auf. IgA PC und IgM zeigten ebenfalls eine Aminosäurenverteilung im mild hydrophilen Bereich. 

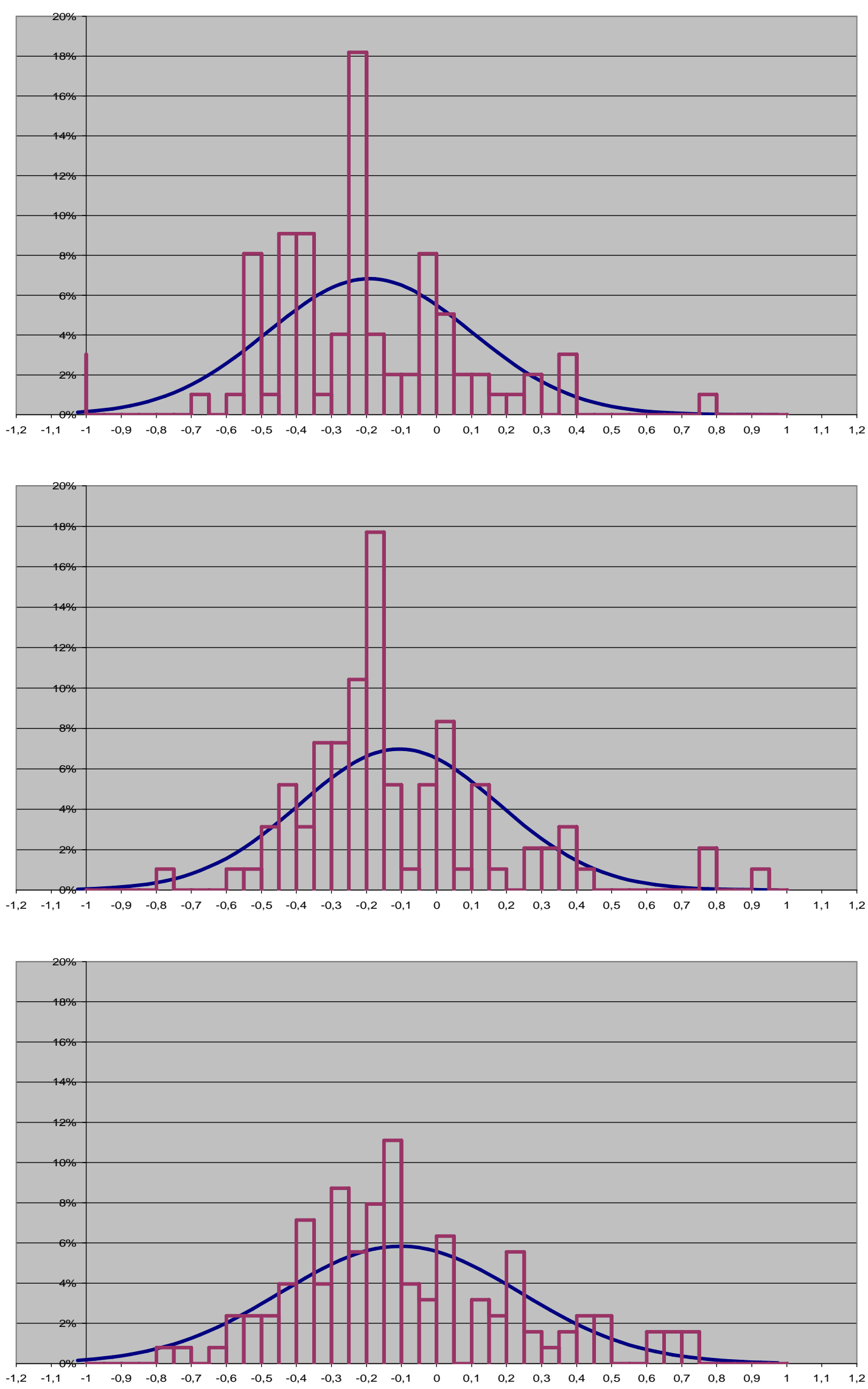

Abbildung 4.14: Kyte-Doolittle-Indizes der IgA MC- , IgA PC- und IgM-Sequenzen im Vergleich zur Gaußschen Normalverteilungskurve 


\section{Diskussion}

In dieser Arbeit wurden erstmals die mRNA-Transkripte der schweren Immunglobulinkette von IgM und IgA aus Peyer-Plaques der Maus untersucht. Diese Transkripte kodieren für die Antigen-Bindungsstelle des Immunglobulins und wirken sich daher wesentlich auf die Antigen-Spezifität und -Affinität des Antikörpers aus. Daher erlauben diese Daten Rückschlüsse auf den Selektionsdruck, der während des Klassenwechsels von IgM zu IgA herrscht. Darüher hinaus wurden Plasma- und Gedächtniszellen separat betrachtet, um zu prüfen, ob während der Rekrutierung in die unterschiedlichen Zell-Subpopulationen ein systematischer Selektionsdruck anhand der Antigen-Bindungsstelle herrscht.

Als Indikatoren für die Vielfalt und den Reifegrad der Immunglobuline verglichen wir die Diversität, $\mathrm{V}_{\mathrm{H}^{-}}$, D- und $\mathrm{J}_{\mathrm{H}^{-}}$Gensegmentnutzung, CDR3- und $\mathrm{ND}_{\mathrm{H}} \mathrm{N}$-Länge, die somatische Mutationsrate sowie die relative Hydrophobizität der Antigenbindungsstelle. Klarheit besteht darüber, dass Peyersche Plaques die vornehmliche Induktionsstätte der Immunantwort darstellen (Makala LH, 2002-2003).

Durch den Vergleich IgM- und IgA-spezifischer Sequenzen kann das Vorhandensein prädisponierender Faktoren untersucht werden, die bestimmte und nicht zufällige Sequenzen bzw. Sequenzcluster zur Differenzierung über den Klassenwechsel induzieren. Die Untersuchung bezieht sich ebenfalls auf wiederkehrende Motive der Ontogenese oder immunologischen Reifung, die eine Ausdifferenzierung zu Plasmaund Gedächtniszellen bedingen könnten.

Durch die Verwendung zweier unterschiedlicher, $\mathrm{V}_{\mathrm{H}}$-Familien-spezifischer Primer können zeitgleich $\mathrm{V}_{\mathrm{H}}$-Familien-spezifische Unterschiede im Horizontalvergleich detektiert werden.

Anhand unserer Untersuchungen sind folgende Aussagen möglich:

- IgA-Transkripte von Gedächtnis- und Plasmazellen weisen gegenüber IgMTranskripten eine eingeschränkte klonale Diversität und erhöhte somatische Mutationsraten auf. Dies belegt eine Antigen-abhängige, fokussierte Selektion während des Klassenwechsels. 
- Zur Bildung des sekundären Repertoires werden Immunglobuline mit kürzeren CDR3-Regionen verwendet.

- IgA-produzierende Gedächtnis- und Plasmazellen stellen separate Populationen mit unterschiedlichen Repertoires an Antigen-Bindungsstellen dar.

\subsection{Die eingeschränkte klonale Diversität sowie die erhöhte} Mutationsrate der IgA-Transkripte gegenüber IgMTranskripten belegen eine Antigen-abhängige fokussierte Selektion während des Klassenwechsels von IgM zu IgA.

\subsubsection{Klonale Diversität}

Um einen effektiven Schutz zu gewährleisten und auch phylogenetisch eng verwandte Pathogene unterscheiden zu können, bedarf es einer großen Vielzahl von B-Zellklonen (Arstila TP, 1999). Die Spezifität der Antigenerkennung wird durch das Produkt der BLymphozyten, die Immunglobuline, gesichert (Kurosawa Y, 1982). Jeder B-Zellklon kann dabei durch sein eigenes Immunglobulin charakterisiert werden. Da die im Wesentlichen für die Antigenspezifität und -affinität verantwortliche CDR3-Region (Xu JL, 2000) die variabelste Region eines Immunglobulins darstellt, korreliert die BZelldiversität stark mit der Variabilität der Antigenbindungsstelle.

Die Vielfalt der Immunglobulinsequenzen ist je nach Nutzung der $\mathrm{V}_{\mathrm{H}}$-Familie verschiedenartig. $\mathrm{V}_{\mathrm{H}} 1 / 14$-Sequenzen zeigen eine deutlich höhere Diversität als $\mathrm{V}_{\mathrm{H}}$ 5Sequenzen. Dies ist durch die unterschiedlichen Familiengrößen $\left(\mathrm{V}_{\mathrm{H}} 1 / 14 \sim 60 \%\right.$ der BZellen; $\mathrm{V}_{\mathrm{H}} 5 \sim 10-15 \%$ der B-Zellen) zu erklären. Innerhalb der $\mathrm{V}_{\mathrm{H}}$ 5-Sequenzgruppe fällt eine deutlich größere Diversität der IgM-Sequenzen als der IgA-Sequenzen auf. Im Rahmen der B-Zell-Entwicklung entstehen primäre, IgM-Antikörper. Nur diejenigen BLymphozyten, die nach erfolgtem Antigenkontakt einen Reifungsprozess durchlaufen und einen Klassenwechsel vollzogen haben, können als sekundäre Antikörper IgA produzieren (Milstein C, 1986). Entsprechend unseren Daten ist demnach die Gruppe der IgM-Sequenzen um ein Vielfaches größer als die Gruppe der IgA-Sequenzen und 
verfügt somit über eine ausgeprägtere Diversität (vgl. Tabelle 4.2). Antikörperproduzierende Plasmazellen, die bei einem Zweitkontakt mit demselben Antigen $\mathrm{zu}$ einer schnellen Immunantwort durch direkte Antikörpersekretion führen, weisen per se eine geringe Diversität auf, da ihre Anzahl vermutlich durch die limitierte Anzahl von Überlebensnischen begrenzt wird (Yoshida T, 2010). Zudem besitzen aktive Plasmazellen 100 bis 1.000 mal mehr RNA-Transkripte für die schwere Immungloblinkette als ruhende B-Zellen, so dass bei der RT-PCR häufiger redundante Sequenzen gefunden werden, die der gleichen Plasmazelle entstammen (de Vos J, 2006).

\subsubsection{Somatische Mutationen}

Die Diversität der durch somatische Rekombination entstandenen Immunglobuline des primären Antikörperrepertoires wird so groß eingestuft, dass alle Antigengruppen mit zumindest mäßiger Affinität gebunden werden können. Nachfolgende somatische Mutationen im Rahmen der Keimzentrumsreaktion und positive Selektion führen zur Affinitätssteigerung, folglich zum effizienteren Schutz des Organismus gegen Pathogene (Rajewsky K, 1996). Mutationen in den gerüstbildenden FR nehmen starken Einfluss auf die Tertiärstruktur der Immunglobulinmoleküle. Da dies die stetige Gefahr der Bildung instabiler Proteine birgt, findet man in den FR vornehmlich silente Mutationen, in den Bereichen, die in direkten Antigenkontakt treten, zeigt sich hingegen die Tendenz zu Replacement-Mutationen (Tabelle 4.3). Über geringe Veränderungen der Schleifenstrukturen kann sich die Affinität des Antikörpers mutationsbedingt um den Faktor 3-10 steigern, wohingegen Mutationen in den CDR-Regionen Affinitätssteigerungen um den Faktor $10^{2}-10^{3}$ ermöglichen (Tomlinson IM, 1995). Die Häufigkeit dieser Mutationen nimmt während der sekundären und tertiären Immunantwort stetig zu, immer mit dem Ziel der Produktion hochaffiner Antikörper für ein spezifisches Antigen (Mix E, 2006).

In unseren Daten entsprachen $43 \%$ des primären Antikörperrepertoires $(\operatorname{IgM})$ den unmutierten Keimbahnsequenzen, wohingegen das sekundäre Repertoire (IgA) 3-9\% keimbahnidentische $\mathrm{V}_{\mathrm{H}}$-Sequenzen enthielt. Somit gab es sowohl einen Anteil somatisch mutierter IgM-Sequenzen als auch einen Anteil unmutierter IgA-Sequenzen. Im Einklang mit früher publizierten Daten lässt dies die Interpretation zu, dass sowohl 
somatische Hypermutationsprozesse als auch Klassenwechsel zwar AID-gesteuert im Keimzentrum stattfinden, aber keine parallel geschalteten Ereignisse darstellen (Fischer M, 1998; Yavuz S, 2001). Sie werden von zwei unabhängig voneinander arbeitenden Domänen der AID katalysiert, wobei der Funktionsverlust einer Domäne nicht den automatischen Ausfall der anderen Domäne bedeutet (Shinkura R, 2004).

Klassischerweise wurde die IgM-Produktion ausschließlich der primären Immunantwort zugeordnet. B-Lymphozyten, die im Rahmen der frühen primären Immunantwort zu Antikörper-produzierenden Zellen differenzieren, durchlaufen keine Keimzentrumsreaktion. Diese Zellen bilden also Immunglobuline, die durch unmutierte IgHV-Gene kodiert werden (McHeyzer-Williams MG, 1993). Bereits vor einiger Zeit wurde jedoch die Hypothese aufgestellt, dass eine große Anzahl IgM-produzierender Zellen in Wirklichkeit Gedächtniszellen sind, die somatische Hypermutationsprozesse vollzogen haben (Klein U, 1997). Diese Hypothese wird von unseren Daten unterstützt, da wir einen kleinen aber reproduzierbaren Anteil somatisch mutierter IgM-Sequenzen fanden.

Die Mutationsrate der IgA-Sequenzen der murinen Peyer-Plaques lag, ähnlich wie bei früheren Untersuchungen an B-Lymphozyten des peripheren Blutes und des follikulären Lymphgewebes (Pascual V, 1994; Klein U, 1994), hier bei ca. 3,5 - 4\%. Humane intestinale IgA-produzierende B-Lymphozyten Peyerscher Plaques wiesen jedoch eine deutlich höhere Mutationsrate von ca. 9\% auf (Fischer M, 1998). Durch chronische Antigenexposition der intestinalen Mukosa mit Nahrungsmittel- und Bakterienantigenen könnte dies zur massiven Induktion von Keimzentren führen. Es wäre denkbar, dass die Bedingungen der spezifisch keimfreien Pflege von Mäusen eine geringere Stimulation für die Bildung von Keimzentren und somatischen Mutationen darstellen als die natürliche Umgebung des Menschen. Einer kontrovers diskutierten Hypothese nach (MacLennan IC, 1992) existieren Gedächtniszellen mit der Fähigkeit, mehrere Keimzentrumsreaktionen zu durchlaufen (Rada C, 1991), um durch eine höhere Mutationsfrequenz zu einer verstärkten Affinitätsreifung zu gelangen. Diese Hypothese wird gestützt durch die Tatsache, dass die somatische Mutationsrate mit wachsendem Alter stetig ansteigt (González-Fernández A, 1994). Es könnte sich jedoch auch um eine vermehrte Ansammlung stark mutierter B-Zellen in den Keimzentren der Peyerschen Plaques im Vergleich zu anderen peripher-lymphatischen Organen oder um eine Kombination beider Mechanismen handeln. 
Durch die steigende Mutationsrate mit wachsendem Alter könnte auch der Unterschied der von uns erhobenen Daten zu oben genannten, bereits publizierten Daten (Fischer M, 1998) humaner Immunglobuline erklärt werden. Die Hochphase der Entwicklung muriner Keimzentren liegt etwa zwischen der 5. und 30. Lebenswoche (Carril MS, 2002). Mit einem Lebensalter von acht Wochen waren die hier untersuchten Mäuse recht jung, was zusätzlich zu den speziesspezifischen Unterschieden zu einer geringeren Mutationsrate beigetragen haben könnte.

Entgegen der Erwartung, zur Bildung hochaffiner Plasmazellen sei eine hohe Mutationsrate nötig, lag diese bei uns geringfügig unter der Mutationsrate der Gedächtniszellen. Frühere Analysen (Smith KG, 1997) legen nahe, dass Plasmazellen im Vergleich zu Gedächtniszellen einer strengeren Selektion unterliegen. Des weiteren belegen Studien, dass ein entscheidender Anteil muriner, intestinaler IgA PC von $\mathrm{CD}^{+}{ }^{+}$ B-Lymphozyten abstammt (Kroese FG, 1989; 1995), von denen ein Großteil unmutierte IgHV-Gene aufweist (Tarlinton D, 1988; Fischer M, 1997) und zudem nur in geringem Maße zur Bildung von Keimzentren beiträgt (Stall AM, 1996). Interessanterweise ist die somatische Mutationsrate bei IgE-produzierenden Gedächtniszellen in der Milz allergisch sensibilisierter Mäuse deutlich niedriger als bei IgE-produzierenden Plasmazellen (Rogosch T, 2010). Dies könnte auf Isotyp-spezifische Selektionsmechanismen des humoralen Immungedächtnisses oder auf Organspezifischen Unterschieden beruhen.

Die Mutationsraten waren bei den $\mathrm{V}_{\mathrm{H}} 1 / 14-$ Sequenzen höher als bei den VH5Sequenzen. Für diese größte murine $\mathrm{V}_{\mathrm{H}}$-Familie sind aktuell ca. 86 unterschiedliche funktionelle Gensegmente bekannt (IMGT, 2008). Die beschriebenen Auffälligkeiten könnten am ehesten dadruch erklärt werden, dass weitere, bisher nicht identifizierte Segmente oder Gen-Polymorphismen existieren, die eine hohe Mutationsrate in den $\mathrm{V}_{\mathrm{H}} 1 / 14-$ Sequenzen vortäuschen. 


\subsection{Seinem Reifegrad entsprechend enthält das sekundäre Immunglobulinrepertoire vorwiegend D-distal gelegene $\mathrm{J}_{\mathrm{H}^{-}}$ Gensegmente.}

Die Immunglobulin-Sequenzen wurden im Rahmen der PCR mit zwei $\mathrm{V}_{\mathrm{H}^{-}}$ familienspezifischen Primern erhoben. Grundsätzlich erfolgt die Auswahl der $\mathrm{V}_{\mathrm{H}^{-}}$ Segmente während der Umlagerung nicht zufällig. Bereits in den 80er Jahren haben einige Arbeitsgruppen gezeigt, dass im Fetalstadium prä-B-Zellen und Lymphozyten aus der Leber von BALB/c-Mäusen vorwiegend Gensegmente der $V_{\mathrm{H}}$ 7183-Familie rekombinieren, derjenigen $\mathrm{V}_{\mathrm{H}}$-Familie, die keimbahngenetisch am weitesten $\mathrm{D}$ proximal liegt (Yancopoulos GD, 1984 und 1988; Perlmutter RM, 1985; Riblet R, 1986). In späteren Entwicklungsstadien, 7 Tage nach der Geburt, werden von der großen Mehrzahl der B-Zellen Mitglieder der $\mathrm{V}_{\mathrm{H}} 1$-Familie (J558) verwendet (Malynn BA, 1990). In der hier vorliegenden Arbeit wurden vier Wochen alte BALB/c-Mäuse verwendet, so dass diese Effekte der frühen Ontogenese nicht von Bedeutung sind. Durch die Amplifikation mittels $\mathrm{V}_{\mathrm{H}} 5$ - und $\mathrm{V}_{\mathrm{H}} 1 / 14$-familienspezifischen Primern wurden insgesamt ca. 70-75\% der Immunglobulin-Transkripte sequenziert (Jeong HD, 1988; Schroeder HW Jr, 2006). Diese separate Untersuchung der beiden größten $\mathrm{V}_{\mathrm{H}^{-}}$ Familien erlaubt einen tieferen Einblick in die Struktur des Antikörper-Repertoires als die Globalanalyse, da sie den Vergleich von morphologisch identischen B-ZellSubpopulationen hinsichtlich ihrer Antigen-Bindungsstellen ermöglicht. Aussagen über die Häufigkeitsverteilung der Segmentnutzung, die Rückschlüsse auf eine eventuelle Selektion durch Superantigene zuließe (Zouali M, 1995), sind mit dieser Methodik nicht möglich.

Das umgelagerte $\mathrm{D}_{\mathrm{H}}$-Gensegment liegt im Zentrum der für die Antigenerkennung wichtigen CDR3-Region. Von den sieben $\mathrm{D}_{\mathrm{H}^{-}}$-Gensegment-Familien wurde $\mathrm{D}_{\mathrm{H}^{-}}$-Familie 2 (DSP2) überzufällig häufig verwendet (Abbildung 4.5). IgM- und IgA PC-Sequenzen zeigten ausserdem eine Überrepräsentation der am weitesten proximal liegenden $\mathrm{D}_{\mathrm{H}^{-}}$ Familie 1 (DFL16) bzw. des Segments DFL16.1 (Abbildung 7.2 im Anhang), was eine mehr als dreimal häufigere Gensegmentnutzung darstellt als sie aus stochastischen Berechnungen zu erwarten wäre. Die Nutzung der zahlenmäßig deutlich größeren $\mathrm{D}_{\mathrm{H}^{-}}$ Familie 2, v.a. Segment 2.4 (DSP2.2) war im Gegenzug bei IgM- und IgA PC- 
Sequenzen deutlich vermindert, ähnlich wie es für das Immunglobulin-Repertoire älterer Mäuse beschrieben ist (Bangs LA, 1991). Umgekehrt verhielt sich die $\mathrm{D}_{\mathrm{H}^{-}}$ Gensegmentnutzung der IgA MC.

Die am weitesten $\mathrm{V}_{\mathrm{H}^{-}}$-distal liegende $\mathrm{D}_{\mathrm{H}}$-Familie 4 (DQ52), an deren 3'-Ende sich das erste $\mathrm{J}_{\mathrm{H}}$-Gensegment anschließt, zeigte bei den hier untersuchten erwachsenen Mäusen keine Überrepräsentation. Auch beim Menschen verlagert sich im Laufe der Ontogenese die $\mathrm{D}_{\mathrm{H}}$-Gen-Nutzung von $\mathrm{J}_{\mathrm{H}}$ proximal $\mathrm{zu} \mathrm{J}_{\mathrm{H}}$ distal. Daher wird das dem murinen DQ52 homologe $\mathrm{D}_{\mathrm{H}}$ 7-27-Gen während der Fetalzeit bevorzugt und beim Erwachsenen kaum noch verwendet (Zemlin M, 2001; Bauer K, 2002),

Da das verwendete $\mathrm{D}_{\mathrm{H}^{-}}$-Segment den Mittelpunkt der CDR3-Region bildet, können Sequenzen, die ein- und dasselbe $\mathrm{D}_{\mathrm{H}}$-Gensegment verwenden, über ihre ähnlichen Aminosäuresequenzen als eigene ,Sub-Repertoires' angesehen werden. An genetisch veränderten Mauslinien konnte gezeigt werden, dass diese ,Sub-Repertoires' unterschiedliche Antigen-Bindungseigenschaften haben, da ihre CDR3-Regionen in ihrer Struktur differieren (Schelonka RL, 2005).

Unabhängig von der $\mathrm{V}_{\mathrm{H}}$-Familien-Spezifität trat innerhalb der drei Sequenzgruppen IgM, IgA MC, IgA PC eine gleichförmige Nutzung der Leserahmen (RF) auf (Abbildung 4.6). Obwohl jedes einzelne $\mathrm{D}_{\mathrm{H}^{-}}$Gensegment potentiell sechs verschiedene RF verwenden könnte, fanden wir, übereinstimmend mit mehreren Studien vor uns, eine vornehmliche Nutzung des Leserahmens 1 (Feeney AJ, 1990; Ishihara Y, 1998). Die limitierte Nutzung der übrigen Leserahmen beruht auf verschiedenen Mechanismen: Da im Rahmen der $\mathrm{D}_{\mathrm{H}}$-Rekombination häufiger Deletionen als Inversionen vorkommen, ergibt sich eine eingeschränkte Nutzung der drei durch Inversion gebildeten i-RF. Der dritte Leserahmen trägt im Zentrum seiner keimbahnkodierenden Sequenz oft ein StopCodon (TAG, TAA, TGA), das zu einer vorzeitigen Beendigung der Translation führt und damit die Nutzung des RF3 limitiert. Die Verwendung des RF2 führt zur vorübergehenden Bildung eines sogenannten $\mathrm{D} \mu$-Proteins, das den Fortschritt der $\mathrm{V}_{\mathrm{H}} \mathrm{DJ}_{\mathrm{H}}-$ Rekombination bremst $(\mathrm{Gu} \mathrm{H}, 1991)$. Die bevorzugte Verwendung des ersten Leserahmens wirkt sich auf die spätere Hydrophobizität der CDR3-Region und damit auf die Bindungseigenschaften der Antigenbindungsstelle aus (Shlomchik MJ, 1990).

Bedeutende Unterschiede in der Verwendung der Gensegmente traten zwischen den hier untersuchten Zell-Populationen bezüglich der $\mathrm{J}_{\mathrm{H}}$-Segmentnutzung auf (Abbildung 4.7). Die Verwendung des $\mathrm{J}_{\mathrm{H}} 1$-Segments war bei einer statistischen Wahrscheinlichkeit von 25\% für die Nutzung eines jeden Segments innerhalb aller Sequenzgruppen 
unterrepräsentiert. Die Häufigkeit der Segmente $\mathrm{J}_{\mathrm{H}} 2$ und $\mathrm{J}_{\mathrm{H}} 3$ lag knapp ober- bzw. unterhalb ihrer stochastischen Wahrscheinlichkeit. Dies entsprach im Wesentlichen bereits publizierten Daten reifer B-Lymphozyten aus dem Knochenmark von BALB/cMäusen (Ivanov II, 2005). Unsere Daten zeigen, dass in der Gesamtheit aller Sequenzen $\mathrm{J}_{\mathrm{H}} 4$ besonders häufig umgelagert wird, wobei dieser Effekt am deutlichsten bei den Sequenzen des sekundären Antikörperrepertoires zu erkennen ist. Ein Trend, der früheren Reifungsstadien humaner B-Lymphozyten der fetalen Leber $\mathrm{D}_{\mathrm{H}}$-proximal gelegene und reifen B-Lymphozyten Erwachsener $\mathrm{D}_{\mathrm{H}^{-}}$-distal gelegene $\mathrm{J}_{\mathrm{H}}$-Gensegmente zuordnet (Shiokawa S, 1999), scheint sich auch auf die Entwicklung des sekundären Antikörperrepertoires übertragen zu lassen. In Abhängigkeit der verwendeten $\mathrm{V}_{\mathrm{H}^{-}}$ Familie wies entgegen früheren Vermutungen die Häufigkeit der verwendeten $\mathrm{J}_{\mathrm{H}^{-}}$ Segmente Unterschiede auf.

\subsection{Zur Bildung des sekundären Repertoires werden Immunglobuline mit kürzeren CDR3-Regionen verwendet, die eine engere Antigen-Antikörper Interaktion mit höherer Affinität gewährleisten.}

Eine erweiterte Diversität und Positionierung im Zentrum der Antigenbindungsstelle verleihen der CDR3-Region eine wichtige Rolle in der Erkennung eines Antigens (Pedlan EA, 1994; Xu JL, 2000). Exonukleatische terminale Aktivität und das Einfügen von P-Nukleotiden tragen zur Längenveränderung rekombinierter Keimbahn- $\mathrm{V}_{\mathrm{H}} \mathrm{DJ}_{\mathrm{H}^{-}}$ Gensegmente ebenso bei wie die TdT-gesteuerte Insertion von N-Nukleotiden.

Es ist bekannt, dass die mittlere CDR3-Länge und deren Verteilung große Auswirkungen auf das Immunglobulin-Repertoire einer Spezies und dessen Funktionen haben (Johnson G, 1998; Collis AV, 2003). CDR3-Längen differieren zwischen verschiedenen Spezies (Wu TT, 1993; Kaushik A, 2002). Murine CDR3-Regionen sind im Durchschnitt kürzer als humane CDR3-Regionen (Zemlin M, 2003). Dies wird auch im Vergleich der von uns erhobenen Daten mit früher veröffentlichten Daten humaner IgM-CDR3-Regionen (Souto-Carneiro MM, 2005; Bauer K, 2002) deutlich. 
In unserer Studie zeigte sich, dass die $\mathrm{ND}_{\mathrm{H}} \mathrm{N}$-Längen und CDR3-Längen im Vergleich zwischen IgM und IgA MC parallel signifikant abnahmen. Ein ähnlicher, allerdings nicht signifikanter Trend ließ sich für die IgA PC detektieren (Abbildung 4.8). Zwar tragen auch $\mathrm{V}_{\mathrm{H}^{-}}$und $\mathrm{J}_{\mathrm{H}^{-}}$-Gensegmente zur Bildung der CDR3-Region bei, für Länge und Affinität der Antigenbindungsstelle ist jedoch die zwischen $\mathrm{V}_{\mathrm{H}^{-}}$und $\mathrm{J}_{\mathrm{H}^{-}}$Gensegment liegende $\mathrm{ND}_{\mathrm{H}} \mathrm{N}$-Region von entscheidender Bedeutung (Zemlin M, 2001; Bauer K, 2002). Erstaunlicherweise können Knockout-Mäuse ohne funktionierende TdT-Aktivität und somit ohne N-Nukleotid-Insertionen nahezu normale Immunantworten hervorbringen (Gilfillan S, 1993). Bei Wildtyp-Tieren fanden sich signifikant kürzere CDR3-Regionen in produktiven als in nicht-produktiven Immunglobulin-Sequenzen (Souto-Carneiro MM, 2005).

Unsere Daten weisen darauf hin, dass bevorzugt Immunglobuline mit kürzeren CDR3Regionen zum Klassenwechsel verwendet werden. Der Klassenwechsel erfolgt nach stattgehabter somatischer Hypermutation im Rahmen der Keimzentrumsreaktion (Kapitel 2.5.2, 2.5.3). Untersuchungen an hypermutierten, humanen, adulten Immunglobulinen zeigten ebenfalls eine Tendenz zu kürzeren CDR3-Regionen als unmutierte Sequenzen (Rosner K, 2001). Theoretisch könnte dieser Längenverlust durch unterschiedliche Gensegment-Nutzungen oder durch veränderte Aktivitäten der TdT und Exonukleasen zustande kommen. Die Aufschlüsselung der Zusammensetzung der CDR3-Region ergab für IgA MC und IgA PC einen signifikanten Längenverlust der N-Nukleotide. Somit kann eine verminderte TdT-Aktivität und nicht die Gen-SegmentNutzung als Grund für den Längenverlust angesehen werden.

Welchen Grund hat die positive Selektion der Immunglobuline mit kürzeren CDR3Regionen für den Klassenwechsel?

Studien an Immunglobulinen Erwachsener haben gezeigt, dass der CDR3-Länge Grenzen gesetzt sind. Mit ansteigender Länge der CDR3-Region nimmt der Anteil unproduktiver Umlagerungen zu. Eine frühere Annahme, dies sei auf die erhöhte Wahrscheinlichkeit der Einführung eines Stop-Codons erklärbar (Brezinschek HP, 1995), konnte durch genauere Analysen widerlegt werden (Brezinschek HP, 1997). Vorstellbar wäre auch eine durch die Länge der schweren Kette beeinträchtigte Paarung mit der leichten Kette. Ein weiterer Erklärungsansatz beschäftigt sich mit der Tertiärstruktur der gebildeten Proteine. Längere CDR3-Regionen bergen ein erhöhtes Risiko zur Bildung instabiler oder unproduktiver Konformationen der antigenbindenden Schleife. Im Gegensatz dazu können kürzere CDR3-Regionen im antigenbindenden 
Bereich Platz bieten, um Antigene neben der Bindung an CDR3 auch mit CDR1 und 2 in Kontakt treten zu lassen. Die Länge der CDR3-Region korreliert also invers mit der Tiefe der Antigen-Bindungs-Kuhle des Antikörpers (Zemlin M, 2003). Gestützt wird diese Hypothese durch Kristallstruktur-Analysen von Komplexen aus Lysozym und Antilysozym-Antikörpern (Amit AG, 1986; Padlan EA, 1989). Je kürzer hierbei die CDR3-Region ist, desto mehr Kontakt findet in den Bereichen der CDR1- und 2-Region statt (Kabat EA, 1991). Dies wird dadurch bestätigt, dass die CDR3-Längen von spezifischen Antikörpern gegen unterschiedliche Antigen-Gruppen differieren. Beispielsweise sind die CDR3-Regionen von Anti-Hapten-Antikörpern kürzer als die von Anti-Kohlenhydrat-Antikörpern (Collis AV, 2003).

Unerwarteterweise fanden wir im Vergleich der Sequenzen des gleichen Isotyps, deutliche Unterschiede in der Zusammensetzung ihrer CDR3-Regionen in Abhängigkeit ihrer $\mathrm{V}_{\mathrm{H}^{-}}$-Segment-Verwendung (Abbildung 4.8, 4.9, 4.10; Tabelle $7.7 \mathrm{im}$ Anhang). $\mathrm{V}_{\mathrm{H}}$ 5- und $\mathrm{V}_{\mathrm{H}}$ 1/14-Sequenzen der IgA MC und IgA PC wiesen einen hochsignifikanten Unterschied der Längen ihrer CDR3-Regionen auf bei unerheblich differierenden $\mathrm{ND}_{\mathrm{H}} \mathrm{N}$-Längen. Dies wurde vorwiegend dadurch verursacht, dass die CDR3-Regionen der $\mathrm{V}_{\mathrm{H}}$ 5- Sequenzen deutlich längere $\mathrm{V}_{\mathrm{H}^{-}}$und $\mathrm{J}_{\mathrm{H}^{-}}$-Anteile enthielten als die $\mathrm{V}_{\mathrm{H}}$ 1/14-Sequenzen. Die CDR3-Längen der IgA PC-Sequenzen der unterschiedlichen $\mathrm{V}_{\mathrm{H}}$-Familien waren in der Summe gleich lang, aber $\mathrm{V}_{\mathrm{H}}$ 5- Sequenzen enthielten kürzere $\mathrm{V}_{\mathrm{H}^{-}}$und $\mathrm{J}_{\mathrm{H}^{-}}$Gensegment-Anteile in $\mathrm{CDR} 3$ und längere $\mathrm{ND}_{\mathrm{H}} \mathrm{N}$ Regionen (Abbildung 4.8, 4.9). Bei IgM-Sequenzen mit $\mathrm{V}_{\mathrm{H}} 5$ waren die in CDR3 enthaltenen Anteile des $\mathrm{V}_{\mathrm{H}^{-}}$-Segments länger als bei $\mathrm{V}_{\mathrm{H}} 1 / 14$-Sequenzen. Je geringer die Exonukleaseaktivität während der Gen-Umlagerung ist, desto länger sind die erhaltenen Anteile von $\mathrm{V}_{\mathrm{H}^{-}}$und $\mathrm{J}_{\mathrm{H}^{-}}$in CDR3. Somit ist die Exonukleaseaktivität bei $\mathrm{V}_{\mathrm{H}^{5}}$ Sequenzen größer als bei $\mathrm{V}_{\mathrm{H}} 1 / 14-$ Sequenzen. Übereinstimmend hiermit haben Gauss et al. beschrieben, dass die Exonuklease stärker bei AT-Basenpaaren als bei GCBasenpaaren arbeitet (Gauss GH, 1996). Durch Beeinflussung der Helix-Struktur der DNA gewährleistet ein hoher GC-Gehalt einer Sequenz offensichtlich eine gewisse Resistenz gegenüber exonukleatischen Prozessen (Gauss GH, 1996).

Aus diesen Beobachtungen schließen wir, dass die $\mathrm{V}_{\mathrm{H}^{-}}$-Familienzugehörigkeit einen entscheidenden Selektionsfaktor für die weitere Zusammensetzung der CDR3-Region eines Immunglobulins darstellt. 


\subsection{Beim Klassenwechsel und bei der Selektion in Subpopulationen spielt die Hydrophobizität der CDR3- Regionen eine Rolle.}

Die Antigen-Bindung wird wesentlich von der Hydrophobizitätsverteilung innerhalb der Antigen-Bindungsregion beeinflusst. Daher haben wir die durchschnittliche Hydrophobizität der CDR3-Schleifen einzelner Sequenzgruppen anhand der normalisierten Kyte-Doolittle-Hydrophobizitäts-Skala ermittelt (Eisenberg D, 1984). Diese Hydrophobizitätsskala wurde verwendet, da die Normalisierung (Summe der Hydrophobizitäten aller 20 Aminosäuren ergibt 0) eine statistische Analyse von Mittelwerten erlaubt. Die Hydrophobizität der CDR3-Regionen bewegte sich vorwiegend im neutralen bis mild polaren Bereich. Dies ist charakteristisch für Peptidschleifen, die aus dem Protein in die wässerige Umgebung hervortreten und mit anderen Strukturen interagieren können. Die Feinverteilung der Hydrophobizität innerhalb der CDR3-Region hat großen Einfluss auf die Antigenerkennung und somit auf die Spezifität und Affinität des Antikörpers (MacCallum RM, 1996). Beispielsweise tragen pathogene anti-ds-DNA-Autoantikörper, wie sie bei systemischem Lupus erythematodes auftreten, bevorzugt positiv geladene Aminosäuren (Lysin, Arginin) innerhalb der CDR3-Region, mit denen sie an negativ geladene Abschnitte des DNAMoleküls binden (Krishnan MR, 1998).

Während der Zellreifung im Knochenmark werden Immunglobuline, deren CDR3Regionen einen stark hydrophoben oder hydrophilen Charakter aufweisen, weitgehend aber nicht vollständig negativ selektioniert (Ivanov II, 2005).

Die von uns untersuchten Subpopulationen unterschieden sich geringfügig aber signifikant in ihrer durchschnittlichen Hydrophobizität: Die CDR3-Regionen der IgAMC-Sequenzen waren im Durchschnitt polarer als die CDR3-Regionen der IgMSequenzen und der IgA-PC. Dies bestätigt die anhand der anderen untersuchten Eigenschaften gefundenen Hinweise darauf, dass die Selektion der IgA-Memory- und Plasmazellen nicht zufällig, sondern anhand ihrer Antigen-Bindungseigenschaften erfolgt. 


\subsection{Schwächen und Stärken der vorliegenden Untersuchungen}

Eine Zellsortierung stellt als potentielle Fehlerquelle naturgemäß eine Limitation der wissenschaftlichen Aussagekraft dar. In den von uns durchgeführten Kontrollen betrug die Reinheit der sortierten Subpopulationen jedoch stets über 97\%, womit wir von einer aussagekräftigen Trennschärfe ausgehen konnten.

In der vorliegenden Arbeit wurden insgesamt 413 Immunglobulinsequenzen analysiert. Diese Transkripte stellen im Verhältnis zur Gesamtheit des Repertoires eine sehr kleine, zufällige Stichprobe dar, so dass die untersuchten Sequenzen nicht zwangsläufig in allen Aspekten repräsentativ sind. Da die Gesamt-RNA für die RT-PCR eingesetzt wurde könnten Zellen überrepräsentiert sein, die viele RNA-Transkripte aufweisen. Ein systematischer Fehler scheint zwar aus theoretischen Erwägungen unwahrscheinlich, könnte aber nur durch eine sehr aufwendige Einzelzell-RT-PCR ausgeschlossen werden. Eine wesentliche Limitation unserer Untersuchung ist die Tatsache, dass wir uns aus methodischen Gründen und aus Gründen der Praktikabilität auf die Analyse der $\mathrm{V}_{\mathrm{H}}$ 1/14- und $\mathrm{V}_{\mathrm{H}}$ 5-Familien beschränken mussten. Es ist technisch nicht möglich, die über $150 \quad \mathrm{~V}_{\mathrm{H}}$-Gensegmente der Maus mit gleicher Affinität zu amplifizieren. Daher haben wir uns - wie in der Literatur üblich - auf die Untersuchung der beiden größten $\mathrm{V}_{\mathrm{H}}$-Familien beschränkt.

Zum ersten Mal wurde in dieser Arbeit das IgA-Repertoire der Maus systematisch analysiert. Nur der direkte Vergleich von IgM und IgA aus ein- und demselben Gewebe lässt Rückschlüsse auf den Selektionsdruck während des Klassenwechsels valide zu. Die Software zur statistischen Analyse der Immunglobulin-Transkripte wurde eigens zu diesem Zweck in unserer Arbeitsgruppe etabliert und ist mittlerweise auch publiziert (Rogosch T, 2012). 


\section{Zusammenfassung}

\subsection{Deutsch}

\section{Hintergrund:}

Das primäre und sekundäre Immunglobulinrepertoire bilden eine bedeutende Grundlage der Pathogenbekämpfung im Wirbeltier. Das Mukosa-assoziierte lymphatische Gewebe stellt hierbei die erste Front des humoralen Immunsystems gegen invasive Infektionen dar. An der Mukosa überwiegt das Immunglobulin A, welches sowohl in das Plasma als auch auf die Schleimhaut sezerniert werden kann. Eine Differenzierung der BLymphozyten zu Plasma- und Gedächtniszellen gewährleistet bei erneuter Infektion mit dem gleichen Pathogen eine viel schnellere und effektivere Immunantwort.

\section{Fragestellung:}

Unklar sind grundlegende Fragen zur Entwicklung der B-Zell- bzw. AntikörperRepertoires im darmassoziierten lymphatischen Gewebe (gut-associated lymphoid tissue: (GALT): Welchem Selektionsdruck unterliegt das B-Zell-Repertoire während des Klassenwechsels zu IgA? Weiterhin ist nicht bekannt, nach welchen Kriterien Lymphozyten in den Pool der IgA-bildenden Gedächtnis- und Plasmazellen rekrutiert werden. In dieser Arbeit haben wir die Hypothese geprüft, dass IgA-bildende Subpopulationen der Gedächtnis- und Plasmazellen nicht zufällig, sondern aufgrund ihrer Antigen-Bindungseigenschaften rekrutiert werden.

\section{Methoden:}

Wir haben mittels Durchflusszytometrie Plasma- und Gedächtniszellen aus Peyerschen Plaques adulter BALB/C Wildtyp-Mäuse separiert und mittels Reverse TranskriptasePCR selektiv IgM- und IgA-Transkripte der schweren Immunglobulin-Ketten amplifiziert und kloniert. Die so gewonnenen Transkripte wurden sequenziert und mittels Datenbankanalyse (Alignment mittels IMGT VQuest) ausgewertet.

\section{Ergebnisse:}

Es wurden insgesamt 413 Immunglobulinsequenzen in vier unabhängigen Experimenten erhoben, von denen sich 323 (78\%) als nicht-redundante Transkripte erwiesen. Immunglobulin A-Sequenzen der Gedächtnis- und Plasmazellen wiesen mit 
74\% bzw. $72 \%$ eine signifikant niedrigere klonale Diversität auf als Immunglobuline der Klasse M (94\%; jeweils p<0,01). Immunglobulin A-Sequenzen der Gedächtnis- und Plasmazellen enthielten mehr somatische Mutationen (37\%o bzw. 35\%o) als IgMSequenzen $(14 \%$, p <0,01). Bei IgA-Sequenzen aus Gedächtniszellen waren weniger zufällige, sogenannte N-Nukleotide innerhalb der Antigen-Bindungsstelle vorhanden als bei IgA-Sequenzen aus Plasmazellen ( $\mathrm{p}<0,01)$. Zusätzlich wiesen IgA-Sequenzen aus Gedächtniszellen im Vergleich zu IgM-Sequenzen signifikant kürzere CDR3-Regionen auf $(p<0,05)$ bei signifikant kürzeren NDN-Regionen $(p<0,01)$. Ein ähnlicher Trend war bei IgA-Sequenzen aus Plasmazellen erkennbar. In unserer Studie korrelierte zudem die Nutzung von $\mathrm{J}_{\mathrm{H}^{-}}$und $\mathrm{V}_{\mathrm{H}^{-}}$Gen-Familien.

\section{Diskussion:}

IgA-Sequenzen weisen die typischen Anzeichen der klassischen Antigenselektion auf. Die eingeschränkte klonale Diversität und die erhöhte Mutationsrate der IgATranskripte aus Gedächtnis- und Plasmazellen gegenüber IgM-Transkripten der gleichen Gewebeproben belegt eine Antigen-abhängige fokussierte Selektion während des Klassenwechsels von IgM zu IgA. Interessanterweise wiesen Immunglobuline A der Gedächtniszellen eine andere Binnenstruktur innerhalb der Antigen-Bindungsstelle (CDR-H3) auf als Immunglobuline M. Daher haben IgA aus Gedächtniszellen gegenüber IgM eine geringere strukturelle Vielfalt und im Durchschnitt eine flachere Antigen-Bindungsstelle, wodurch eine engere Interaktion mit dem Antigen möglich ist. Im Gegensatz zu früheren Annahmen beeinflußt die $\mathrm{V}_{\mathrm{H}^{-}}$Segment-Nutzung die $\mathrm{J}_{\mathrm{H}^{-}}$ Segment-Nutzung und damit die Zusammensetzung der CDR3-Region eines Immunglobulins.

\section{Schlussfolgerung:}

Immunglobulin A produzierende Gedächtnis- und Plasmazellen stellen separate Populationen mit unterschiedlichen Repertoires an Antigen-Bindungsstellen innerhalb ihrer Antikörper dar. Sie weisen alle Charakteristika einer individuellen Antigenabhängigen Selektion auf. Dies weist darauf hin, dass die CDR3-Region ein entscheidender Selektionsfaktor während des Klassenwechsels zu IgA darstellt. 


\subsection{Englisch}

\section{Background:}

The primary and secondary immunoglobulin repertoires represent an important basis of the pathogen defence in the vertebrate. The mucosa-associated lymphoid tissue plays a crucial role in the establishment and maintenance of mucosal homeostasis against invasive infections. Inside mucosal tissues, Immunoglobulin $A$ (Ig A) is the predominating immunoglobulin that is secreted into the blood plasma, as well as onto the mucous membrane.

The differentiation of antigen-activated B-cells into plasma and memory cells allows a quicker and more effective immune response in case of a recurrent confrontation with the same pathogen. Basic mechanisms concerning the development of B-cell and antibody repertoires are still unclear.

\section{Objective:}

It remains uncertain which selective pressure acts upon the B-cell repertoire during the class switch recombination from $\operatorname{IgM}$ to $\operatorname{IgA}$ in germinal centres. Furthermore it is unknown which criteria drive the recruitment of lymphocytes into the pool of IgA producing memory and plasma cells. In this work, we tested the hypothesis that subpopulations of IgA producing memory and plasma cells are not recruited by chance, but on the basis of their antigen binding properties.

\section{Methods:}

IgM producing B-cells as well as IgA producing memory and plasma cells were separated from Peyer's patches of four adult BALB/C wildtype mice using flow cytometry. Using reverse transcriptase-PCR, we selectively amplified and cloned IgM and IgA transcripts of the immunoglobulin heavy chains. The transcripts were sequenced and nucleotide sequences were compared with the IMGT databases of germline sequences (Alignment via IMGT VQuest).

\section{Results:}

We collected a total number of 413 immunoglobulin sequences in four independent experiments of which $323(78 \%)$ were unique. The IgA sequences of memory and 
plasma cells showed a significantly lower clonal diversity than IgM sequences (74\% and $72 \%$ vs. $94 \%$; p <0.01). IgA sequences of memory and plasma cells contained more somatic mutations than IgM sequences (37\%o and $35 \%$ vs. $14 \%$, p <0.01). IgA transcripts from memory cells contained a lower number of random, so-called nnucleotides within the CDR3-regions than IgA transcripts from plasma cells $(\mathrm{p}<0.01)$. In comparison to the IgM sequences, the IgA sequences from memory cells showed significantly shorter CDR3 regions $(\mathrm{p}=0.02)$ and significantly shorter NDN regions $(\mathrm{p}=0.0002)$. A similar trend was observed with IgA plasma sequences; however this was not statistically significant. Moreover, we found a preference of single $J_{H}$ segments depending on the rearranged $\mathrm{V}_{\mathrm{H}}$ family.

\section{Discussion:}

IgA showed the typical signs of classical antigen selection. In comparison to IgM transcripts from the same tissue sample, the limited clonal diversity and the increased mutation rate of $\operatorname{IgA}$ memory and plasma cell transcripts document an antigen dependent focused selection during the class switch from IgM to IgA. Interestingly, CDR3-regions from IgA of memory cells and $\operatorname{IgM}$ were differently composed. As a consequence, $\operatorname{Ig}$ A of memory cells showed a lower structural variety and, on average, a deeper antigen binding grove compared to $\operatorname{IgM}$ facilitating a closer interaction with the antigen.

In contrast to earlier assumptions, the use of the $\mathrm{V}_{\mathrm{H}}$ family influences the $\mathrm{J}_{\mathrm{H}}$ utilization and the composition of the CDR3 region.

\section{Conclusion:}

IgA producing memory and plasma cells represent separate populations with differing repertoires of antigen binding sites inside their antibodies. They both show characteristic features of an individual antigen dependent selection.

Our data demonstrate that the CDR3 region is an important selection factor during class switch recombination to $\operatorname{IgA}$ in germinal centers. 


\section{Abbildungs- und Tabellenanhang}
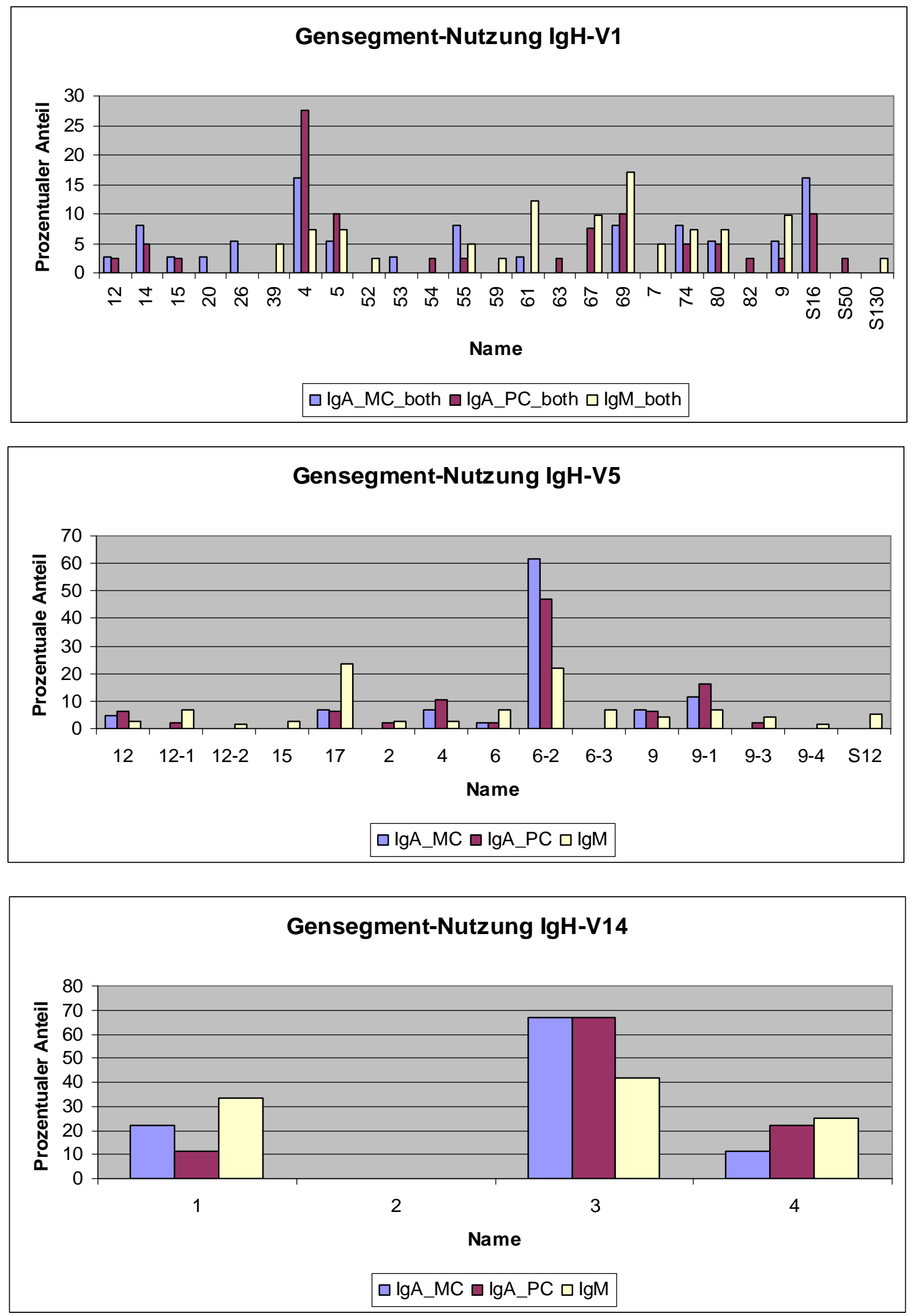

Abbildung 7.1: $\mathrm{V}_{\mathrm{H}^{-}}$-familienspezifische Gensegmentnutzung 


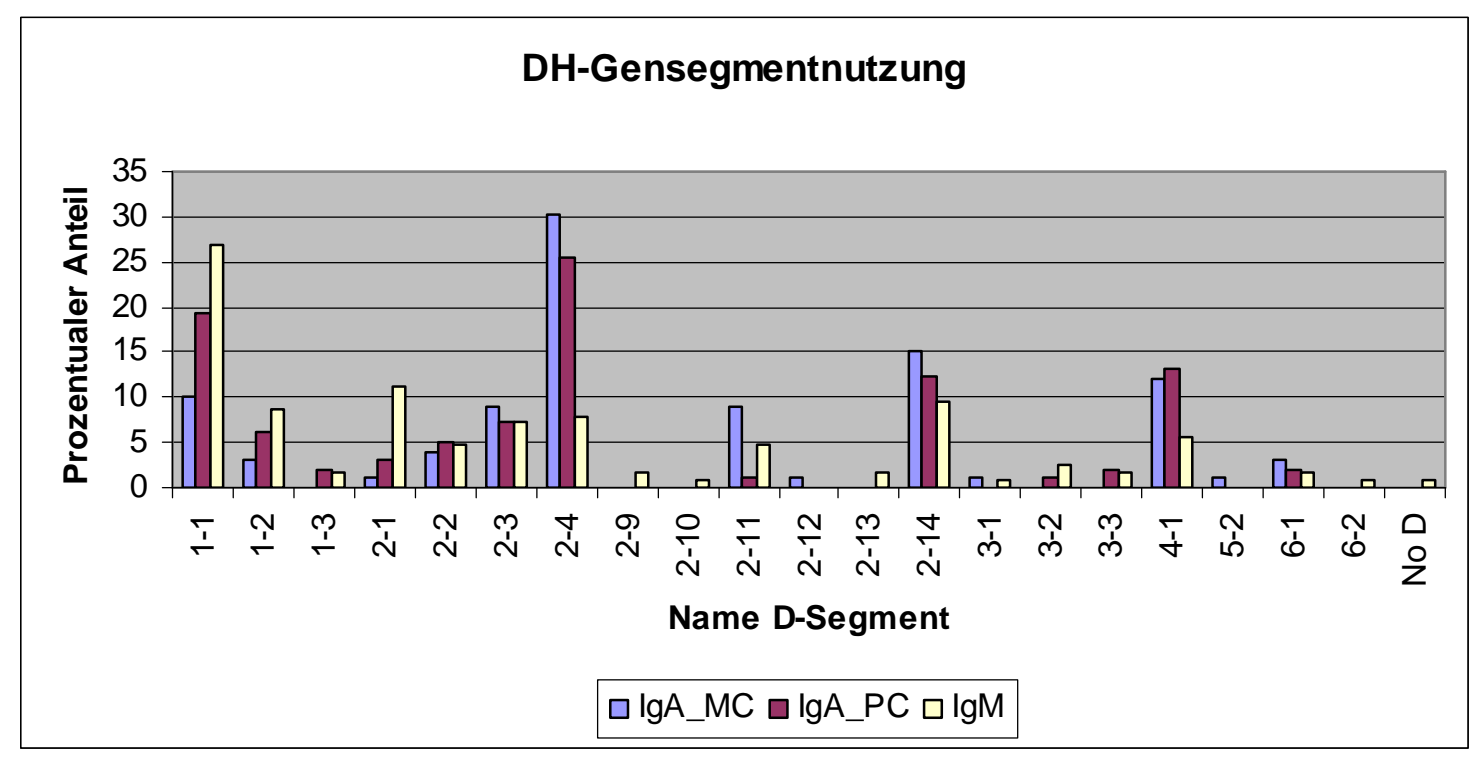

Abbildung 7.2: DH-Gensegmentnutzung 


\begin{tabular}{|c|c|c|c|c|c|c|}
\hline Sequenzgruppe & V-Familie & Absolute Zahl & Prozent & D-Segment & Absolute Zah & Prozent \\
\hline IgA_MC_AF303 & $\begin{array}{l}\text { IGHV1 } \\
\text { IGHV2 } \\
\text { IGHV3 } \\
\text { IGHV5 } \\
\text { IGHV14 }\end{array}$ & $\begin{array}{r}0 \\
0 \\
0 \\
44 \\
0\end{array}$ & $\begin{array}{r}0,0 \% \\
0,0 \% \\
0,0 \% \\
100,0 \% \\
0,0 \% \\
\end{array}$ & $\begin{array}{l}\text { No D } \\
\text { IGHD1 } \\
\text { IGHD2 } \\
\text { IGHD3 } \\
\text { IGHD4 } \\
\text { IGHD5 } \\
\text { IGHD6 }\end{array}$ & $\begin{array}{r}0 \\
4 \\
31 \\
0 \\
6 \\
0 \\
3\end{array}$ & \begin{tabular}{|r|}
$0,0 \%$ \\
$9,1 \%$ \\
$70,5 \%$ \\
$0,0 \%$ \\
$13,6 \%$ \\
$0,0 \%$ \\
$6,8 \%$ \\
\end{tabular} \\
\hline IgA_PC_AF303 & $\begin{array}{l}\text { IGHV1 } \\
\text { IGHV2 } \\
\text { IGHV3 } \\
\text { IGHV5 } \\
\text { IGHV14 }\end{array}$ & $\begin{array}{r}0 \\
0 \\
0 \\
49 \\
0\end{array}$ & $\begin{array}{r}0,0 \% \\
0,0 \% \\
0,0 \% \\
100,0 \% \\
0,0 \%\end{array}$ & $\begin{array}{l}\text { No D } \\
\text { IGHD1 } \\
\text { IGHD2 } \\
\text { IGHD3 } \\
\text { IGHD4 } \\
\text { IGHD5 } \\
\text { IGHD6 }\end{array}$ & \begin{tabular}{r|}
0 \\
6 \\
35 \\
0 \\
6 \\
0 \\
2 \\
\end{tabular} & \begin{tabular}{r|}
$0,0 \%$ \\
$12,2 \%$ \\
$71,4 \%$ \\
$0,0 \%$ \\
$12,2 \%$ \\
$0,0 \%$ \\
$4,1 \%$ \\
\end{tabular} \\
\hline IgM_AF303 & $\begin{array}{l}\text { IGHV1 } \\
\text { IGHV2 } \\
\text { IGHV3 } \\
\text { IGHV5 } \\
\text { IGHV14 }\end{array}$ & $\begin{array}{r}0 \\
0 \\
0 \\
73 \\
0\end{array}$ & $\begin{array}{r}0,0 \% \\
0,0 \% \\
0,0 \% \\
100,0 \% \\
0,0 \%\end{array}$ & $\begin{array}{l}\text { No D } \\
\text { IGHD1 } \\
\text { IGHD2 } \\
\text { IGHD3 } \\
\text { IGHD4 } \\
\text { IGHD5 } \\
\text { IGHD6 }\end{array}$ & \begin{tabular}{r|}
1 \\
25 \\
38 \\
4 \\
5 \\
0 \\
0 \\
\end{tabular} & $\begin{array}{r}1,4 \% \\
34,2 \% \\
52,1 \% \\
5,5 \% \\
6,8 \% \\
0,0 \% \\
0,0 \% \\
\end{array}$ \\
\hline
\end{tabular}

\begin{tabular}{|c|c|c|c|}
\hline Sequenzgruppe & J-Segment & Absolute Zahl & Prozent \\
\hline IgA_MC_AF303 & $\begin{array}{l}\text { IGHJ1 } \\
\text { IGHJ2 } \\
\text { IGHJ3 } \\
\text { IGHJ4 }\end{array}$ & $\begin{array}{r}1 \\
4 \\
6 \\
33\end{array}$ & $\begin{array}{r}2,3 \% \\
9,1 \% \\
13,6 \% \\
75,0 \%\end{array}$ \\
\hline IgA_PC_AF303 & $\begin{array}{l}\text { IGHJ1 } \\
\text { IGHJ2 } \\
\text { IGHJ3 } \\
\text { IGHJ4 }\end{array}$ & \begin{tabular}{r|}
1 \\
9 \\
6 \\
33
\end{tabular} & $\begin{array}{r}2,0 \% \\
18,4 \% \\
12,2 \% \\
67,3 \%\end{array}$ \\
\hline IgM_AF303 & $\begin{array}{l}\text { IGHJ1 } \\
\text { IGHJ2 } \\
\text { IGHJ3 } \\
\text { IGHJ4 }\end{array}$ & \begin{tabular}{r|}
8 \\
17 \\
17 \\
31
\end{tabular} & $\begin{array}{l}11,0 \% \\
23,3 \% \\
23,3 \% \\
42,5 \%\end{array}$ \\
\hline
\end{tabular}

Tabelle 7.1: IgH-VDJ-Segmentnutzung der VH5-Familie 


\begin{tabular}{|c|c|c|c|c|c|c|}
\hline Sequenzgruppe & V-Familie & Absolute Zahl & Prozent & D-Segment & \begin{tabular}{|l|} 
Absolute Zahl \\
\end{tabular} & Prozent \\
\hline IgA_MC_J558 & \begin{tabular}{|l} 
IGHV1 \\
IGHV2 \\
IGHV3 \\
IGHV5 \\
IGHV14
\end{tabular} & $\begin{array}{r}37 \\
0 \\
0 \\
0 \\
18\end{array}$ & $\begin{array}{r}67,3 \% \\
0,0 \% \\
0,0 \% \\
0,0 \% \\
32,7 \%\end{array}$ & $\begin{array}{l}\text { No D } \\
\text { IGHD1 } \\
\text { IGHD2 } \\
\text { IGHD3 } \\
\text { IGHD4 } \\
\text { IGHD5 } \\
\text { IGHD6 } \\
\end{array}$ & $\begin{array}{r}0 \\
9 \\
38 \\
1 \\
6 \\
1 \\
0 \\
\end{array}$ & \begin{tabular}{|r|}
$0,0 \%$ \\
$16,4 \%$ \\
$69,1 \%$ \\
$1,8 \%$ \\
$10,9 \%$ \\
$1,8 \%$ \\
$0,0 \%$ \\
\end{tabular} \\
\hline IgA_PC_J558 & $\begin{array}{l}\text { IGHV1 } \\
\text { IGHV2 } \\
\text { IGHV3 } \\
\text { IGHV5 } \\
\text { IGHV14 }\end{array}$ & $\begin{array}{r}40 \\
0 \\
0 \\
0 \\
9\end{array}$ & $\begin{array}{r}81,6 \% \\
0,0 \% \\
0,0 \% \\
0,0 \% \\
18,4 \%\end{array}$ & $\begin{array}{l}\text { No D } \\
\text { IGHD1 } \\
\text { IGHD2 } \\
\text { IGHD3 } \\
\text { IGHD4 } \\
\text { IGHD5 } \\
\text { IGHD6 } \\
\end{array}$ & $\begin{array}{r}0 \\
21 \\
18 \\
3 \\
7 \\
0 \\
0 \\
\end{array}$ & $\begin{array}{r}0,0 \% \\
42,9 \% \\
36,7 \% \\
6,1 \% \\
14,3 \% \\
0,0 \% \\
0,0 \% \\
\end{array}$ \\
\hline $\operatorname{lgM} \_J 558$ & $\begin{array}{l}\text { IGHV1 } \\
\text { IGHV2 } \\
\text { IGHV3 } \\
\text { IGHV5 } \\
\text { IGHV14 }\end{array}$ & \begin{tabular}{r|}
4 \\
0 \\
0 \\
0 \\
12
\end{tabular} & $\begin{array}{r}77,4 \% \\
0,0 \% \\
0,0 \% \\
0,0 \% \\
22,6 \%\end{array}$ & $\begin{array}{l}\text { No D } \\
\text { IGHD1 } \\
\text { IGHD2 } \\
\text { IGHD3 } \\
\text { IGHD4 } \\
\text { IGHD5 } \\
\text { IGHD6 }\end{array}$ & $\begin{array}{r}0 \\
22 \\
24 \\
2 \\
2 \\
0 \\
3\end{array}$ & $\begin{array}{r}0,0 \% \\
41,5 \% \\
45,3 \% \\
3,8 \% \\
3,8 \% \\
0,0 \% \\
5,7 \%\end{array}$ \\
\hline
\end{tabular}

\begin{tabular}{|l|l|r|r|}
\hline Sequenzgruppe & J-Segment & Absolute Zahl & Prozent \\
\hline IgA_MC_J558 & IGHJ1 & 20 & $3,6 \%$ \\
& IGHJ2 & 13 & $36,4 \%$ \\
& IGHJ3 & $20,6 \%$ \\
& IGHJ4 & $36,4 \%$ \\
& & & \\
& & 4 & \\
\hline IgA_PC_J558 & IGHJ1 & 25 & $51,0 \%$ \\
& IGHJ2 & 7 & $14,3 \%$ \\
& IGHJ3 & 13 & $26,5 \%$ \\
& IGHJ4 & & \\
& & & \\
\hline IgM_J558 & & 6 & $11,3 \%$ \\
& IGHJ1 & 21 & $39,6 \%$ \\
& IGHJ2 & 13 & $24,5 \%$ \\
& IGHJ3 & 13 & $24,5 \%$ \\
& IGHJ4 & & \\
& & & \\
& & &
\end{tabular}

Tabelle 7.2: IgH-VDJ-Segmentnutzung der VH1/14-Familie 


\begin{tabular}{|c|c|c|c|c|c|c|}
\hline Sequenzgruppe & V-Familie & \begin{tabular}{|l|} 
Absolute Zahl \\
\end{tabular} & Prozent & \begin{tabular}{|l|} 
D-Segment \\
\end{tabular} & \begin{tabular}{|l|} 
Absolute Zahl \\
\end{tabular} & Prozent \\
\hline IgA_MC & $\begin{array}{l}\text { IGHV1 } \\
\text { IGHV2 } \\
\text { IGHV3 } \\
\text { IGHV5 } \\
\text { IGHV14 }\end{array}$ & $\begin{array}{r}37 \\
0 \\
0 \\
44 \\
18\end{array}$ & $\begin{array}{r}37,4 \% \\
0,0 \% \\
0,0 \% \\
44,4 \% \\
18,2 \% \\
\end{array}$ & $\begin{array}{l}\text { No D } \\
\text { IGHD1 } \\
\text { IGHD2 } \\
\text { IGHD3 } \\
\text { IGHD4 } \\
\text { IGHD5 } \\
\text { IGHD6 }\end{array}$ & \begin{tabular}{r|}
0 \\
13 \\
69 \\
1 \\
12 \\
1 \\
3
\end{tabular} & $\begin{array}{r}0,0 \% \\
13,1 \% \\
69,7 \% \\
1,0 \% \\
12,1 \% \\
1,0 \% \\
3,0 \%\end{array}$ \\
\hline IgA_PC & $\begin{array}{l}\text { IGHV1 } \\
\text { IGHV2 } \\
\text { IGHV3 } \\
\text { IGHV5 } \\
\text { IGHHV14 }\end{array}$ & $\begin{array}{r}40 \\
0 \\
0 \\
49 \\
9\end{array}$ & $\begin{array}{r}40,8 \% \\
0,0 \% \\
0,0 \% \\
50,0 \% \\
9,2 \%\end{array}$ & $\begin{array}{l}\text { No D } \\
\text { IGHD1 } \\
\text { IGHD2 } \\
\text { IGHD3 } \\
\text { IGHD4 } \\
\text { IGHD5 } \\
\text { IGHD6 } \\
\end{array}$ & \begin{tabular}{r|}
0 \\
27 \\
53 \\
3 \\
13 \\
0 \\
2 \\
\end{tabular} & $\begin{array}{r}0,0 \% \\
27,6 \% \\
54,1 \% \\
3,1 \% \\
13,3 \% \\
0,0 \% \\
2,0 \% \\
\end{array}$ \\
\hline $\lg M$ & \begin{tabular}{|l} 
IGHV1 \\
IGHV2 \\
IGHV3 \\
IGHV5 \\
IGHV14
\end{tabular} & $\begin{array}{r}4 \\
0 \\
0 \\
73 \\
12\end{array}$ & $\begin{array}{r}32,5 \% \\
0,0 \% \\
0,0 \% \\
57,9 \% \\
9,5 \%\end{array}$ & $\begin{array}{l}\text { No D } \\
\text { IGHD1 } \\
\text { IGHD2 } \\
\text { IGHD3 } \\
\text { IGHD4 } \\
\text { IGHD5 } \\
\text { IGHD6 }\end{array}$ & \begin{tabular}{r|}
1 \\
47 \\
62 \\
6 \\
7 \\
0 \\
3
\end{tabular} & $\begin{array}{r}0,8 \% \\
37,3 \% \\
49,2 \% \\
4,8 \% \\
5,6 \% \\
0,0 \% \\
2,4 \%\end{array}$ \\
\hline
\end{tabular}

\begin{tabular}{|c|c|c|c|}
\hline Sequenzgruppe & J-Segment & \begin{tabular}{|l|} 
Absolute Zahl \\
\end{tabular} & Prozent \\
\hline $\lg A$ AC & $\begin{array}{l}\text { IGHJ1 } \\
\text { IGHJ2 } \\
\text { IGHJ3 } \\
\text { IGHJ4 }\end{array}$ & $\begin{array}{r}3 \\
24 \\
19 \\
53\end{array}$ & $\begin{array}{r}3,0 \% \\
24,2 \% \\
19,2 \% \\
53,5 \%\end{array}$ \\
\hline IgA_PC & $\begin{array}{l}\text { IGHJ1 } \\
\text { IGHJ2 } \\
\text { IGHJ3 } \\
\text { IGHJ4 }\end{array}$ & \begin{tabular}{r|}
5 \\
34 \\
13 \\
46
\end{tabular} & $\begin{array}{r}5,1 \% \\
34,7 \% \\
13,3 \% \\
46,9 \%\end{array}$ \\
\hline $\lg M$ & $\begin{array}{l}\text { IGHJ1 } \\
\text { IGHJ2 } \\
\text { IGHJ3 } \\
\text { IGHJ4 }\end{array}$ & $\begin{array}{l}14 \\
38 \\
30 \\
44\end{array}$ & $\begin{array}{l}11,1 \% \\
30,2 \% \\
23,8 \% \\
34,9 \%\end{array}$ \\
\hline
\end{tabular}

Tabelle 7.3: IgH-VDJ-Segmentnutzung gesamt 


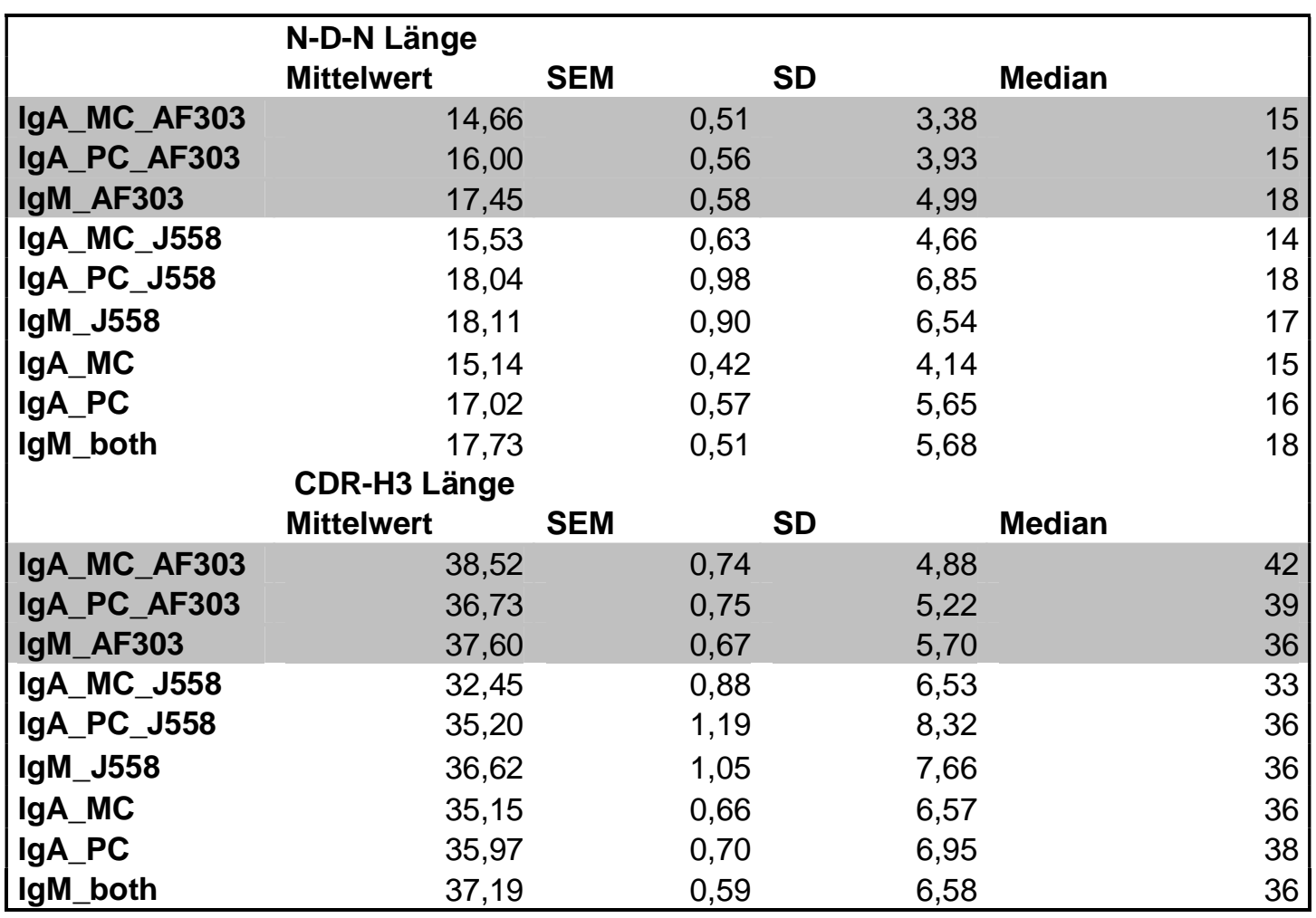

Tabelle 7.4: CDR3- und NDN-Längen in Nukleotiden

\begin{tabular}{|c|c|c|c|}
\hline \multicolumn{4}{|c|}{ T-Tests CDR3-Längen } \\
\hline & \multicolumn{3}{|c|}{ IgA_MC_AF303 IgA_PC_AF303 IgM_AF303 } \\
\hline IgA_MC_AF303 & $\mathrm{X}$ & $\mathrm{X}$ & \\
\hline IgA_PC_AF303 & 0,0923 & $\mathrm{x}$ & $\mathrm{X}$ \\
\hline IgM_AF303 & $X$ & $X$ & $X$ \\
\hline & IgA_MC_J558 & IgA_PC_J558 & IgM_J558 \\
\hline IgA_MC_J558 & $\mathrm{X}$ & $\mathrm{X}$ & $\mathrm{X}$ \\
\hline IgA_PC_J558 & 0,0625 & $\mathrm{X}$ & $\mathrm{X}$ \\
\hline IgM_J558 & $\mathrm{X}$ & $X$ & $X$ \\
\hline & IgA_MC_both & IgA_PC_both & IgM_both \\
\hline IgA_MC_both & $\mathrm{X}$ & $\mathrm{X}$ & $\mathrm{X}$ \\
\hline IgA_PC_both & 0,3971 & $\mathrm{X}$ & \\
\hline IgM_both & 0,0219 & 0,2223 & $x$ \\
\hline & IgA_MC_AF303 & IgA_PC_AF303 & IgM_AF303 \\
\hline IgA_MC_J558 & 1,5482E-06 & $\mathrm{X}$ & $\mathrm{X}$ \\
\hline IgA_PC_J558 & $\mathrm{X}$ & 0,2781 & $\mathrm{X}$ \\
\hline IgM_J558 & $\mathrm{X}$ & $\mathrm{x}$ & 0,4117 \\
\hline
\end{tabular}

Tabelle 7.5: p-Werte der CDR3-Längen rot: signifikante Werte 


\begin{tabular}{|c|c|c|c|}
\hline \multicolumn{4}{|c|}{ T-Tests der NDN-Längen } \\
\hline & \multicolumn{3}{|c|}{ IgA_MC_AF303 IgA_PC_AF303 IgM_AF303 } \\
\hline IgA_MC_AF303 & $-x$ & $\mathrm{X}$ & $x$ \\
\hline IgA_PC_AF303 & 0,0824 & $X$ & \\
\hline \multirow[t]{2}{*}{ IgM_AF303 } & $x$ & $X$ & \\
\hline & IgA_MC_J558 & IgA_PC_J558 & IgM_J558 \\
\hline IgA_MC_J558 & $-x$ & $\mathrm{X}$ & $x$ \\
\hline IgA_PC_J558 & 0,0295 & $x$ & \\
\hline \multirow[t]{2}{*}{ IgM_J558 } & $\mathrm{X}$ & $X$ & \\
\hline & IgA_MC_both & $\lg$ A_PC_both & IgM_both \\
\hline IgA_MC_both & $\mathrm{X}$ & $x$ & \\
\hline IgA_PC_both & 0,0084 & $x$ & \\
\hline \multirow[t]{2}{*}{ IgM_both } & 0,0002 & 0,3534 & \\
\hline & \multicolumn{3}{|c|}{ IgA_MC_AF303 IgA_PC_AF303 IgM_AF303 } \\
\hline IgA_MC_J558 & 3,0226E-01 & $X$ & \\
\hline IgA_PC_J558 & $x$ & 0,0736 & $x$ \\
\hline IgM_J558 & $\mathrm{X}$ & $\mathrm{X}$ & 0,5211 \\
\hline
\end{tabular}

Tabelle 7.6: p-Werte der NDN-Längen

rot: signifikante Werte

\section{Längenverteilung CDR3}

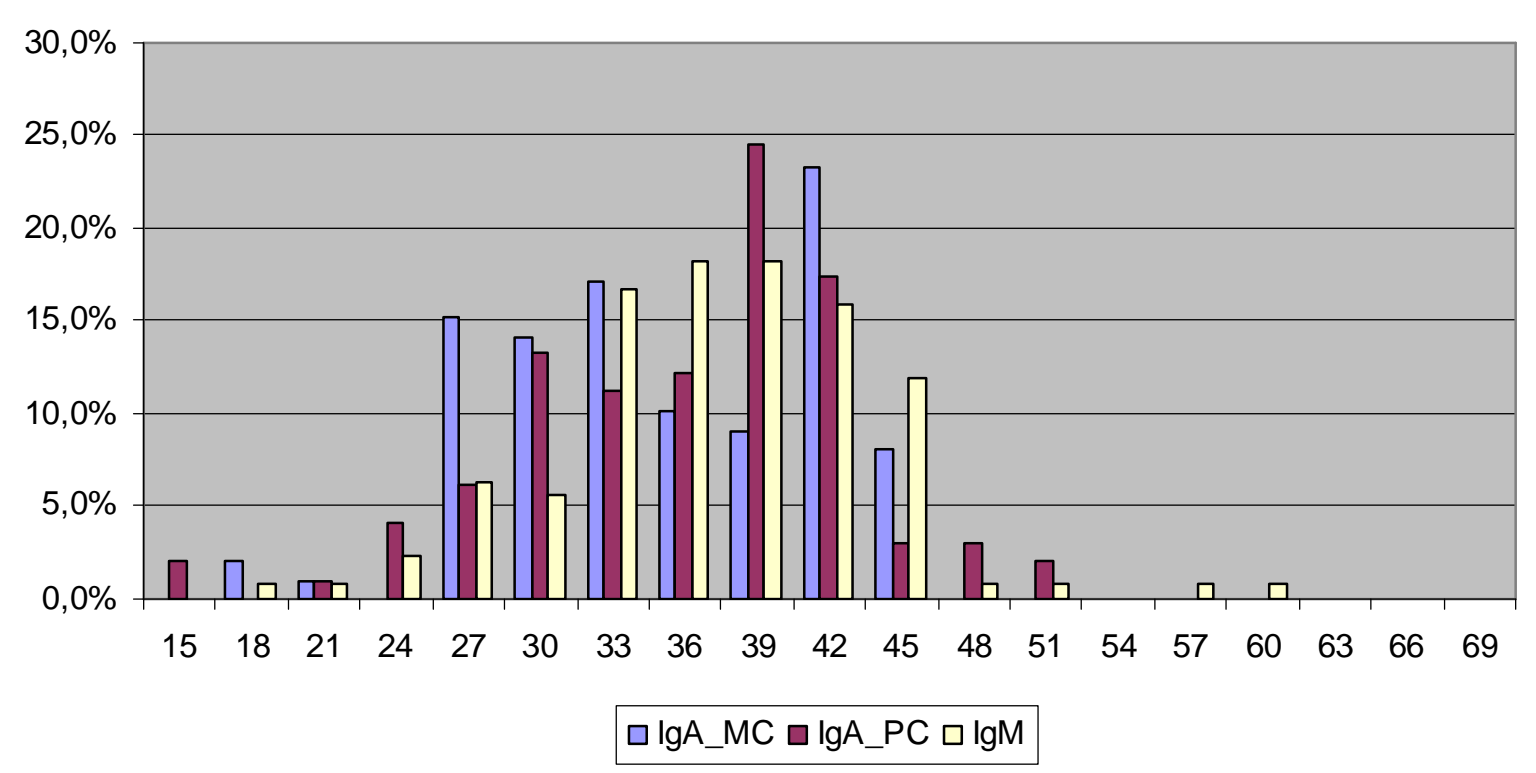

Abbildung 7.3: Längenverteilung von CDR3 in Nukleotiden (VH1/14- und VH5-Sequenzen) 


\section{CDRH3-Längen Verteilung in Nukleotiden}
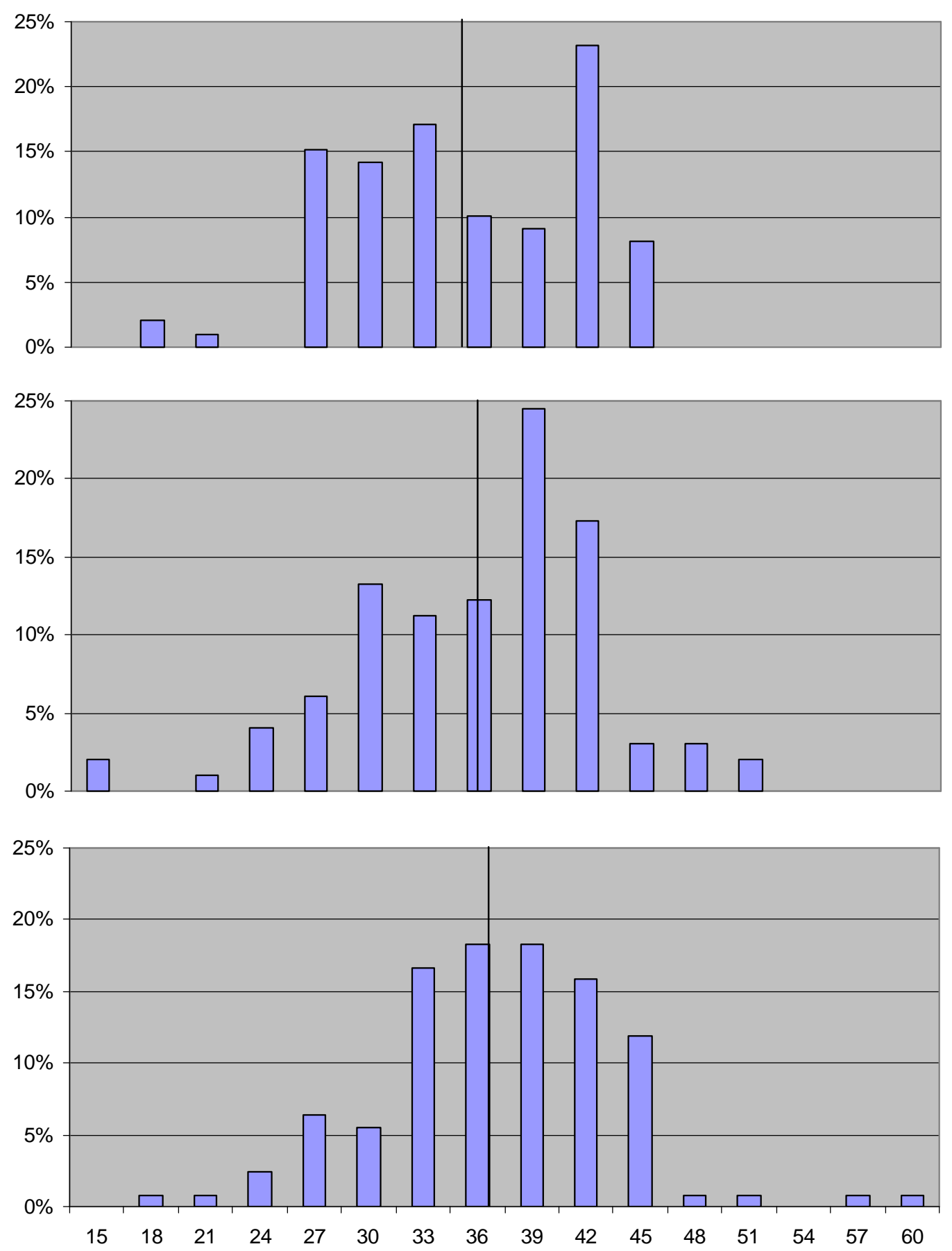

Abbildung 7.4: Längenverteilung von CDR3 in Nukleotiden (IgA MC; IgA PC; IgM)

Die schwarzen vertikalen Linien geben den jeweiligen Mittelwert an. 


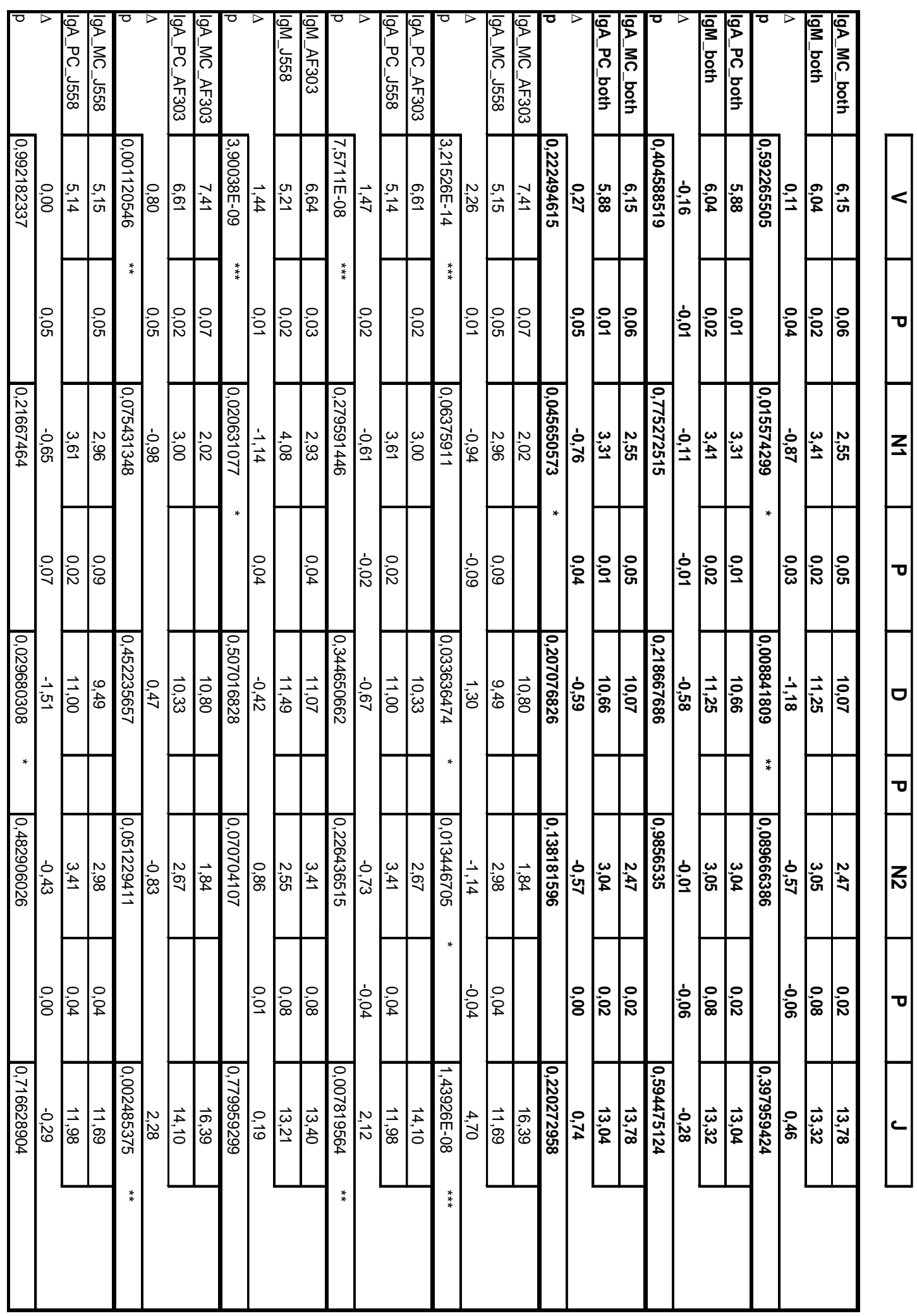

Tabelle 7.7: Zusammensetzung der CDR3-Region in Nukleotiden (Mittelwerte) mit Ergebnis des TTests 


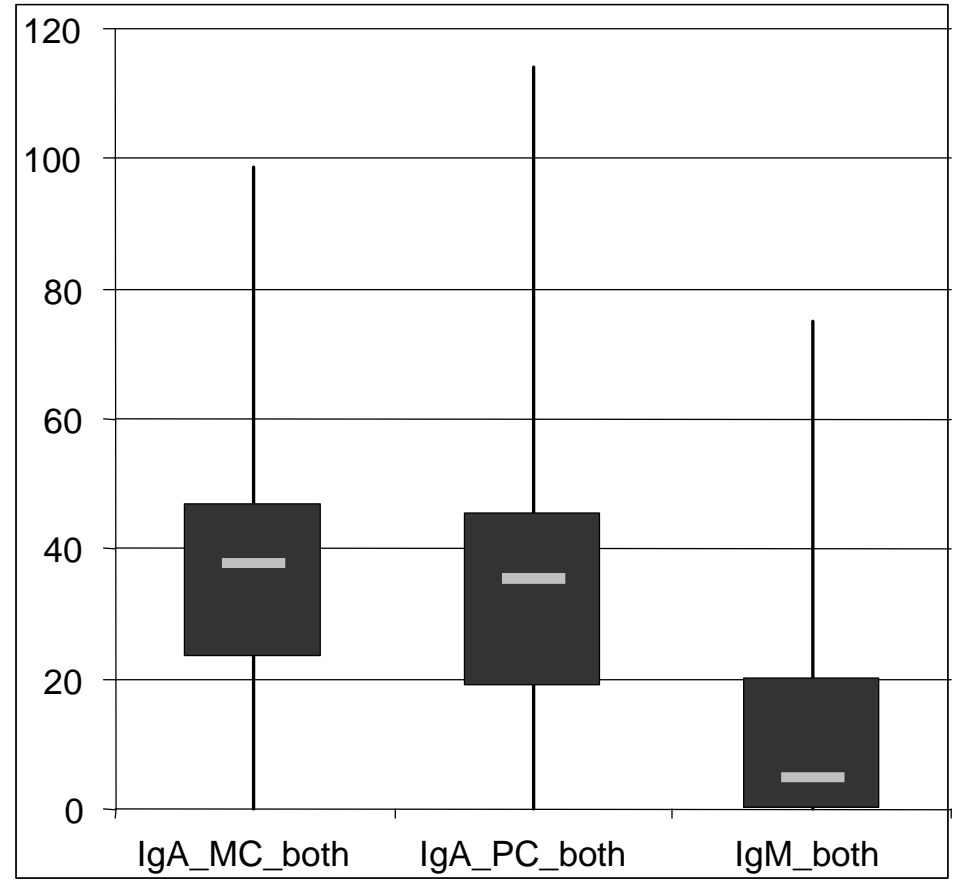

Abbildung 7.5: Mutationsraten von CDR3 im Median mit Streuung und Quartilen

\begin{tabular}{|lcccc|}
\hline & \multicolumn{2}{c}{$\begin{array}{l}\text { Kyte Doolittle } \\
\text { Mittelwert }\end{array}$} & SEM & \multicolumn{2}{c|}{ SD } & \multicolumn{2}{c|}{ Median } \\
IgA_MC_AF303 & $-0,23$ & 0,03 & 0,18 & $-0,24$ \\
IgA_PC_AF303 & $-0,18$ & 0,03 & 0,18 & $-0,18$ \\
IgM_AF303 & $-0,13$ & 0,04 & 0,34 & $-0,14$ \\
IgA_MC_J558 & $-0,16$ & 0,05 & 0,36 & $-0,09$ \\
IgA_PC_J558 & $-0,03$ & 0,05 & 0,35 & $-0,04$ \\
IgM_J558 & $-0,07$ & 0,05 & 0,35 & $-0,12$ \\
\hline \hline IgA_MC & $-0,19$ & 0,03 & 0,29 & $-0,24$ \\
IgA_PC & $-0,11$ & 0,03 & 0,29 & $-0,18$ \\
IgM & $-0,10$ & 0,03 & 0,34 & $-0,14$ \\
\hline
\end{tabular}

Tabelle 7.8: Hydrophobizitäten von CDR3 nach Kyte-Doolittle 


\section{Literaturverzeichnis}

Alt FW, Baltimore D. Joining of immunoglobulin heavy chain gene segments: implications from a chromosome with evidence of three D-JH fusions. Proc Natl Acad Sci U S A. 1982 Jul;79(13):4118-22.

Alt FW, Oltz EM, Young F, Gorman J, Taccioli G, Chen J. VDJ recombination. Immunol Today. 1992 Aug;13(8):306-14.

Amit AG, Mariuzza RA, Phillips SE, Poljak RJ. Three-dimensional structure of an antigen-antibody complex at 2.8 A resolution. Science. 1986 Aug 15;233(4765):747-53.

Arstila TP, Casrouge A, Baron V, Even J, Kanellopoulos J, Kourilsky P. A direct estimate of the human alphabeta $T$ cell receptor diversity. Science. 1999 Oct 29;286(5441):958-61.

Bangs LA, Sanz IE, Teale JM. Comparison of D, JH, and junctional diversity in the fetal, adult, and aged B cell repertoires. J Immunol. 1991 Mar 15;146(6):1996-2004

Bauer K, Zemlin M, Hummel M, Pfeiffer S, Karstaedt J, Steinhauser G, Xiao X, Versmold H, Berek C. Diversification of Ig heavy chain genes in human preterm neonates prematurely exposed to environmental antigens. J Immunol. 2002 Aug $1 ; 169(3): 1349-56$.

Bengtén E, Wilson M, Miller N, Clem LW, Pilström L, Warr GW. Ig isotypes: structure, function, and genetics. Curr Top Microbiol Immunol. 2000;248:189-219.

Berek C, Griffiths GM, Milstein C. Molecular events during maturation of the immune response to oxazolone. Nature. 1985 Aug 1-7;316(6027):412-8.

Betz AG, Neuberger MS, Milstein C. Discriminating intrinsic and antigen-selected mutational hotspots in Ig V genes. Immunol Today. 1993 Aug;14(8):405-11.

Bofill M, Janossy G, Janossa M, Burford GD, Seymour GJ, Wernet P, Kelemen E. Human B cell development. II. Subpopulations in the human fetus. J Immunol. 1985 Mar;134(3):1531-8.

Boyd SD, Gaëta BA, Jackson KJ, Fire AZ, Marshall EL, Merker JD, Maniar JM, Zhang LN, Sahaf B, Jones CD, Simen BB, Hanczaruk B, Nguyen KD, Nadeau KC, Egholm M, Miklos DB, Zehnder JL, Collins AM. Individual variation in the germline Ig gene repertoire inferred from variable region gene rearrangements. J Immunol. 2010 Jun 15;184(12):6986-92.

Brandtzaeg P, Johansen FE. Mucosal B cells: phenotypic characteristics, transcriptional regulation, and homing properties. Immunol Rev. 2005 Aug;206:32-63.

Brezinschek HP, Brezinschek RI, Lipsky PE. Analysis of the heavy chain repertoire of human peripheral B cells using single-cell polymerase chain reaction. J Immunol. 1995 Jul 1;155(1):190-202. 
Brezinschek HP, Foster SJ, Brezinschek RI, Dörner T, Domiati-Saad R, Lipsky PE. Analysis of the human VH gene repertoire. Differential effects of selection and somatic hypermutation on human peripheral CD5(+)/IgM+ and CD5(-)/IgM+ B cells. J Clin Invest. 1997 May 15;99(10):2488-501.

Burrows PD, Cooper MD. B cell development and differentiation. Curr Opin Immunol. 1997 Apr;9(2):239-44.

Carril MS, Aragón JP, González Fernández A. Age-related accumulation of memory cells in mouse Peyer's patches. Immunol Lett. 2002 Aug 1;83(1):39-45.

Chang Y, Paige CJ, Wu GE. Enumeration and characterization of DJH structures in mouse fetal liver. EMBO J. 1992 May;11(5):1891-9.

Chevenet F, Brun C, Bañuls AL, Jacq B, Christen R. TreeDyn: towards dynamic graphics and annotations for analyses of trees. BMC Bioinformatics. 2006 Oct $10 ; 7: 439$.

Chevillard C, Ozaki J, Herring CD, Riblet R. A three-megabase yeast artificial chromosome contig spanning the C57BL mouse Igh locus. J Immunol. 2002 Jun 1;168(11):5659-66.

Chowdhury D, Sen R. Regulation of immunoglobulin heavy-chain gene rearrangements. Immunol Rev. 2004 Aug;200:182-96.

Collins AM, Sewell W, Edwards MR. Immunoglobulin gene rearrangement, repertoire diversity, and the allergic response. Pharmacol Ther. 2003 Nov;100(2):157-70.

Collis AV, Brouwer AP, Martin AC. Analysis of the antigen combining site: correlations between length and sequence composition of the hypervariable loops and the nature of the antigen. J Mol Biol. 2003 Jan 10;325(2):337-54.

Connor AM, Fanning LJ, Celler JW, Hicks LK, Ramsden DA, Wu GE. Mouse VH7183 recombination signal sequences mediate recombination more frequently than those of VHJ558. J Immunol. 1995 Dec 1;155(11):5268-72.

Cooper MD. Current concepts. B lymphocytes. Normal development and function. N Engl J Med. 1987 Dec 3;317(23):1452-6.

Cornes JS. Peyer's patches in the human gut. Proc R Soc Med. 1965 Sep;58(9):716.

Cozine CL, Wolniak KL, Waldschmidt TJ. The primary germinal center response in mice. Curr Opin Immunol. 2005 Jun;17(3):298-302.

Davies DR, Cohen GH. Interactions of protein antigens with antibodies. Proc Natl Acad Sci U S A. 1996 Jan 9;93(1):7-12.

Davies DR, Padlan EA, Sheriff S. Antibody-antigen complexes. Annu Rev Biochem. 1990;59:439-73. 
Desiderio SV, Yancopoulos GD, Paskind M, Thomas E, Boss MA, Landau N, Alt FW, Baltimore D. Insertion of $\mathrm{N}$ regions into heavy-chain genes is correlated with expression of terminal deoxytransferase in B cells. Nature. 1984 Oct 2531;311(5988):752-5.

Early P, Huang H, Davis M, Calame K, Hood L. An immunoglobulin heavy chain variable region gene is generated from three segments of DNA: VH, D and JH. Cell. 1980 Apr;19(4):981-92.

Eisenberg D Three-dimensional structure of membrane and surface proteins. Annu Rev Biochem. 1984;53:595-623.

Fanning LJ, Connor AM, Wu GE. Development of the immunoglobulin repertoire. Clin Immunol Immunopathol. 1996 Apr;79(1):1-14.

Feeney AJ. Lack of $\mathrm{N}$ regions in fetal and neonatal mouse immunoglobulin V-D-J junctional sequences. J Exp Med. 1990 Nov 1;172(5):1377-90.

Fernandez MI, Pedron T, Tournebize R, Olivo-Marin JC, Sansonetti PJ, Phalipon A. Anti-inflammatory role for intracellular dimeric immunoglobulin a by neutralization of lipopolysaccharide in epithelial cells. Immunity. 2003 Jun;18(6):739-49.

Fischer M, Klein U, Küppers R. Molecular single-cell analysis reveals that CD5positive peripheral blood B cells in healthy humans are characterized by rearranged Vkappa genes lacking somatic mutation. J Clin Invest. 1997 Oct 1;100(7):1667-76.

Fischer M, Küppers R. Human IgA- and IgM-secreting intestinal plasma cells carry heavily mutated VH region genes. Eur J Immunol. 1998 Sep;28(9):2971-7.

Frasca D, Landin AM, Lechner SC, Ryan JG, Schwartz R, Riley RL, Blomberg BB. Aging Down-Regulates the Transcription Factor E2A, Activation-Induced Cytidine Deaminase, and Ig Class Switch in Human B Cells. J Immunol. 2008 Apr 15;180(8):5283-90.

Fujimura Y, Owen RL. M cells as portals of infection: clinical and pathophysiological aspects. Infect Agents Dis. 1996 Jun;5(3):144-56.

Fujioka H, Emancipator SN, Aikawa M, Huang DS, Blatnik F, Karban T, DeFife K, Mazanec MB. Immunocytochemical colocalization of specific immunoglobulin A with sendai virus protein in infected polarized epithelium. J Exp Med. 1998 Oct 5;188(7):1223-9.

Garside P, Ingulli E, Merica RR, Johnson JG, Noelle RJ, Jenkins MK. Visualization of specific B and $\mathrm{T}$ lymphocyte interactions in the lymph node. Science. $1998 \mathrm{Jul}$ 3;281(5373):96-9.

Gathings WE, Kubagawa H, Cooper MD. A distinctive pattern of B cell immaturity in perinatal humans. Immunol Rev. 1981;57:107-26. 
Gauss GH, Lieber MR. Mechanistic constraints on diversity in human V(D)J recombination. Mol Cell Biol. 1996 Jan;16(1):258-69.

Gebert A, Göke M, Rothkötter HJ, Dietrich CF. [The mechanisms of antigen uptake in the small and large intestines: the roll of the $\mathrm{M}$ cells for the initiation of immune responses] Z Gastroenterol. 2000 Oct;38(10):855-72.

Gilfillan S, Dierich A, Lemeur M, Benoist C, Mathis D. Mice lacking TdT: mature animals with an immature lymphocyte repertoire. Science. 1993 Aug 27;261(5125):1175-8.

Giudicelli V, Chaume D, Lefranc MP. IMGT/V-QUEST, an integrated software program for immunoglobulin and $\mathrm{T}$ cell receptor V-J and V-D-J rearrangement analysis. Nucleic Acids Res. 2004 Jul 1;32.W435-40.

González-Fernández A, Gilmore D, Milstein C. Age-related decrease in the proportion of germinal center B cells from mouse Peyer's patches is accompanied by an accumulation of somatic mutations in their immunoglobulin genes. Eur J Immunol. 1994 Nov;24(11):2918-21.

Gu H, Kitamura D, Rajewsky K. B cell development regulated by gene rearrangement: arrest of maturation by membrane-bound $\mathrm{D} \mathrm{mu}$ protein and selection of $\mathrm{DH}$ element reading frames. Cell. 1991 Apr 5;65(1):47-54.

Honjo T, Muramatsu M, Fagarasan S. AID: how does it aid antibody diversity? Immunity. 2004 Jun;20(6):659-68.

Honjo T. A memoir of AID, which engraves antibody memory on DNA. Nat Immunol. 2008 Apr;9(4):335-7.

Ichihara Y, Hayashida H, Miyazawa S, Kurosawa Y. Only DFL16, DSP2, and DQ52 gene families exist in mouse immunoglobulin heavy chain diversity gene loci, of which DFL16 and DSP2 originate from the same primordial DH gene. Eur J Immunol. 1989 Oct;19(10):1849-54.

Insel RA, Varade WS. Characteristics of somatic hypermutation of human immunoglobulin genes. Curr Top Microbiol Immunol. 1998;229:33-44.

Ivanov II, Schelonka RL, Zhuang Y, Gartland GL, Zemlin M, Schroeder HW Jr. Development of the expressed Ig CDR-H3 repertoire is marked by focusing of constraints in length, amino acid use, and charge that are first established in early B cell progenitors. J Immunol. 2005 Jun 15;174(12):7773-80.

Jacobs H, Bross L. Towards an understanding of somatic hypermutation. Curr Opin Immunol. 2001 Apr;13(2):208-18.

Jeong HD, Teale JM. Comparison of the fetal and adult functional B cell repertoires by analysis of VH gene family expression. J Exp Med. 1988 Aug 1;168(2):589-603. 
Johnson G, Wu TT. Preferred CDRH3 lengths for antibodies with defined specificities. Int Immunol. 1998 Dec;10(12):1801-5.

Joho R, Weissman IL, Early P, Cole J, Hood L. Organization of kappa light chain genes in germ-line and somatic tissue. Proc Natl Acad Sci U S A. 1980 Feb;77(2):1106-10.

Kabat EA, Wu TT. Identical V region amino acid sequences and segments of sequences in antibodies of different specificities. Relative contributions of VH and VL genes, minigenes, and complementarity-determining regions to binding of antibody-combining sites. J Immunol. 1991 Sep 1;147(5):1709-19.

Kaushik A, Shojaei F, Saini SS. Novel insight into antibody diversification from cattle. Vet Immunol Immunopathol. 2002 Sep 10;87(3-4):347-50.

Klein U, Küppers R, Rajewsky K. Variable region gene analysis of B cell subsets derived from a 4-year-old child: somatically mutated memory B cells accumulate in the peripheral blood already at young age. J Exp Med. 1994 Oct 1;180(4):1383-93.

Klein U, Küppers R, Rajewsky K. Evidence for a large compartment of IgM-expressing memory B cells in humans. Blood. 1997 Feb 15;89(4):1288-98.

Komori T, Okada A, Stewart V, Alt FW. Lack of N regions in antigen receptor variable region genes of TdT-deficient lymphocytes. Science. 1993 Aug 27;261(5125):1171-5.

van Kooten C, Banchereau J. CD40-CD40 ligand. J Leukoc Biol. 2000 Jan;67(1):2-17.

Koralov SB, Novobrantseva TI, Hochedlinger K, Jaenisch R, Rajewsky K. Direct in vivo $\mathrm{VH}$ to $\mathrm{JH}$ rearrangement violating the 12/23 rule. J Exp Med. $2005 \mathrm{Feb}$ 7;201(3):341-8.

Krishnan MR, Marion TN. Comparison of the frequencies of arginines in heavy chain CDR3 of antibodies expressed in the primary B-cell repertoires of autoimmune-prone and normal mice. Scand J Immunol. 1998 Sep;48(3):223-32.

Kroese FG, Butcher EC, Stall AM, Lalor PA, Adams S, Herzenberg LA. Many of the IgA producing plasma cells in murine gut are derived from self-replenishing precursors in the peritoneal cavity. Int Immunol. 1989;1(1):75-84.

Kroese FG, Ammerlaan WA, Deenen GJ, Adams S, Herzenberg LA, Kantor AB. A dual origin for IgA plasma cells in the murine small intestine. Adv Exp Med Biol. 1995;371 A:435-40.

Kurosawa Y, Tonegawa S. Organization, structure, and assembly of immunoglobulin heavy chain diversity DNA segments. J Exp Med. 1982 Jan 1;155(1):201-18.

Kyte J, Doolittle RF. A simple method for displaying the hydropathic character of a protein. J Mol Biol. 1982 May 5;157(1):105-32. 
Lebecque SG, Gearhart PJ. Boundaries of somatic mutation in rearranged immunoglobulin genes: 5' boundary is near the promoter, and 3' boundary is approximately $1 \mathrm{~kb}$ from V(D)J gene. J Exp Med. 1990 Dec 1;172(6):1717-27.

Lederman S, Yellin MJ, Inghirami G, Lee JJ, Knowles DM, Chess L. Molecular interactions mediating T-B lymphocyte collaboration in human lymphoid follicles. Roles of T cell-B-cell-activating molecule (5c8 antigen) and CD40 in contact-dependent help. J Immunol. 1992 Dec 15;149(12):3817-26.

Lewis SM, Wu GE. The origins of V(D)J recombination. Cell. 1997 Jan 24;88(2):15962.

Lin WC, Desiderio S. V(D)J recombination and the cell cycle. Immunol Today. 1995 Jun;16(6):279-89.

Liu YJ, Zhang J, Lane PJ, Chan EY, MacLennan IC. Sites of specific B cell activation in primary and secondary responses to $\mathrm{T}$ cell-dependent and $\mathrm{T}$ cell-independent antigens. Eur J Immunol. 1991 Dec;21(12):2951-62.

Liu YJ, Malisan F, de Bouteiller O, Guret C, Lebecque S, Banchereau J, Mills FC, Max $\mathrm{EE}$, Martinez-Valdez $\mathrm{H}$. Within germinal centers, isotype switching of immunoglobulin genes occurs after the onset of somatic mutation. Immunity. 1996 Mar;4(3):241-50.

Liu YJ, de Bouteiller O, Fugier-Vivier I. Mechanisms of selection and differentiation in germinal centers. Curr Opin Immunol. 1997 Apr;9(2):256-62.

MacCallum RM, Martin AC, Thornton JM. Antibody-antigen interactions: contact analysis and binding site topography. J Mol Biol. 1996 Oct 11;262(5):732-45.

MacLennan IC, Liu YJ, Johnson GD. Maturation and dispersal of B-cell clones during T cell-dependent antibody responses. Immunol Rev. 1992 Apr;126:143-61.

MacLennan IC. Germinal centers. Annu Rev Immunol. 1994;12:117-39.

MacLennan IC, Gulbranson-Judge A, Toellner KM, Casamayor-Palleja M, Chan E, Sze DM, Luther SA, Orbea HA. The changing preference of T and B cells for partners as Tdependent antibody responses develop. Immunol Rev. 1997 Apr;156:53-66.

Maheshwari A, Zemlin M. Ontogeny of the intestinal immune system. Haematologica Reports. 2006;2(10):18-26

Mainville CA, Sheehan KM, Klaman LD, Giorgetti CA, Press JL, Brodeur PH. Deletional mapping of fifteen mouse $\mathrm{VH}$ gene families reveals a common organization for three Igh haplotypes. J Immunol. 1996 Feb 1;156(3):1038-46.

Makala LH, Suzuki N, Nagasawa H. Peyer's patches: organized lymphoid structures for the induction of mucosal immune responses in the intestine. Pathobiology. 20022003;70(2):55-68. 
Malynn BA, Yancopoulos GD, Barth JE, Bona CA, Alt FW. Biased expression of JHproximal VH genes occurs in the newly generated repertoire of neonatal and adult mice. J Exp Med. 1990 Mar 1;171(3):843-59.

McGhee JR, Mestecky J, Dertzbaugh MT, Eldridge JH, Hirasawa M, Kiyono H. The mucosal immune system: from fundamental concepts to vaccine development. Vaccine. $1992 ; 10(2): 75-88$.

McHeyzer-Williams MG, McLean MJ, Lalor PA, Nossal GJ. Antigen-driven B cell differentiation in vivo. J Exp Med. 1993 Jul 1;178(1):295-307.

McKean D, Huppi K, Bell M, Staudt L, Gerhard W, Weigert M. Generation of antibody diversity in the immune response of $\mathrm{BALB} / \mathrm{c}$ mice to influenza virus hemagglutinin. Proc Natl Acad Sci U S A. 1984 May;81(10):3180-4.

Milstein C, Neuberger MS, Staden R. Both DNA strands of antibody genes are hypermutation targets. Proc Natl Acad Sci U S A. 1998 Jul 21;95(15):8791-4.

Milstein C. From antibody structure to immunological diversification of immune response. Science. 1986 Mar 14;231(4743):1261-8.

Mix E, Goertsches R, Zett UK. Immunoglobulins--basic considerations. J Neurol. 2006 Sep;253 Supp1 5:V9-17.

Mowat AM. Anatomical basis of tolerance and immunity to intestinal antigens. Nat Rev Immunol. 2003 Apr;3(4):331-41.

Muramatsu M, Kinoshita K, Fagarasan S, Yamada S, Shinkai Y, Honjo T. Class switch recombination and hypermutation require activation-induced cytidine deaminase (AID), a potential RNA editing enzyme. Cell. 2000 Sep 1;102(5):553-63.

Murphy KM, Travers P, Walport M. Janeway's Immunobiology, Seventh Edition Garland Science, 2007.

Neutra MR, Mantis NJ, Kraehenbuhl JP. Collaboration of epithelial cells with organized mucosal lymphoid tissues. Nat Immunol. 2001 Nov;2(11):1004-9.

Nadel B, Feeney AJ. Influence of coding-end sequence on coding-end processing in V(D)J recombination. J Immunol. 1995 Nov 1;155(9):4322-9.

Nadel B, Feeney AJ. Nucleotide deletion and $\mathrm{P}$ addition in $\mathrm{V}(\mathrm{D}) \mathrm{J}$ recombination: a determinant role of the coding-end sequence. Mol Cell Biol. 1997 Jul;17(7):3768-78.

Nagler-Anderson C. Man the barrier! Strategic defences in the intestinal mucosa. Nat Rev Immunol. 2001 Oct;1(1):59-67.

Neuberger MS, Milstein C. Somatic hypermutation. Curr Opin Immunol. 1995 Apr;7(2):248-54. 
Nezlin R. Combinatorial events in generation of antibody diversity. Comb Chem High Throughput Screen. 2001 Aug;4(5):377-83.

Oettinger MA, Schatz DG, Gorka C, Baltimore D. RAG-1 and RAG-2, adjacent genes that synergistically activate V(D)J recombination. Science. 1990 Jun 22;248(4962):1517-23.

Ohno S, Mori N, Matsunaga T. Antigen-binding specificities of antibodies are primarily determined by seven residues of VH. Proc Natl Acad Sci U S A. 1985 May;82(9):29459.

Padlan EA, Silverton EW, Sheriff S, Cohen GH, Smith-Gill SJ, Davies DR. Structure of an antibody-antigen complex: crystal structure of the HyHEL-10 Fab-lysozyme complex. Proc Natl Acad Sci U S A. 1989 Aug;86(15):5938-42.

Padlan EA. Anatomy of the antibody molecule. Mol Immunol. 1994 Feb;31(3):169-217.

Papavasiliou FN, Schatz DG. Somatic hypermutation of immunoglobulin genes: merging mechanisms for genetic diversity. Cell. 2002 Apr;109 Suppl:S35-44.

Pascual V, Liu YJ, Magalski A, de Bouteiller O, Banchereau J, Capra JD. Analysis of somatic mutation in five B cell subsets of human tonsil. J Exp Med. 1994 Jul 1;180(1):329-39.

Perlmutter RM, Kearney JF, Chang SP, Hood LE. Developmentally controlled expression of immunoglobulin VH genes. Science. 1985 Mar 29;227(4694):1597-601.

Petersen-Mahrt SK, Harris RS, Neuberger MS. AID mutates E. coli suggesting a DNA deamination mechanism for antibody diversification. Nature. 2002 Jul 4;418(6893):99103.

Rada C, Gupta SK, Gherardi E, Milstein C. Mutation and selection during the secondary response to 2-phenyloxazolone. Proc Natl Acad Sci U S A. 1991 Jul 1;88(13):5508-12.

Rada C, Milstein C. The intrinsic hypermutability of antibody heavy and light chain genes decays exponentially. EMBO J. 2001 Aug 15;20(16):4570-6.

Rada C, Yélamos J, Dean W, Milstein C. The 5' hypermutation boundary of kappa chains is independent of local and neighbouring sequences and related to the distance from the initiation of transcription. Eur J Immunol. 1997 Dec;27(12):3115-20.

Rajewsky K. Clonal selection and learning in the antibody system. Nature. 1996 Jun 27;381(6585):751-8.

Revy P, Muto T, Levy Y, Geissmann F, Plebani A, Sanal O, Catalan N, Forveille M, Dufourcq-Labelouse R, Gennery A, Tezcan I, Ersoy F, Kayserili H, Ugazio AG, Brousse N, Muramatsu M, Notarangelo LD, Kinoshita K, Honjo T, Fischer A, Durandy A. Activation-induced cytidine deaminase (AID) deficiency causes the autosomal recessive form of the Hyper-IgM syndrome (HIGM2). Cell. 2000 Sep 1;102(5):565-75. 
Riblet R, Brodeur PH. The Igh-V gene repertoire of the mouse. Mt Sinai J Med. 1986 Mar;53(3):170-4.

Robinson JK, Blanchard TG, Levine AD, Emancipator SN, Lamm ME. A mucosal IgAmediated excretory immune system in vivo. J Immunol. 2001 Mar 15;166(6):3688-92.

Rogosch T, Kerzel S, Sikula L, Gentil K, Liebetruth M, Schlingmann KP, Maier RF, Zemlin M. Plasma cells and nonplasma B cells express differing IgE repertoires in allergic sensitization. J Immunol. 2010 May 1;184(9):4947-54.

Rogosch T, Kerzel S, Hoi KH, Zhang Z, Maier RF, Ippolito GC, Zemlin M. IgAT (Immunoglobulin Analysis Tool): A novel tool for the analysis of human and mouse heavy and light chain transcripts. Frontiers in Immunology 2012 in press

Rogozin IB, Kolchanov NA. Somatic hypermutagenesis in immunoglobulin genes. II. Influence of neighbouring base sequences on mutagenesis. Biochim Biophys Acta. 1992 Nov 15;1171(1):11-8.

Rosner K, Winter DB, Tarone RE, Skovgaard GL, Bohr VA, Gearhart PJ. Third complementarity-determining region of mutated $\mathrm{VH}$ immunoglobulin genes contains shorter V, D, J, P, and N components than non-mutated genes. Immunology. 2001 Jun;103(2):179-87.

Sagaert X, Sprangers B, De Wolf-Peeters C. The dynamics of the B follicle: understanding the normal counterpart of B-cell-derived malignancies. Leukemia. 2007 Jul;21(7):1378-86.

Saito H, Kanamori Y, Takemori T, Nariuchi H, Kubota E, Takahashi-Iwanaga H, Iwanaga $\mathrm{T}$, Ishikawa $\mathrm{H}$. Generation of intestinal $\mathrm{T}$ cells from progenitors residing in gut cryptopatches. Science. 1998 Apr 10;280(5361):275-8.

Sakano H, Maki R, Kurosawa Y, Roeder W, Tonegawa S. Two types of somatic recombination are necessary for the generation of complete immunoglobulin heavychain genes. Nature. 1980 Aug 14;286(5774):676-83.

Sakano H, Kurosawa Y, Weigert M, Tonegawa S. Identification and nucleotide sequence of a diversity DNA segment (D) of immunoglobulin heavy-chain genes.

Nature. 1981 Apr 16;290(5807):562-5.

Sanz I. Multiple mechanisms participate in the generation of diversity of human $\mathrm{H}$ chain CDR3 regions. J Immunol. 1991 Sep 1;147(5):1720-9.

Schelonka RL, Ivanov II, Jung DH, Ippolito GC, Nitschke L, Zhuang Y, Gartland GL, Pelkonen J, Alt FW, Rajewsky K, Schroeder HW Jr. A single DH gene segment creates its own unique CDR-H3 repertoire and is sufficient for B cell development and immune function. J Immunol. 2005 Nov 15;175(10):6624-32.

Schelonka RL, Tanner J, Zhuang Y, Gartland GL, Zemlin M, Schroeder HW Jr. Categorical selection of the antibody repertoire in splenic B cells. Eur J Immunol. 2007 Apr;37(4):1010-21. 
Schroeder HW Jr, Mortari F, Shiokawa S, Kirkham PM, Elgavish RA, Bertrand FE 3rd. Developmental regulation of the human antibody repertoire. Ann N Y Acad Sci. 1995 Sep 29;764:242-60.

Schroeder HW Jr. Similarity and divergence in the development and expression of the mouse and human antibody repertoires. Dev Comp Immunol. 2006;30(1-2):119-35.

Schroeder HW Jr, Zemlin M, Khass M, Nguyen HH, Schelonka RL. Genetic control of DH reading frame and its effect on B-cell development and antigen-specifc antibody production. Crit Rev Immunol. 2010;30(4):327-44.

Shinkura R, Ito S, Begum NA, Nagaoka H, Muramatsu M, Kinoshita K, Sakakibara Y, Hijikata H, Honjo T. Separate domains of AID are required for somatic hypermutation and class-switch recombination. Nat Immunol. 2004 Jul;5(7):707-12.

Shiokawa S, Mortari F, Lima JO, Nuñez C, Bertrand FE 3rd, Kirkham PM, Zhu S, Dasanayake AP, Schroeder HW Jr. IgM heavy chain complementarity-determining region 3 diversity is constrained by genetic and somatic mechanisms until two months after birth. J Immunol. 1999 May 15;162(10):6060-70.

Shirai H, Kidera A, Nakamura H. Structural classification of CDR-H3 in antibodies. FEBS Lett. 1996 Dec 9;399(1-2):1-8.

Shlomchik MJ, Mascelli MA, Shan H. Anti-DNAantibodies from autoimmune mice arise by clonal expansion and somatic mutation. J Exp Med. 1990, 171, 265-297

Smith KG, Light A, Nossal GJ, Tarlinton DM. The extent of affinity maturation differs between the memory and antibody-forming cell compartments in the primary immune response. EMBO J. 1997 Jun 2;16(11):2996-3006.

Souto-Carneiro MM, Sims GP, Girschik H, Lee J, Lipsky PE. Developmental changes in the human heavy chain CDR3. J Immunol. 2005 Dec 1;175(11):7425-36.

Stall AM, Wells SM, Lam KP. B-1 cells: unique origins and functions. Semin Immunol. $1996 \mathrm{Feb} ; 8(1): 45-59$.

Stavnezer J. Immunoglobulin class switching. Curr Opin Immunol. 1996 Apr;8(2):199205

Stiehm ER, Fudenberg HH. Serum levels of immune globulins in health and disease: a survey. Pediatrics. 1966 May;37(5):715-27.

Storb U, Stavnezer J. Immunoglobulin genes: generating diversity with AID and UNG. Curr Biol. 2002 Oct 29;12(21):R725-7.

Tarlinton D, Stall AM, Herzenberg LA. Repetitive usage of immunoglobulin VH and D gene segments in CD5+ Ly-1 B clones of (NZB x NZW)F1 mice. EMBO J. 1988 Dec 1;7(12):3705-10. 
Tarlinton DM, Smith KG. Dissecting affinity maturation: a model explaining selection of antibody-forming cells and memory B cells in the germinal centre. Immunol Today. 2000 Sep;21(9):436-41.

Tomlinson IM, Cox JP, Gherardi E, Lesk AM, Chothia C. The structural repertoire of the human V kappa domain. EMBO J. 1995 Sep 15;14(18):4628-38.

Tonegawa S. Somatic generation of antibody diversity. Nature. 1983 Apr 14;302(5909):575-81.

Vale AM, Tanner JM, Schelonka RL, Zhuang Y, Zemlin M, Gartland GL, Schroeder HW Jr. The peritoneal cavity B-2 antibody repertoire appears to reflect many of the same selective pressures that shape the B-1a and B-1b repertoires. J Immunol. 2010 Nov 15;185(10):6085-95.

de Villartay JP, Fischer A, Durandy A. The mechanisms of immune diversification and their disorders. Nat Rev Immunol. 2003 Dec;3(12):962-72.

de Vos J, Hose D, Rème T, Tarte K, Moreaux J, Mahtouk K, Jourdan M, Goldschmidt H, Rossi JF, Cremer FW, Klein B. Microarray-based understanding of normal and malignant plasma cells. Immunol Rev. 2006 Apr;210:86-104.

Wagner SD, Neuberger MS. Somatic hypermutation of immunoglobulin genes. Annu Rev Immunol. 1996;14:441-57.

Weissman IL. Development and distribution of immunoglobulin-bearing cells in mice. Transplant Rev. 1975;24:159-76.

Wilson PC, de Bouteiller O, Liu YJ, Potter K, Banchereau J, Capra JD, Pascual V. Somatic hypermutation introduces insertions and deletions into immunoglobulin $\mathrm{V}$ genes. J Exp Med. 1998 Jan 5;187(1):59-70.

Wolniak KL, Shinall SM, Waldschmidt TJ. The germinal center response. Crit Rev Immunol. 2004;24(1):39-65.

Wu TT, Johnson G, Kabat EA. Length distribution of CDRH3 in antibodies. Proteins. 1993 May;16(1):1-7.

Xu JL, Foy TM, Laman JD, Elliott EA, Dunn JJ, Waldschmidt TJ, Elsemore J, Noelle RJ, Flavell RA. Mice deficient for the CD40 ligand. Immunity. 1994 Aug;1(5):423-31.

$\mathrm{Xu}$ JL, Davis MM. Diversity in the CDR3 region of $\mathrm{V}(\mathrm{H})$ is sufficient for most antibody specificities. Immunity. $2000 \mathrm{Jul} ; 13(1): 37-45$.

Yancopoulos GD, Desiderio SV, Paskind M, Kearney JF, Baltimore D, Alt FW. Preferential utilization of the most JH-proximal VH gene segments in pre-B-cell lines. Nature. 1984 Oct 25-31;311(5988):727-33.

Yancopoulos GD, Malynn BA, Alt FW. Developmentally regulated and strain-specific expression of murine VH gene families. J Exp Med. 1988 Jul 1;168(1):417-35. 
Yavuz S, Grammer AC, Yavuz AS, Nanki T, Lipsky PE. Comparative characteristics of mu chain and alpha chain transcripts expressed by individual tonsil plasma cells. Mol Immunol. 2001 Jan;38(1):19-34.

Yoshida T, Mei H, Dörner T, Hiepe F, Radbruch A, Fillatreau S, Hoyer BF. Memory B and memory plasma cells. Immunol Rev. 2010 Sep;237(1):117-39.

Yurovsky VV, Kelsoe G. Pairing of VH gene families with the lambda 1 light chain: evidence for a non-stochastic association. Eur J Immunol. 1993 Aug;23(8):1975-9.

Zemlin M, Bauer K, Hummel M, Pfeiffer S, Devers S, Zemlin C, Stein H, Versmold HT. The diversity of rearranged immunoglobulin heavy chain variable region genes in peripheral blood B cells of preterm infants is restricted by short third complementaritydetermining regions but not by limited gene segment usage. Blood. 2001 Mar 1;97(5):1511-3.

Zemlin M, Schelonka RL, Bauer K, Schroeder HW Jr. Regulation and chance in the ontogeny of B and T cell antigen receptor repertoires. Immunol Res. 2002;26(1-3):26578.

Zemlin M, Klinger M, Link J, Zemlin C, Bauer K, Engler JA, Schroeder HW Jr, Kirkham PM. Expressed murine and human CDR-H3 intervals of equal length exhibit distinct repertoires that differ in their amino acid composition and predicted range of structures. J Mol Biol. 2003 Dec 5;334(4):733-49.

Zhang Z, Zemlin M, Wang YH, Munfus D, Huye LE, Findley HW, Bridges SL, Roth $\mathrm{DB}$, Burrows PD, Cooper MD. Contribution of Vh gene replacement to the primary B cell repertoire. Immunity. $2003 \mathrm{Jul} ; 19(1): 21-31$.

Zouali M. B-cell superantigens: implications for selection of the human antibody repertoire. Immunol Today. 1995 Aug;16(8):399-405.

Zuckerkandl E, Pauling L. Molecules as documents of evolutionary history. J Theor Biol. 1965 Mar;8(2):357-66. 


\section{Anhang}

\subsection{Abkürzungsverzeichnis}

$\mathrm{Ag}$

AID

$\mathrm{Ak}$

bp

CD

cDNA

CDR

$\mathrm{C}_{\mathrm{H}}$

$\mathrm{C}_{\mathrm{L}}$

CSR

Cy5

dATP

DC

dCTP

ddNTP

D-Gensegment

dGTP

DNA

dNTP

ds-DNA

dTTP

E. Coli

FACS

FAE

Fc-Rezeptor

FDC

FITC

FR
Antigen

Aktivierungsinduzierte Cytidindeaminase

Antikörper

Basenpaar

cluster of differentiation

'Complementary'-DNA

Complementarity Determining Region

Konstante Region der schweren Kette

Konstante Region der leichten Kette

Klassenwechsel (class switch recombination)

Cyanine 5

Desoxyadenosintriphosphat

Dendritische Zelle (dendritic cell)

Desoxycytidintriphosphat

Didesoxyribonukleotidtriphosphat

,Diversity'-Gensegment

Desoxyguanosintriphosphat

Desoxyribonukleinsäure (desoxyribonucleoid acid)

Desoxyribonuleotidtriphosphat

Doppelstrang-DNA

Desoxythymidintriphosphat

Escherichia coli

Fluoreszenz-Aktivierte-Zellanalyse (Fluorescence

Activated Cell Sorting)

Follikel-assoziiertes Epithel

,fragment crystallizable'-Rezeptor

Follikuläre dendritische Zelle

Fluorescein

Gerüstregion (framework region) 
FSC

GALT

H-Kette

HIGM

Ig

$\mathrm{IgH}$

$\mathrm{IgL}$

$\mathrm{IMGT}^{\circledR}$

J-Gensegment

L-Kette

MALT

$\mathrm{Mb}$

$\mathrm{MC}$

$\mathrm{mIg}$

mRNA

MW

M-Zellen

N-Nukleotide

ORF

PC

PCR

PE

P-Nukleotide

PP

RAG

RF

RNA

RSS

RT

SD

SED
Vorwärtsstreulicht (forward scatter)

Darmassoziiertes lymphatisches Gewebe (gut-associated lymphoid tissues)

Schwere Kette (heavy chain)

Hyper-IgM-Syndrom

Immunglobulin

Immunglobulin-Schwerkette

Immunglobulin-Leichtkette

The international ImMunoGeneTics information system ${ }^{\circledR}$

,Joining' Gensegment

Leichte Kette (light chain)

Mucosa-assoziiertes lymphatisches Gewebe (mисоsa-

associated lymphoid tissues)

Megabase

Gedächtniszellen (memory cells)

Membranständiges Immunglobulin

messenger RNA

Mittelwert

,Microfold'-Zellen

,Nontemplated' Nukleotide

Offener Leserahmen (open reading frame)

Plasmazellen (plasma cells)

Polymerase Kettenreaktion (polymerase chain reaction)

Phycoerythrin

Palindromische Nukleotide

Peyersche Plaques (Peyer's patches)

Rekombinationsaktivierendes Gen

Leserahmen (reading frame)

Ribonukleinsäure (ribonucleoid acid)

Rekombinationssignalsequenz

Reverse Transkriptase

Standardabweichung (Standard Deviation)

Subepitheliales Domareal 
SEM

SHM

SPF

SPRD

SSC

SSW

Taq-Polymerase

TdT

TGF

$\mathrm{T}_{\mathrm{H}}$-Zelle

TNF

$\mathrm{U}$

UNG

V-Gensegment

$\mathrm{V}_{\mathrm{H}}$

$\mathrm{V}_{\mathrm{L}}$
Standard-Fehler des Mittelwerts (Standard Error of the of the Mean)

Somatische Hypermutation

Spezifisch pathogen-frei

Spectral Red

Seitwärtsstreulicht (side scatter)

Schwangerschaftswoche

DNA-Polymerase des Bakteriums Thermus aquaticus (Taq)

Terminale Desoxynukleotidyltransferase

transforming growth factor

T-Helfer-Zelle

Tumornekrosefaktor

Formelzeichen für elektrische Spannung

Uracil-DNA-Glycosylase

,Variable' Gensegment

Variable Region der schweren Kette

Variable Region der leichten Kette 


\subsection{Abbildungsverzeichnis}

Abbildung 2.1: Schematische Darstellung eines Immunglobulinmoleküls. ............. 8

Abbildung 2.2: $\quad$ Organisation des murinen IgH-Locus .........................................10

Abbildung 2.3: $\quad$ Schematische Darstellung der VDJ-Rekombination........................13

Abbildung 2.4: Immunfluoreszenz-Aufnahme (links) und schematische

Darstellung einesPeyerschen Plaques (rechts) ...........................18

Abbildung 2.5: Schematische Darstellung eines Keimzentrums .............................19

Abbildung 3.1: Beispielhaftes Ergebnis der mittels Kapillarsequenzer detektierten

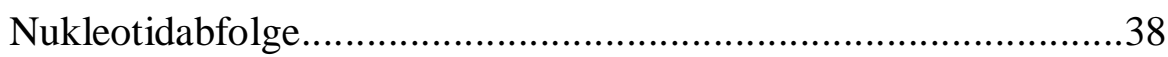

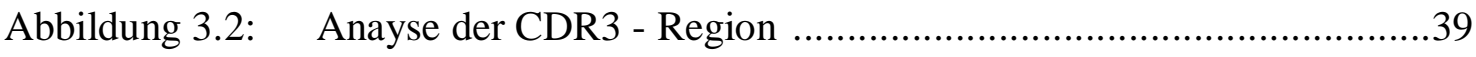

Abbildung 4.1: $\quad$ Phylogenetischer Baum der funktionellen IgM-Sequenzen ............43

Abbildung 4.2: $\quad$ Phylogenetischer Baum der funktionellen IgA-Gedächtniszell-

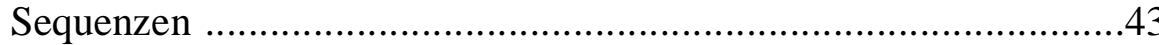

Abbildung 4.3: Phylogenetischer Baum der funktionellen

IgA-Plasmazell-Sequenzen .................................................44

Abbildung 4.4: Relative Häufigkeit der IgH V-Familien Nutzung. ........................45

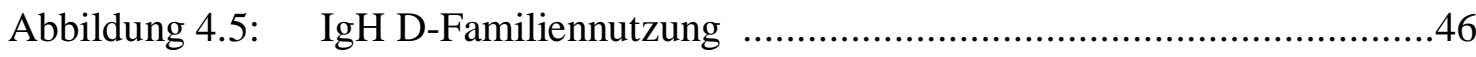

Abbildung 4.6: Verwendung der Leserahmen des D-Gen-Segmentes.....................46

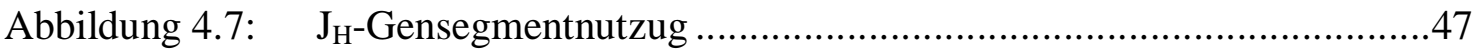

Abbildung 4.8: CDR3-Längen in Nukleotiden .................................................48

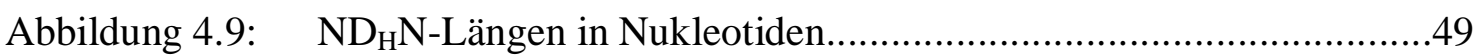

Abbildung 4.10: Zusammensetzung der CDR3-Region in Nukleotiden....................50

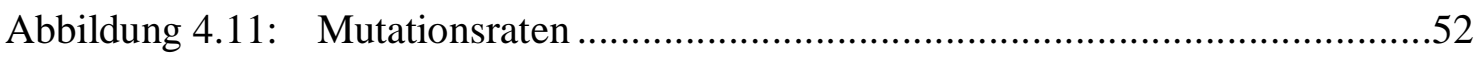

Abbildung 4.12: Aminosäuren-Varianz am Beispiel der IgA PC-Sequenzen.............53

Abbildung 4.13: Durchschnittliche Kyte-Doolittle-Indizes der CDR3-Regionen.......54

Abbildung 4.14: Kyte-Doolittle-Indizes der IgA MC- , IgA PC- und IgM-Sequenzen im Vergleich zur Gaußschen Normalverteilungskurve...................55

Abbildung 7.1: $\quad \mathrm{V}_{\mathrm{H}}$-familienspezifische Gensegmentnutzung .............................72

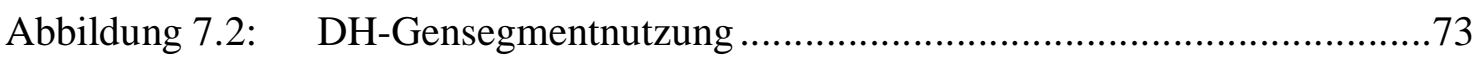

Abbildung 7.3: Längenverteilung von CDR3 (VH1/14- und VH5-Sequenzen)........78

Abbildung 7.4: Längenverteilung von CDR3 (IgA MC; IgA PC; IgM) ..................79

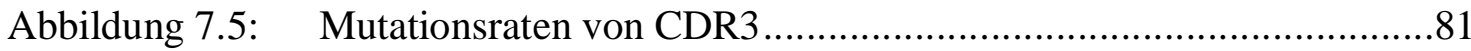




\subsection{Tabellenverzeichnis}

Tabelle 3.1: Monoklonale Antikörper gegen Zelloberflächenmoleküle ...................23

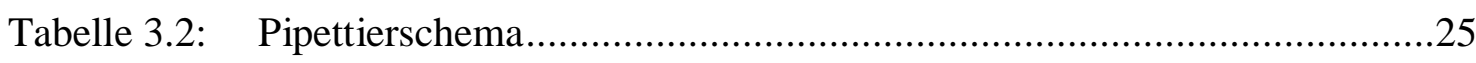

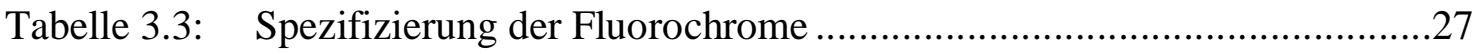

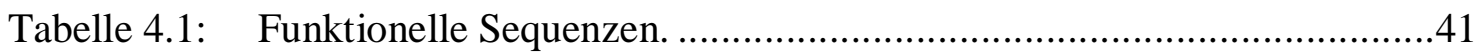

Tabelle 4.2: $\quad$ Diversität der Immunglobulin-Sequenzen. ........................................42

Tabelle 4.3: Verhältnis von Replacement-Mutationen zu silenten Mutationen ..........52

Tabelle 7.1: IgH-VDJ-Segmentnutzung der VH5-Familie ...................................74

Tabelle 7.2: IgH-VDJ-Segmentnutzung der VH1/14-Familie...............................75

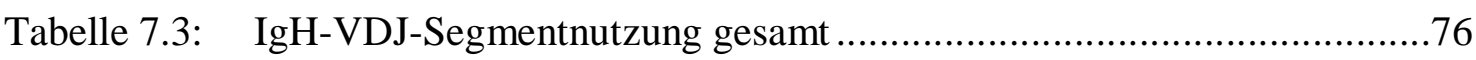

Tabelle 7.4: CDR3- und NDN-Längen in Nukleotiden ........................................77

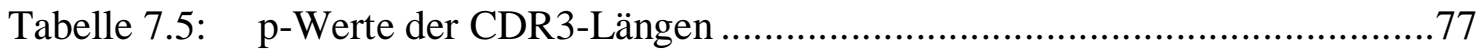

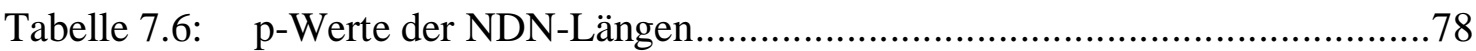

Tabelle 7.7: Zusammensetzung der CDR3-Region in Nukleotiden mit

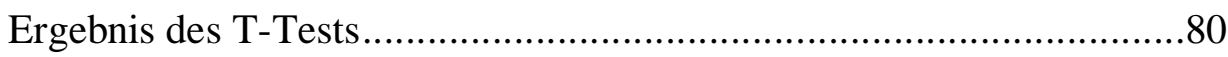




\subsection{Verzeichnis der akademischen Lehrer}

Meine akademischen Lehrer waren:

An der Philipps-Universität Marburg:Albert, Alter, Aumüller, Barth, Basler, Baum, Beyer, Bien, Bock, Bolm, Cetin, Christiansen, Daut, Duda, Engenardt-Cabilic, Feuser, Gemsa, Geus, Goerke, Görg, Gotzen, Grimm, Griss, Grzeschik, Gudermann, Hadji, Happle, Hoyer, Hörle, Kalder, Kann, Kern, Kim-Berger, Klaus, Klose, Koolman, Kretschmer, Kroll, Kühnert, Lange, Lohoff, Lorentz, Löffler, Maier, Maisch, Moll, Moosdorf, Müller, Mutters, Neubauer, Oertel, Ramaswamy, Remschmidt, Renz, Richter, Rosenow, Rothmund, Röhm, Schäfer, Schmidt, Schnabel, Seifart, Seitz, Slenska, Steiniger, von Knobloch, Vohland, Voigt, Wagner, Waldegger, Weihe, Werner, Wilke, Wulf, Zemlin, Zwiorek.

An der Université Louis Pasteur Strasbourg / Frankreich: Prof. Dr. Jacqmin, Prof. Dr. Dupeyron, Prof. Dr. Cribier, Prof. Dr. Gentine

Am Auguste-Viktoria-Klinikum Berlin: Prof. Dr. Heino Kienapfel

An der Universität Hong Kong / China: Prof. Dr. John Wong

Am Inselspital Bern / Schweiz: Prof. Dr. Martin Schöni 


\subsection{Danksagung}

Mein Dank gilt Herrn Prof. Dr. R. F. Maier für die interessante Aufgabenstellung und die vielfältige Unterstützung durch eine immerwährende Diskussionsbereitschaft sowie die fachliche Bewertung der Arbeit.

Herrn PD Dr. med. M. Zemlin danke ich herzlich für die Anregung zu dieser Arbeit, die großartige Unterstützung bei der Durchführung und die kontinuierliche Betreuung. Seine Begeisterungsfähigkeit und zwischenmenschliche Kompetenz sind mir ein großes Vorbild. Dr. Tobias Rogosch und Dr. Sebastian Kerzel danke ich für ihre äußerst kompetente und geduldige Beratung sowie kontinuierliche Unterstützung im Rahmen der statistischen Auswertung. Mein besonderer Dank gilt dem Team des Forschungslabors für Neonatologie und pädiatrische Immunologie der Klinik für Kinder- und Jugendmedizin der Philipps-Universität Marburg, allen voran und stellvertretend Regina Stöhr und Sabine Jennemann, für die tatkräftige Unterstützung bei der Durchführung der Versuche und das unermüdliche Engagement in ausgesprochen angenehmer Atmosphäre. Nicht nur die unvergessliche Zeit der Zusammenarbeit im Labor, sondern auch wundervolle Abende in Marburg oder im Skigebiet haben aus einem Arbeitsverhältnis eine herzliche Freundschaft entstehen lassen. Ich danke Euch, dass Ihr Euch immer Zeit nahmt, wenn ich Hilfe oder ein offenes Ohr brauchte.

Für die Durchführung der Zellsortierung danke ich Frau Dr. C. Brendel aus der Klinik für Innere Medizin, Institut für Hämatologie, Onkologie und Immunologie des Universitätsklinikums Giessen und Marburg, Standort Marburg; Direktor: Prof. Dr. A. Neubauer.

Mein sehr herzlicher Dank gilt meinen Eltern, die mir stets mit Rat und Tat sowie mit kontinuierlicher Motivationsarbeit zur Seite stehen. Meinem Freund Dr. Robert Schier, meiner Schwester Dr. Carolin Miestereck und ihrem Mann Jan danke ich für die fachliche Unterstützung und die ausgleichenden Stunden. Sie alle haben auf ihre Weise zum Gelingen dieser Arbeit beigetragen. 